Interpretação de clusters gerados por algoritmos de clustering hierárquico 



\section{Interpretação de clusters gerados por algoritmos de clustering hierárquico}

Jean Metz

Orientadora: $\operatorname{Prof}^{a} . \operatorname{Dr}^{a}$. Maria Carolina Monard

Dissertação apresentada ao Instituto de Ciências Matemáticas e de Computação - ICMC-USP, como parte dos requisitos para obtenção do título de Mestre em Ciências de Computação e Matemática Computacional. 

Este documento foi preparado com o formatador de textos $\mathrm{LAT}_{\mathrm{E}} \mathrm{X}$. Sua bibliografia é gerada automaticamente pelo sistema bibTeX, utilizando o padrão Apalike. O estilo de formatação deste trabalho foi elaborado por Ronaldo Cristiano Prati. 

Ao sábio bastam apenas três coisas:

Pensar, Pensar e Pensar.

Sir Isaac Newton (1642-1727) 



\section{Dedicatória}

À minha amada mãe e querida irmã, Marlene e Jéssica Metz. 



\section{Agradecimentos}

Agradeço primeiramente à minha família por todo apoio nos momentos mais difíceis. Minha mãe, uma mulher de extrema dedicação e perseverança, uma pessoa que não mediu esforços para me ajudar na conquista de mais esse objetivo. Obrigado pelos doces sorrisos a cada reencontro. Minha querida irmã, pelas lágrimas derramadas a cada despedida e pelo abraço carinhoso a cada volta para casa. Muito obrigado a vocês duas. Com certeza eu não conseguiria passar tanto tempo longe sem o incentivo de vocês. Amo vocês.

Agradeço em especial à professora Maria Carolina Monard, por ter sido mais que uma orientadora. Em muitos momentos a sua função como orientadora foi esquecida, e no lugar passou a atuar uma companheira e amiga, quase uma mãe para seus alunos. Obrigado por sua dedicação, atenção e paciência. A senhora é um exemplo de postura ética e honestidade.

Ao professor Feng Chung Wu e à professora Huei Diana Lee, pelas inestimáveis contribuições.

Às moças da secretaria de pós-graduação, Ana Paula, Laura e Beth, sempre dispostas e pretativas. Obrigado pelo grande auxílio.

Aos meus irmãos Pablio F. Neri e Leandro W. Moreira, pelos momentos de alegria, distração e companheirismo. Também pelo constante incentivo para continuar trilhando o meu caminho. Vocês, mais uma vez, contribuíram de maneira significativa para o desenvolvimento deste trabalho.

À minha grande amiga Adriana O. Schmitz, pelos conselhos e palavras tranqüilizantes nos momentos de tormenta. Tenho muito carinho por você.

À Thaís R. Lucca, uma companheira para todas as horas. Obrigado por toda ajuda e incentivo nos últimos dias. O seu carinho foi muito importante para mim. Adoro você.

Aos meus colegas de república Maikon, Augusto e Luis. Valeu Rep. Saara.

Aos colegas do LABIC. Em especial ao Richardson, Takashi e Ronaldo (o rei do $\mathrm{LAT}_{\mathrm{E}} \mathrm{X}$ ), pelo auxílio na execução de diversas tarefas.

A todos os colegas da PgCompUSP-04 pelos momentos inesquecíveis de descontração, principalmente nas Jam Sessions. Valeu Casa Velha.

Ao CNPq pelo apoio financeiro para o desenvolvimento deste trabalho. 



\section{Resumo}

O processo de Mineração de Dados (MD) consiste na extração automática de padrões que representam o conhecimento implícito em grandes bases de dados. Em geral, a MD pode ser classificada em duas categorias: preditiva e descritiva. Tarefas da primeira categoria, tal como a classificação, realizam inferências preditivas sobre os dados enquanto que tarefas da segunda categoria, tal como o clustering, exploram o conjunto de dados em busca de propriedades que o descrevem. Diferentemente da classificação, que analisa exemplos rotulados, o clustering utiliza exemplos para os quais o rótulo da classe não é previamente conhecido. Nessa tarefa, agrupamentos são formados de modo que exemplos de um mesmo cluster apresentam alta similaridade, ao passo que exemplos em clusters diferentes apresentam baixa similaridade. O clustering pode ainda facilitar a organização de clusters em uma hierarquia de agrupamentos, na qual são agrupados eventos similares, criando uma taxonomia que pode simplificar a interpretação de clusters. Neste trabalho, é proposto e desenvolvido um módulo de aprendizado não-supervisionado, que agrega algoritmos de clustering hierárquico e ferramentas de análise de clusters para auxiliar o especialista de domínio na interpretação dos resultados do clustering. Uma vez que o clustering hierárquico agrupa exemplos de acordo com medidas de similaridade e organiza os clusters em uma hierarquia, o usuário/especialista pode analisar e explorar essa hierarquia de agrupamentos em diferentes níveis para descobrir conceitos descritos por essa estrutura. O módulo proposto está integrado em um sistema maior, em desenvolvimento no Laboratório de Inteligência Computacional - LABIC - , que contempla todas as etapas do processo de MD, desde o pré-processamento de dados ao pós-processamento de conhecimento. Para avaliar o módulo proposto e seu uso para descoberta de conceitos a partir da estrutura hierárquica de clusters, foram realizados diversos experimentos sobre conjuntos de dados naturais, assim como um estudo de caso utilizando um conjunto de dados real. Os resultados mostram a viabilidade da metodologia proposta para interpretação dos clusters, apesar da complexidade do processo ser dependente das características do conjunto de dados. 



\section{Abstract}

The Data Mining (DM) process consists of the automated extraction of patterns representing knowledge implicitly stored in large databases. In general, DM tasks can be classified into two categories: predictive and descriptive. Tasks in the first category, such as classification and prediction, perform inference on the data in order to make predictions, while tasks in the second category, such as clustering, characterize the general properties of the data. Unlike classification and prediction, which analyze class-labeled data objects, clustering analyses data objects without a known class-label. Clusters of objects are formed so that objects that are in the same cluster have a close similarity among them, but are very dissimilar to objects in other clusters. Clustering can also facilitate the organization of clusters into a hierarchy of clusters that group similar events together. This taxonomy formation can facilitate interpretation of clusters. In this work, we propose and develop tools to deal with this task by implementing a module which comprises hierarchical clustering algorithms and several cluster analysis tools, aiming to help the domain specialist to interpret the clustering results. Once clusters group objects based on similarity measures which are organized into a hierarchy, the user/specialist is able to carry out an analysis and exploration of the agglomeration hierarchy at different levels of the hierarchy in order to discover concepts described by this structure. The proposed module is integrated into a large system under development by researchers from the Computational Intelligence Laboratory - LABIC -which contemplates all the DM process steps, from data pre-processing to knowledge post-processing. To evaluate the implemented module and its use to discover concepts from the hierarchical structure of clusters, several experiments on natural databases were carried out as well as a case study using a real database. Results show the viability of the proposed methodology although the process could be complex depending on the characteristics of the database. 



\section{Sumário}

Sumário $\quad$ ix

Lista de Figuras $\quad$ xi

Lista de Tabelas $\quad$ xiii

Lista de Abreviaturas $\quad$ xv

Tabela de Símbolos $\quad$ xvii

1 Introdução 1

2 Aprendizado de Máquina $\quad 9$

2.1 Considerações Iniciais . . . . . . . . . . . . . . . . . 9

2.2 Estratégias do Aprendizado de Máquina . . . . . . . . . . . . 9

2.3 Aprendizado Supervisionado . . . . . . . . . . . . . . 12

2.4 Aprendizado Não-Supervisionado . . . . . . . . . . . . 14

2.5 Aprendizado Semi-Supervisionado . . . . . . . . . . . 16

2.6 Considerações Finais . . . . . . . . . . . . . . . . 17

3 Agrupamento de Dados 19

3.1 Considerações Iniciais . . . . . . . . . . . . . . . . . . 19

3.2 Abordagens de Clustering . . . . . . . . . . . . . . 19

3.3 Etapas do Processo de Clustering . . . . . . . . . . . . 25

3.3.1 Pré-processamento . . . . . . . . . . . 26

3.3.2 Seleção da Medida de Similaridade . . . . . . . . . . 28

3.3.3 Avaliação de Clusters . . . . . . . . . . . . . 37

3.3.4 Interpretação de Clusters . . . . . . . . . . . . . . 39

3.4 Representação do Clustering Hierárquico . . . . . . . . . . . . . 41

3.5 Considerações Finais . . . . . . . . . . . . . 48

4 Ferramentas e Algoritmos de Clustering Hierárquico $\mathbf{5 1}$

4.1 Considerações Iniciais . . . . . . . . . . . . . . . 51

4.2 Algoritmos de Clustering Hierárquico . . . . . . . . . . . . . 51

4.3 Ferramentas e Bibliotecas de Clustering Hierárquico . . . . . . 61

4.4 Considerações Finais . . . . . . . . . . . . . . 63

5 O Módulo de Clustering Hierárquico do Discover 65

5.1 Considerações Iniciais . . . . . . . . . . . . . . . . 65

5.2 A Biblioteca de Classes DOL . . . . . . . . . . . . . . . 66

5.3 O Gerenciador de Experimentos SNIFFER . . . . . . . . . . 67

5.4 Sintaxe de Descrição dos Dados do Discover . . . . . . . . . . 68

5.5 Descrição do Módulo de Clustering Hierárquico . . . . . . . . . 69 
5.5.1 O Módulo Cluster.pm .............. 71

5.5.2 Gerenciador de Experimentos e Análise do Clustering . $\quad 72$

5.6 Interpretação da Hierarquia de Clusters . . . . . . . . . 75

5.7 Considerações Finais ． . . . . . . . . . . . . 76

6 Avaliação Experimental com Conjuntos de Dados Naturais $\quad 77$

6.1 Considerações Iniciais . . . . . . . . . . . . . . . . 77

6.2 Descrição dos Conjuntos de Dados . . . . . . . . . . . 77

6.3 Execução dos experimentos . . . . . . . . . . . . . . . 79

6.4 Interpretação de Clusters e Discussão dos Resultados . . . . . 87

6.5 Considerações Finais . . . . . . . . . . . . . . . . . 93

7 Estudo de caso $\quad 95$

7.1 Considerações Iniciais . . . . . . . . . . . . . . . . . 95

7.2 Domínio da Aplicação - Análise Seminal e Processamento de Sêmen Diagnóstico . . . . . . . . . . . . . . . . . 96

7.3 Coleta, Limpeza e Preparação dos Dados . . . . . . . . . . . . 99

7.4 Avaliação Experimental . . . . . . . . . . . . . . . . . 101

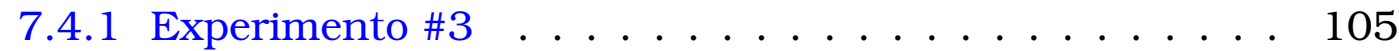

7.4 .2 Experimento \#4 . . . . . . . . . . . . 110

7.5 Considerações Finais . . . . . . . . . . . . . . . . 113

8 Conclusões $\quad 115$

$\begin{array}{ll}\text { Referências Bibliográficas } & 119\end{array}$ 


\section{Lista de Figuras}

2.1 Hierarquia do aprendizado indutivo. . . . . . . . . . 11

2.2 Processo de classificação. . . . . . . . . . . . . . . . . . . . . . . . . . . . . 13

2.3 Clusters versus classes. . . . . . . . . . . . . . . . 15

3.1 Representação de agrupamentos com sobreposição. . . . . . . 22

3.2 Clusters com diferentes densidades. . . . . . . . . . . . . 25

3.3 Tipos e escalas de atributos. . . . . . . . . . . . . . . 27

3.4 Cluster curvilíneo. . . . . . . . . . . . . . . 28

3.5 Distância de Manhattan. . . . . . . . . . . . . . . 31

3.6 Efeito da variação de $r$ na métrica de Minkowsky. . . . . . . . 32

3.7 Metodologia para interpretação de clusters. . . . . . . . . . 41

3.8 Diagrama de Venn. . . . . . . . . . . . . . . . . . 43

3.9 Banner. . . . . . . . . . . . . . . . 44

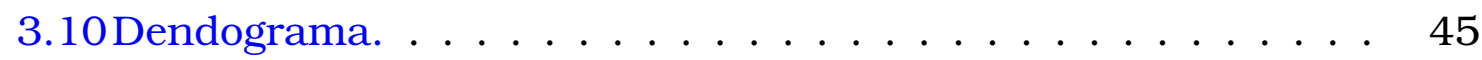

3.11 Comparação de dendogramas. . . . . . . . . . . . . 46

4.1 Single Link. . . . . . . . . . . . . . . . . . . . . . . . 52

4.2 Minimal Spanning Tree. ............... 53

4.3 Complete Link. . . . . . . . . . . . . . . . . . . . . . . . . . . . . . . . . . . . . . 54

4.4 Average Link. . . . . . . . . . . . . . . . . . . . . . . 54

4.5 Etapas do algoritmo BIRCH. . . . . . . . . . . . . . . . 56

4.6 Etapas do algoritmo CURE. . . . . . . . . . . . . . 58

4.7 Etapas do algoritmo CHAMELEON. . . . . . . . . . . . . . . . . . 59

4.8 Ilustração do conceito de ligações. . . . . . . . . . . . . . . . . . 59

4.9 Etapas do algoritmo ROCK. . . . . . . . . . . . . . 60

5.1 Módulo cluster.pm. ................. 72

5.2 Visão geral do sHellCluster. . . . . . . . . . . . . . 73

5.3 Módulo de clustering hierárquico do Discover. . . . . . . . . . 74

5.4 Hierarquia de clusters. . . . . . . . . . . . 75

6.1 Dendograma obtido por meio do algoritmo Single Link utilizando a medida de correlação de Spearman sobre o conjunto de dados Bupa. . . . . . . . . . . . . . . .

6.2 Dendograma obtido por meio do algoritmo Complete Link utilizando a medida de distância de Manhattan sobre o conjunto de dados Bupa. . . . . . . . . . . . . . . .

6.3 Dendograma obtido por meio do algoritmo Average Link utilizando a medida de distância de Manhattan sobre o conjunto de dados German. 
6.4 Dendograma obtido por meio do algoritmo Average Link utilizando a medida de distância de Manhattan sobre o conjunto de dados Hungaria. . . . . . . . . . . . . . . . . . . .

6.5 Dendograma obtido por meio do algoritmo Complete Link utilizando a medida de distância Euclidiana sobre o conjunto de dados Pima. . . . . . . . . . . . . . . .

6.6 Dendograma obtido por meio do algoritmo Average Link utilizando a medida de distância Euclidiana sobre o conjunto de dados Vehicle. . . . . . . . . . . . . . . . . . 86

7.1 (a) e (b): Dendogramas obtidos a partir do exp \#3. . . . . . . 106

7.2 Exemplo de um gráfico de coordenadas paralelas sobre um conjunto de dados com 5 atributos. . . . . . . . . . . . 108

7.3 Representação dos clusters do experimento \#3 por meio de coordenadas paralelas. . . . . . . . . . . . . . . 109

7.4 (a) e (b): Dendogramas obtidos a partir do exp \#4. . . . . . . 112

7.5 Representação dos clusters do experimento \#4 por meio de coordenadas paralelas. . . . . . . . . . . . . . . . 113 


\section{Lista de Tabelas}

2.1 Representação do conjunto de dados por meio da tabela atributovalor. . . . . . . . . . . . . . . . . . . 13

2.2 Matriz de similaridade utilizada pelos algoritmos de clustering. 15

3.1 Ranques dos atributos utilizados na correlação de Kendall's $\tau$. 36

3.2 Coeficientes utilizados no cálculo de medidas de associação. . 37

5.1 Conjunto de dados toy. . . . . . . . . . . . . . . . . 68

5.2 Arquivo toy . names. . . . . . . . . . . . . . . . . . 69

5.3 Arquivo toy dat. . . . . . . . . . . . 70

5.4 Arquivo toy.mask. . . . . . . . . . . . . . 71

6.1 Resumo dos conjuntos de dados utilizados nos experimentos. 79

6.2 Coeficiente cophenético dos 60 experimentos realizados com conjuntos de dados naturais. . . . . . . . . . . . . . 79

6.3 Distribuição dos exemplos entre clusters e classes. . . . . . . . 82

6.4 Resultado do indutor sobre os conjuntos de dados naturais. . 88

7.1 Valores normais do espermograma segundo a Organização Mundial de Saúde (OMS). . . . . . . . . . . . . . . . . . . . . . . 98

7.2 Resumo do conjunto de dados Processamento de Sêmen. . . . 99

7.3 Atributos do conjunto de dados utilizados no estudo de caso. 100

7.4 Coeficiente cophenético para o clustering sobre o conjunto de dados original. . . . . . . . . . . . . . . . . 102

7.5 Relação de exemplos considerados outliers em cada experimento. 103

7.6 Coeficiente cophenético para o clustering sobre o conjunto de dados sem os outliers. . . . . . . . . . . . . . . . . . . 103

7.7 Clusters identificados em cada experimento selecionado para análise. . . . . . . . . . . . . . . . . 104

7.8 Padrões para análise dos clusters. . . . . . . . . . . . 105

7.9 Erro do classificador $\mathcal{C} 4.5$ rules. . . . . . . . . . . . . . . . . 105

7.10 Experimento 3: clusters encontrados. . . . . . . . . . . . 107

7.11 Experimento 3: comparação entre os clusters. . . . . . . . . 107

7.12 Experimento 3: comparação entre os clusters utilizando atributos cujos valores de referência não são definidos pela OMS. 107

7.13Tratamento indicado. . . . . . . . . . . . . . 110

7.14 Experimento 4: clusters encontrados. . . . . . . . . . 111

7.15 Experimento 4: comparação entre os clusters. . . . . . . . 111

7.16 Experimento 4: comparação entre os clusters utilizando atributos cujos valores de referência não são definidos pela OMS. 111 



\section{Lista de Abreviaturas}

AC Aquisição de Conhecimento

AM Aprendizado de Máquina

DLE Discover Learning Environment

DOL Discover Object Library

DSX Discover Standard Sintax

GPS General Problem Solver

IA Inteligência Artificial

KNN $k$-Nearest Neighbor

LABIC Laboratório de Inteligência Computacional do ICMC/USP

MD Mineração de Dados

MST Minimal Spanning Tree

MT Mineração de Texto

OMS Organização Mundial de Saúde

UCI University of California at Irvine 



\section{Tabela de Símbolos}

\begin{tabular}{|c|c|}
\hline Símbolo & Descrição \\
\hline$N:$ & número de exemplos do conjunto de dados \\
\hline$M:$ & número de atributos dos exemplos \\
\hline$N_{C_{l}}$ : & número de classes do conjunto de dados \\
\hline$\left|C_{i}\right|:$ & $\begin{array}{l}\text { número de exemplos que constituem } \\
\text { o cluster } C_{i}\end{array}$ \\
\hline$E_{i}, i=1,2, \ldots N:$ & exemplo $i$ do conjunto de dados \\
\hline$X_{l}, l=1,2, \ldots M:$ & rótulo dos atributos dos exemplos \\
\hline$x_{i l}:$ & valor do atributo $l$ do exemplo $i$ \\
\hline$w_{E_{i}}:$ & peso do exemplo $E_{i}$ \\
\hline$w_{X_{l}}:$ & peso do atributo $X_{l}$ \\
\hline $\operatorname{sim}\left(E_{i}, E_{j}\right):$ & similaridade entre os exemplos $E_{i}$ e $E_{j}$ \\
\hline$\mu_{\text {sim }}$ & média de similaridade do conjunto de dados \\
\hline $\operatorname{coph}\left(E_{i}, E_{j}\right):$ & $\begin{array}{l}\text { similaridade cophenética entre os } \\
\text { exemplos } E_{i} \text { e } E_{j}\end{array}$ \\
\hline$\mu_{\text {coph }}$ & $\begin{array}{l}\text { média das similaridades cophenéticas } \\
\text { do dendograma }\end{array}$ \\
\hline $\operatorname{dist}\left(E_{i}, E_{j}\right)$ : & distância entre os exemplos $E_{i}$ e $E_{j}$ \\
\hline $\operatorname{dist}\left(C_{i}, C_{j}\right)$ : & distância entre os clusters $C_{i}$ e $C_{j}$ \\
\hline$r:$ & $\begin{array}{l}\text { parâmetro de configuração da métrica } \\
\text { de Minkowsky }\end{array}$ \\
\hline $\operatorname{cor}\left(E_{i}, E_{j}\right)$ : & correlação entre os exemplos $E_{i}$ e $E_{j}$ \\
\hline $\operatorname{Cov}():$. & matriz de covariância \\
\hline$\overline{x_{i}}:$ & $\begin{array}{l}\text { média dos valores dos atributos } \\
\text { do exemplo } E_{i} \text {, i.e., } \frac{\sum_{l=1}^{M} x_{i l}}{M}\end{array}$ \\
\hline$\sigma_{i}:$ & $\begin{array}{l}\text { desvio padrão dos valores dos atributos } \\
\text { do exemplo } E_{i}\end{array}$ \\
\hline$\tau:$ & coeficiente de correlação de Kendall \\
\hline$n c_{\tau}:$ & $\begin{array}{l}\text { número de pares concordantes para } \\
\text { o cálculo do } \tau\end{array}$ \\
\hline$n d_{\tau}:$ & $\begin{array}{l}\text { número de pares discordantes para } \\
\text { o cálculo do } \tau\end{array}$ \\
\hline$k:$ & número de clusters \\
\hline
\end{tabular}





\section{Capítulo}

\section{Introdução}

A história da computação começa aproximadamente 2000 anos atrás, a partir da criação do ábaco. Com o tempo, as invenções e avanços tecnológicos deram origem a outras ferramentas, como a "Tábua de Napier"1 proposta por John Napier (1550-1617), a calculadora mecânica de Blaise Pascal (1623-1662) e o calculador analítico de Charles Babbage (1792-1871)2.

Alguns dos grandes eventos mundiais impulsionaram o desenvolvimento tecnológico. Mecanismos controlados por meio de cartões perfurados, máquinas de tabular e ordenar, por exemplo, foram utilizados para processar os dados de censos urbanos em 1880, reduzindo o tempo de processamento de 7 anos e meio para 2 anos e meio. Além disso, as grandes guerras mundiais deram início às construções dos primeiros computadores, que funcionavam com uma tecnologia, hoje ultrapassada, de relês eletromagnéticos. Em conseqüência do avanço tecnológico, mecanismos mais poderosos e com custo mais baixo foram produzidos, facilitando o acesso e utilização em massa. Além disso, redes de computadores, correios eletrônicos e veículos de publicação eletrônicos têm se difundido em grande escala nos últimos anos, o que acarreta o aumento do armazenamento e troca de informações através desses meios de comunicação.

A quantidade de dados armazenados em meios digitais aumenta diariamente com rapidez assustadora. Muitas das organizações que produzem esses dados em suas tarefas cotidianas percebem o valor que eles representam, e investem no desenvolvimento de pesquisas e na elaboração de

${ }^{1}$ A Tábua de Napier reduzia multiplicações e divisões a adições e subtrações. Usando esse princípio, em 1620 foram criadas as réguas de cálculo, usadas até 1970, antes das calculadoras de bolso.

${ }^{2}$ Charles Babbage (1792-1871) conhecido como o "Pai do Computador", projetou o calculador analítico. Esse mecanismo nunca foi implementado, devido às dificuldades com a tecnologia da época, que era inadequada para a construção de componentes mecânicos com a precisão necessária a essa concepção moderna e muito próxima da concepção de um computador atual. 
estratégias que permitam tirar algum proveito desse grande acúmulo de dados. Para isso, há necessidade de transformá-los, de algum modo, em informações que possam gerar conhecimento útil aos processos de tomada de decisão dessas organizações e, conseqüentemente, obter alguma vantagem nesse mundo tão competitivo. Companhias distribuidoras de energia elétrica, por exemplo, produzem em um dia de trabalho uma grande quantidade de dados referentes à carga de distribuição de energia, consumo diário residencial e industrial, além de diversas outras informações. Outro exemplo são as empresas de comércio eletrônico, as quais armazenam dados relacionados às suas transações financeiras em meios digitais. Entretanto, existem muitos setores que não fazem uso das tecnologias disponiveis. Nesses casos, se há algum interesse em descobrir conhecimento a partir dos dados armazenados, o processo de análise é feito de maneira manual, tornando essa tarefa ainda mais difícil.

A medicina é uma das grandes áreas de conhecimento que recentemente vem se destacando no uso de tecnologias avançadas. Nesse caso, são desenvolvidos equipamentos e softwares que facilitam o trabalho dos profissionais da área e também contribuem para melhorias na organização e no armazenamento dos dados oriundos dos diferentes procedimentos, por exemplo, exames clínicos e laboratoriais ou mesmo procedimentos cirúrgicos complexos. Com a disponibilidade desses dados, é possivel utilizar sistemas de aprendizado para extração de conhecimento útil e, com esse conhecimento facilitar a resolução de problemas envolvidos nos diversos procedimentos.

Nesse processo de desenvolvimento de tecnologias, muitas ferramentas computacionais são projetadas e implementadas com o objetivo de facilitar a análise de dados. Algumas dessas ferramentas atendem às etapas realizadas no processo de descoberta de conhecimento e mineração de dados, o qual é composto por três etapas principais (Rezende, 2003): préprocessamento de dados, extração de padrões e pós-processamento do conhecimento extraído. Freqüentemente, na etapa de extração de padrões são utilizados algoritmos de aprendizado para aquisição automática ou semiautomática de conhecimento. Entretanto, outras ferramentas também são utilizadas, por exemplo, softwares para construção de gráficos que permitem a análise visual dos conjuntos de dados. Para atender essa demanda, softwares com suporte às tarefas de mineração de dados são desenvolvidos e/ou aprimorados constantemente. O Mineset ${ }^{3}$ (Rathjens, 2000), por exemplo, é utilizado em aplicações de Mineração de Dados (MD). Essa ferramenta, desenvolvida pela SGI - Silicon Graphics, é composta por um con-

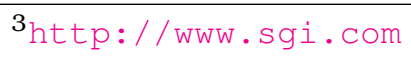


junto de recursos para a execução de tarefas de análise multi-dimensional e mineração de dados. Alguns dos principais algoritmos de Aprendizado de Máquina (AM), recursos de visualização de dados e de estatísticas descritivas, são exemplos desses recursos. Entretanto, o Mineset é um software comercial e faz uso de algoritmos proprietários, o que torna difícil a sua utilização em massa, pois, para muitos usuários e pesquisadores, o custo pode inviabilizar a sua utilização. Além disso, devido à dificuldade de acesso às heurísticas, estruturas e representações internas dos algoritmos, os softwares comerciais não contribuem adequadamente para o desenvolvimento científico e para elaboração de novas ferramentas e metodologias.

Algumas alternativas para as limitações do custo de software comercial podem ser encontradas em ferramentas de domínio público, por exemplo, o WEKA - Waikato Environment for Knowledge Analysis(Witten \& Frank, 2000), o YALE - Yet Another Learning Environment ${ }^{4}$ (Ritthoff et al., 2001) e o Orange ${ }^{5}$ (Demsar \& Zupan, 2004). Por outro lado, essas ferramentas apresentam algumas características que podem limitar seu uso em ambientes de pesquisa, no qual é importante ter controle total do software utilizado. O WEKA reimplementa os algoritmos de aprendizado utilizando a linguagem de programação $\mathrm{JAVA}^{6}$, o que padroniza as interfaces dos algoritmos e produz código uniforme facilitando a inclusão de novas funcionalidades. Mas apresenta outro problema: a recodificação dos algoritmos, que está sempre sujeita às tomadas de decisão do implementador, podem acarretar a obtenção de resultados diferentes dos encontrados com o código original.

O ambiente YALE também é implementado em JAVA, mas ao contrário do WEKA, utiliza alguns algoritmos em suas implementações originais, e, conseqüentemente, possibilita a reprodução dos mesmos resultados apresentados pelos idealizadores desses algoritmos se aplicados sobre os mesmos conjuntos de dados.

O Orange é uma ferramenta para MD baseada em componentes escritos em linguagem $\mathcal{C}^{++}$(Stroustrup, 1997). Esses componentes podem ser acessados a partir de scripts Phyton ${ }^{7}$ ou por meio de uma interface de objetos chamados de Orange Widgets. Assim como o YALE, essa ferramenta disponibiliza a implementação original de alguns algoritmos amplamente referenciados na literatura, mas também possui implementações próprias de diversos indutores e outros algoritmos para análise de dados e extração de conhecimento.

Além desses ambientes de software de domínio público, que integram

\footnotetext{
$4_{\text {http: //www.yale.cs.uni-dortmund.de }}$

$5_{\text {http: }} / /$ www.ailab.si/orange

$6_{\text {http: //java.sun.com/reference/index.html }}$

${ }^{7}$ http://www.python.org/
} 
uma grande quantidade de ferramentas para as mais diversas técnicas utilizadas em aplicações de aprendizado de máquina, há também um pacote de software, Cluto (Karypis, 2003), implementado exclusivamente para a execução do clustering particional e hierárquico, principal objeto de estudo deste trabalho. Outros algoritmos podem ser encontrados também em ambientes estatísticos, tal como o $\mathrm{R}$ (Team, 2005) ${ }^{8}$, que dispõe de diversos pacotes com implementações de algoritmos de clustering.

Para a construção de sistemas de aprendizado a serem utilizados na etapa de extração de padrões do processo de mineração de dados, o desenvolvedor deve considerar a estratégia de aprendizado que será utilizada pelo sistema, equilibrando sempre o grau de complexidade da estratégia utilizada e o grau de complexidade do conhecimento que se deseja extrair. A disponibilidade e as características dos dados também devem ser consideradas para a construção desses sistemas, pois essas características determinam qual modo de aprendizado é mais adequado para a aplicação. Quando um grande número de exemplos contidos nos conjuntos de dados estão previamente rotulados com um atributo classe, o modo de aprendizado supervisionado é mais apropriado. Se apenas poucos exemplos possuem o rótulo da classe, então o aprendizado semi-supervisionado deve ser utilizado. Por outro lado, quando a classe dos exemplos não é conhecida, o modo de aprendizado não-supervisionado é mais indicado.

Para obter conjuntos de dados com exemplos supervisionados, é normalmente necessário o comprometimento de um especialista do domínio para classificar um grande número de exemplos. Em geral, esse processo deve ser realizado de maneira manual, o que o torna lento e altamente custoso. Devido a esse fato, algoritmos de clustering têm sido freqüentemente utilizados em tarefas de exploração de dados e extração de conhecimento, como detecção de características e segmentação de imagens, extração de padrões em expressões gênicas e seqüências de proteínas e outras aplicações em bioinformática. Os resultados obtidos por meio dessa técnica de aprendizado de máquina não-supervisionado são altamente dependentes da escolha de parâmetros como as medidas de similaridade e os métodos de agrupamentos. Além disso, para que o processo seja realizado com sucesso, algumas etapas devem ser executadas: preparação dos dados, seleção das medidas de similaridade e do algoritmo de clustering, execução do algoritmo, avaliação dos resultados e interpretação dos clusters encontrados.

Apesar de toda essa gama de ferramentas, poucas suportam todas as etapas envolvidas na mineração de dados. Considerando essa característica, aliada ao fato de que muitas pesquisas em aquisição automática de

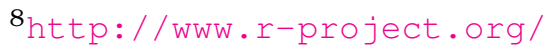


conhecimento desenvolvidas no Laboratório de Inteligência Computacional do ICMC/USP (LABIC) por diferentes pesquisadores têm, em geral, alguns componentes em comum, existindo em algumas situações a replicação de esforços no desenvolvimento de softwares, foi proposto o projeto DisCOVER (Baranauskas \& Batista, 2000). De modo geral, o Discover pode ser entendido como um ambiente computacional composto de um conjunto de métodos de aprendizado de máquina e rotinas para pré-processamento de dados e pós-processamento de conhecimento. Para que esses métodos possam ser aplicados corretamente, é importante que o Discover disponha de uma base sólida para a manipulação de dados e conhecimento descritos por meio de sintaxes padronizadas e bibliotecas que ofereçam um conjunto de funcionalidades básicas para manipulação de arquivos nessas sintaxes (Batista \& Monard, 2003; Prati et al., 2001b,a).

A vantagem do projeto Discover como ferramenta de apoio à pesquisa em mineração de dados, em relação a outros sistemas, é a visão unificada que a padronização das sintaxes propicia para o desenvolvedor de novos componentes, além de um conjunto de ferramentas de manipulação dessas sintaxes. Diferentemente dos projetos comerciais, o DiScover tem como finalidade seu uso e extensão por pesquisadores de aprendizado de máquina, mineração de dados e mineração de textos. O ponto crucial desse projeto é sua flexibilidade em permitir que novas pesquisas sejam englobadas e, simultaneamente, imponha determinados padrões de projeto e desenvolvimento que proporcionem a integração de todos os seus componentes, além de um conjunto de processos para a construção de um ambiente de execução apropriado para o sistema. Para atingir esses objetivos foi realizado um estudo que resultou na definição do processo de desenvolvimento do Discover (Rozante, 2003; Prati, 2003).

Atualmente, o Discover dispõe de diversos módulos, como pré-processamento de dados (normalização, filtros, randomização, seleção e outros), cálculos de distância e estatísticas básicas, módulo de execução dos algoritmos de aprendizado supervisionado (classificação e regressão), semisupervisionado, mineração de textos e pós-processamento de conhecimento simbólico. Porém, ainda não tinha sido considerada a integração de algoritmos de aprendizado não-supervisionado, mais especificamente, de algoritmos de clustering hierárquico, objeto de estudo deste trabalho.

A necessidade de métodos eficientes para análise de dados não-supervisionados, e de um ambiente integrado que contemple todas as tarefas realizadas no processo de análise e descoberta de conhecimento em bases de dados, são os principais fatores que motivaram o desenvolvimento do módulo de clustering hierárquico proposto neste trabalho. Além disso, a 
proposta de uma sintaxe padrão para representar os clusters encontrados usando diversos algoritmos de clustering hierárquico, constituiu um desafio enfrentado durante o desenvolvimento deste trabalho, e também mais uma motivação.

Nesse contexto, um dos objetivos deste trabalho consiste no projeto, implementação e integração de um módulo de clustering hierárquico ao DiscoVER. No desenvolvimento desse módulo foi utilizada uma biblioteca escrita na linguagem ANSI C com implementações de diversas rotinas para execução do clustering. Além disso, a biblioteca de classes do Discover foi utilizada para fazer a integração do módulo proposto com os demais módulos disponiveis nesse ambiente, o que também facilitou a execução de experimentos de clustering, no sentido de que outras técnicas podem ser aplicadas aos conjuntos de dados nas etapas de pré e pós-processamento em um ambiente único e integrado. Para isso, foi elaborada uma sintaxe para descrição dos clusters de modo que as saídas de todos os algoritmos são representadas de maneira coerente e padronizada. Em um trabalho desenvolvido anteriormente (Metz \& Monard, 2006a), foi realizado um levantamento bibliográfico dos algoritmos de clustering hierárquico mais freqüentemente utilizados assim como as representações e estruturas de dados internas. Com base nesse estudo, foram decididas as características do módulo de clustering do DiscOVER.

Outro objetivo deste trabalho, é avaliar a utilização de metodologias de interpretação de clusters para facilitar o trabalho do especialista de domínio na realização da etapa de interpretação dos padrões extraídos pelos algoritmos. Nessa etapa, de extrema importância para o sucesso da aplicação, o especialista de domínio desempenha um papel fundamental, pois, a partir do seu esforço e conhecimento, podem ser interpretados e/ou atribuídos significados conceituais aos clusters. Para facilitar essa tarefa, é interessante que existam metodologias semi-automáticas que auxiliem o especialista na compreensão das estruturas embutidas no conjunto de dados, as quais são representadas pelos clusters após a execução dos algoritmos de agrupamento.

Uma proposta apresentada neste trabalho, é utilizar a estrutura hierárquica de agrupamentos, representada por meio do dendograma construído a partir da execução de algoritmos de clustering hierárquico, para descobrir conhecimento de maneira semi-automática. Com essa estratégia, a análise do dendograma é realizada a cada nível da hierarquia para tentar identificar os conceitos que descrevem os exemplos nos clusters. Inicialmente, o dendograma pode ser cortado, por exemplo, no primeiro nível de agrupamento, resultando na separação dos exemplos em dois clusters. A partir desses 
clusters, é aplicada a metodologia de interpretação de clusters proposta por Martins (2003), na qual os cluster são utilizados para rotular os exemplos e construir um conjunto de dados supervisionado, a partir do qual são induzidas regras de decisão que explicam, simbolicamente, o conhecimento descrito pelos clusters. Caso o especialista não consiga definir o conceito do cluster somente a partir desse conjunto de regras, o processo todo pode ser refeito em um nível abaixo na hierarquia e, com isso, refinar a análise do dendograma. Uma vez que o conceito do cluster foi compreendido, os exemplos desse cluster são isolados dos demais e o processo aplicado em outro cluster.

Para ilustrar a utilização da metodologia de interpretação de clusters hierárquicos e de análise do dendograma apresentadas neste trabalho, e, ainda, com o objetivo de avaliar cada um dos algoritmos disponíveis no módulo proposto, medindo a adequabilidade dos clusters aos respectivos dados utilizados, foram realizados diversos experimentos com conjuntos de dados naturais. Esses conjuntos de dados foram selecionados a partir do repositório de dados da Universidade da Califórnia, UCI - University of California at Irvine (Newman et al., 1998). Além desses experimentos, foi realizado um estudo de caso utilizando um conjunto de dados real concedido pelo Centro de Referência em Infertilidade Masculina - Androfert. Esse conjunto de dados trata especificamente do problema da infertilidade masculina. O desenvolvimento desse estudo de caso teve a participação de pesquisadores e especialistas do domínio que atuam em projetos de Computação Aplicada à Medicina e Análise Inteligente de Dados e fazem parte do Laboratório de Bioinformática - LABI - Universidade Estadual do Oeste do Paraná, UNIOESTE; do Laboratório de Inteligência Computacional - LABIC - Universidade de São Paulo, USP/São Carlos e do Centro de Referência em Infertilidade Masculina - Androfert. Esse estudo de caso com a participação do especialista foi muito importante para avaliar a adequabilidade da metodologia proposta para interpretar clusters hierárquicos, bem como as facilidades de interação que devem ser fornecidas para que o especialista possa interagir confortavelmente com o módulo de clustering hierárquico implementado.

Este trabalho está organizado da seguinte maneira:

No Capítulo 2 são apresentados alguns conceitos relacionados ao aprendizado de máquina e as possiveis estratégias de aprendizado considerando o grau de supervisão dos conjuntos de dados utilizados.

No Capítulo 3 são apresentados os conceitos e definições principais do aprendizado não-supervisionado ou clustering. São descritas as diversas abordagens utilizadas no processo de clustering, com foco maior na aborda- 
gem hierárquica. Além das etapas envolvidas para a realização desse processo, são descritas várias medidas de similaridade utilizadas para agrupar exemplos. As representações da hierarquia de agrupamentos mais utilizadas para descrever graficamente o resultados dos algoritmos de clustering hierárquico são também apresentadas.

No Capítulo 4 são apresentados os algoritmos clássicos utilizados em clustering hierárquico e diversos outros algoritmos que foram desenvolvidos a partir desses algoritmos clássicos. Algumas ferramentas e bibliotecas existentes para realizar aprendizagem não-supervisionada e, mais especificamente, clustering hierárquico, são também apresentadas neste capítulo.

No Capítulo 5 é descrito o módulo de clustering hierárquico proposto neste trabalho, as bibliotecas, bem como as facilidades do ambiente DiscoVER, no qual este módulo está inserido, utilizadas pelo módulo implementado. A metodologia para avaliação de clusters obtidos a partir da estrutura hierárquica do dendograma é também descrita neste capítulo.

No Capítulo 6 são apresentados alguns experimentos realizados com conjuntos de dados naturais para avaliação do módulo proposto.

No Capítulo 7 é apresentado o estudo de caso analisado neste trabalho, o qual trata especificamente do problema da infertilidade masculina.

As conclusões são apresentadas no Capítulo 8. 


\section{Aprendizado de Máquina}

\subsection{Considerações Iniciais}

Oficialmente, a área de Inteligência Artificial nasceu em 1956 em uma conferência em Dartmouth College, NH, USA. Na proposta dessa conferência submetida à fundação Rockfeller, consta a intenção dos autores de realizar um estudo cujo tema era a inteligência artificial. Neste ano, completando 50 anos de história, percebe-se a evolução dessa área de pesquisa que passou pela construção de sistemas de resolução de problemas gerais - General Problem Solver (GPS) (Ernst \& Newell, 1969), de sistemas especialistas projetados para simular o comportamento de um especialista humano na resolução de um problema de domínio específico e pela elaboração de metodologias para aquisição e análise de conhecimento.

Atualmente, o processo de mineração de dados está sendo amplamente aplicado com objetivo de descobrir conhecimento novo em bases de dados de diversos domínios e áreas de aplicação. Na execução desse processo de exploração de dados e descoberta de conhecimento, são utilizadas, entre outros, técnicas e conceitos de aprendizado de máquina. Neste capítulo, são apresentados alguns dos principais conceitos relacionados ao aprendizado de máquina.

\subsection{Estratégias do Aprendizado de Máquina}

Os objetivos do aprendizado de máquina são o desenvolvimento de técnicas computacionais que permitem simular o processo de aprendizado e a construção de sistemas capazes de adquirir conhecimento de maneira automática (Mitchell, 1997). Esses sistemas utilizam o conhecimento do 
domínio e os resultados de experiências anteriores para auxiliar o processo de tomada de decisão e melhorar o seu desempenho futuro.

O processo de aprendizagem é composto por um conjunto de atividades que buscam adquirir conhecimento sobre um dado domínio por meio de experimentações e observações do mundo real. Essas atividades incluem o desenvolvimento de habilidades cognitivas, organização e representação do conhecimento e descoberta de novo conhecimento. De maneira geral, seres humanos adquirem conhecimento por meio da prática repetida de uma atividade ou por meio de generalizações de fatos observados. Essa habilidade de generalização, ou descoberta de padrões, em coleções de eventos (fatos) aparentemente caóticos, caracteriza o aprendizado por indução, o qual é um modo de raciocínio lógico que utiliza exemplos particulares para inferir conclusões gerais sobre um conceito (Alpaydin, 2004).

Usualmente, em processos de aprendizado o aprendiz utiliza o conhecimento que possui para obter novo conhecimento. O aprendizado de um novo conceito pode ser realizado de diversas maneiras. Cinco estratégias de aprendizado podem ser enumeradas segundo o grau de complexidade de inferência: hábito, instrução, dedução, analogia e indução. A primeira estratégia apresenta menor complexidade de inferência, ao passo que a estratégia indutiva exige maior esforço para o aprendizado (Monard \& Baranauskas, 2003).

Segundo Michalski et al. (1998), no aprendizado por hábito, todo conhecimento é transmitido do instrutor para o aprendiz, o qual não realiza nenhuma inferência sobre as informações fornecidas, apenas as memoriza. No aprendizado por instrução, o aprendiz adquire conceitos de uma fonte (professor e livros textos, por exemplo) mas não transfere diretamente a informação recebida para a memória. Essa estratégia engloba a seleção dos fatos mais importantes e a transformação da informação fonte em formas mais apropriadas. No aprendizado por dedução, o aprendiz adquire um conceito por meio da dedução sobre o conceito já conhecido, i.e., essa estratégia inclui qualquer processo no qual o conhecimento aprendido é o resultado de uma transformação sobre um conhecimento que o indivíduo possui a priori. Essa transformação do conhecimento sempre preserva a verdade. O aprendizado por analogia é caracterizado quando o aprendiz modifica conceitos previamente adquiridos para aprender novos conceitos. Assim, ele não cria regras, mas adapta regras existentes para que possam descrever o novo conceito. Por exemplo, se o aprendiz conhece o conceito "lápis", será mais simples aprender o conceito "caneta".

O aprendizado por indução é caracterizado pelo raciocínio que parte do específico para o geral; é um modo de inferência lógica que permite obter 
generalizações a partir de exemplos para induzir um conceito que pode ou não preservar a verdade. Assim, mesmo que as premissas sejam verdadeiras, pode-se chegar a conclusões falsas. Justamente por ser essa uma estratégia de aprendizado complexa, uma vez que o aprendiz desempenha a maior parte do esforço para a aquisição do conhecimento, esta permite que conceitos muito mais amplos possam ser aprendidos e, portanto, constitui uma das estratégias de aprendizado de maior interesse para pesquisas relacionadas ao aprendizado de máquina.

Além da estratégia utilizada, na construção de um algoritmo de aprendizado deve-se considerar o modo de aprendizado. Sob esse aspecto, o aprendizado indutivo pode ser dividido em supervisionado e não-supervisionado. O que distingüe esses dois modos de aprendizado é a presença ou não do atributo classe que rotula os exemplos do conjunto de dados (Michalski et al., 1983). No aprendizado supervisionado, esse rótulo é conhecido, ao passo que no aprendizado não-supervisionado os exemplos não estão previamente rotulados. Estudos mais recentes têm apresentado um terceiro modo de aprendizado, denominado semi-supervisionado, no qual somente poucos exemplos encontram-se rotulados. Esse fato impossibilita o uso direto de algoritmos de aprendizado supervisionado, pois esse modo de aprendizado requer um número razoável de exemplos rotulados (Blum \& Mitchell, 1998). Na Figura 2.1 é ilustrada a hierarquia do aprendizado indutivo, na qual os nós sombreados direcionam ao tema principal deste trabalho, o clustering hierárquico.

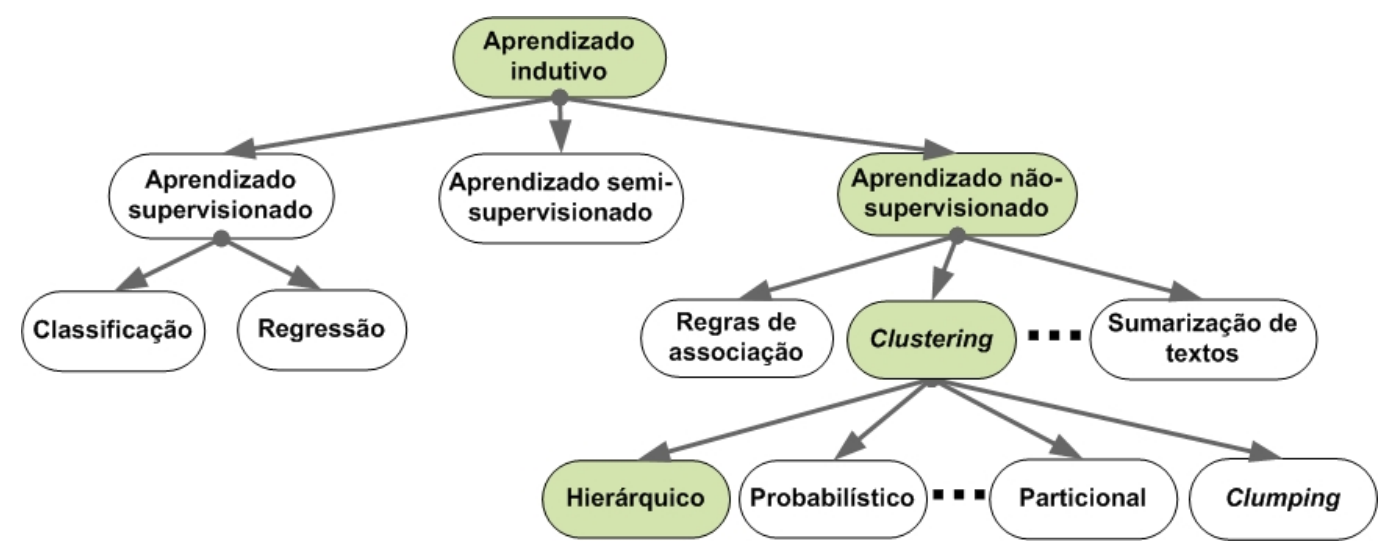

Figura 2.1: Hierarquia do aprendizado indutivo.

Em resumo, os exemplos fornecidos a um algoritmo de aprendizado podem, ou não, estar rotulados com uma classe conhecida. De acordo com esse critério, três modos de aprendizado de máquina podem ser listados:

1. Supervisionado: utilizado quando existe um número expressivo de exemplos rotulados; 
2. Não-supervisionado: utilizado quando os exemplos não estão rotulados; e

3. Semi-supervisionado: utilizado quando existem poucos exemplos rotulados.

Dessa maneira, a escolha do modo de aprendizado depende, muitas vezes, da existência ou da quantidade disponível de exemplos rotulados com o atributo classe. A seguir, esses modos de aprendizado são descritos com maiores detalhes.

\subsection{Aprendizado Supervisionado}

Nesse modo de aprendizado o objetivo é induzir um classificador (ou hipótese), por meio de um conjunto expressivo de dados previamente rotulados, para classificar novos exemplos ainda não rotulados. Se os rótulos das classes possuem valores discretos, como diferentes marcas de carro por exemplo, o problema é conhecido como classificação. Caso as classes possuam valores contínuos, como o peso ou altura de uma pessoa, o problema é conhecido como regressão. No aprendizado supervisionado, o conjunto de dados inicial é, usualmente, dividido em outros três conjuntos de exemplos, denominados conjunto de treinamento, de teste e de validação, descritos a seguir (Alpaydin, 2004):

- conjunto de treinamento: esse conjunto é a principal entrada dos algoritmos de aprendizado supervisionado. É a partir dele que são induzidas as hipóteses, e portanto ele deve representar a distribuição da população para que se possa realizar com sucesso a indução de classificadores;

- conjunto de teste: esse conjunto é utilizado para avaliar o modelo induzido. Para que essa avaliação seja válida estatisticamente, os exemplos contidos nesse conjunto devem ser exemplos não utilizados pelo algoritmo durante a construção da hipótese, i.e., a intersecção desse conjunto com o conjunto de treinamento deve ser o conjunto vazio; e

- conjunto de validação: em alguns casos, pode ser necessário utilizar exemplos para realizar ajustes no modelo induzido. Esses exemplos não são utilizados diretamente na indução do modelo, mas são utilizados na escolha da complexidade mais adequada para o modelo. Dessa maneira, esses casos são indiretamente "vistos" pelo algoritmo durante o processo de indução, o que implica que os exemplos de validação devem ser distintos dos exemplos de teste. 
Em tarefas de aprendizado de máquina, é comum que o conjunto de dados utilizado para análise seja representado por meio de uma estrutura de matriz, denominada tabela atributo-valor - Tabela 2.1. Assim, a entrada para um algoritmo de aprendizado supervisionado consiste, usualmente, de um conjunto $E$ de $N$ exemplos (ou casos) de treinamento $E=$ $\left\{\left(\mathbf{x}_{1}, y_{1}\right), \ldots,\left(\mathbf{x}_{N}, y_{N}\right)\right\}$ rotulados com os valores $y$ de uma função $f$ desconhecida, $y=f(\mathbf{x})$, onde os valores $\mathbf{x}_{i}$ são vetores da forma $\left(x_{i 1}, x_{i 2}, \ldots, x_{i M}\right)$ cujos componentes são valores discretos ou contínuos relacionados ao conjunto de atributos $X=\left\{X_{1}, X_{2}, \ldots, X_{M}\right\}$. Ou seja, $x_{i l}$ denota o valor do atributo $X_{l}$ do exemplo $i$. Dado esse conjunto de exemplos de treinamento, o algoritmo induz uma hipótese $h$ que deve aproximar a verdadeira função $f$, tal que dado um novo exemplo $\mathbf{x}, h(\mathbf{x})$ prediz o valor $y$ correspondente.

\begin{tabular}{c|cccc|c}
\cline { 2 - 4 } & $X_{1}$ & $X_{2}$ & $\cdots$ & $X_{M}$ & Classe $(Y)$ \\
\hline \hline$E_{1}$ & $x_{11}$ & $x_{12}$ & $\vdots$ & $x_{1 M}$ & $y_{1}$ \\
$E_{2}$ & $x_{21}$ & $x_{22}$ & $\vdots$ & $x_{2 M}$ & $y_{2}$ \\
$\vdots$ & $\vdots$ & $\vdots$ & $\ddots$ & $\vdots$ & $\vdots$ \\
$E_{N}$ & $x_{N 1}$ & $x_{N 2}$ & $\vdots$ & $x_{N M}$ & $y_{N}$ \\
\hline \hline
\end{tabular}

Tabela 2.1: Representação do conjunto de dados por meio da tabela atributo-valor.

O processo de classificação, ilustrado na Figura 2.2, consiste em selecionar e pré-processar alguns exemplos, ou ainda fornecer algumas informações adicionais ao indutor, utilizando-se do conhecimento sobre o domínio. Após a indução do classificador, ele deve ser avaliado e, se necessário, o processo repetido para melhorar o modelo induzido.

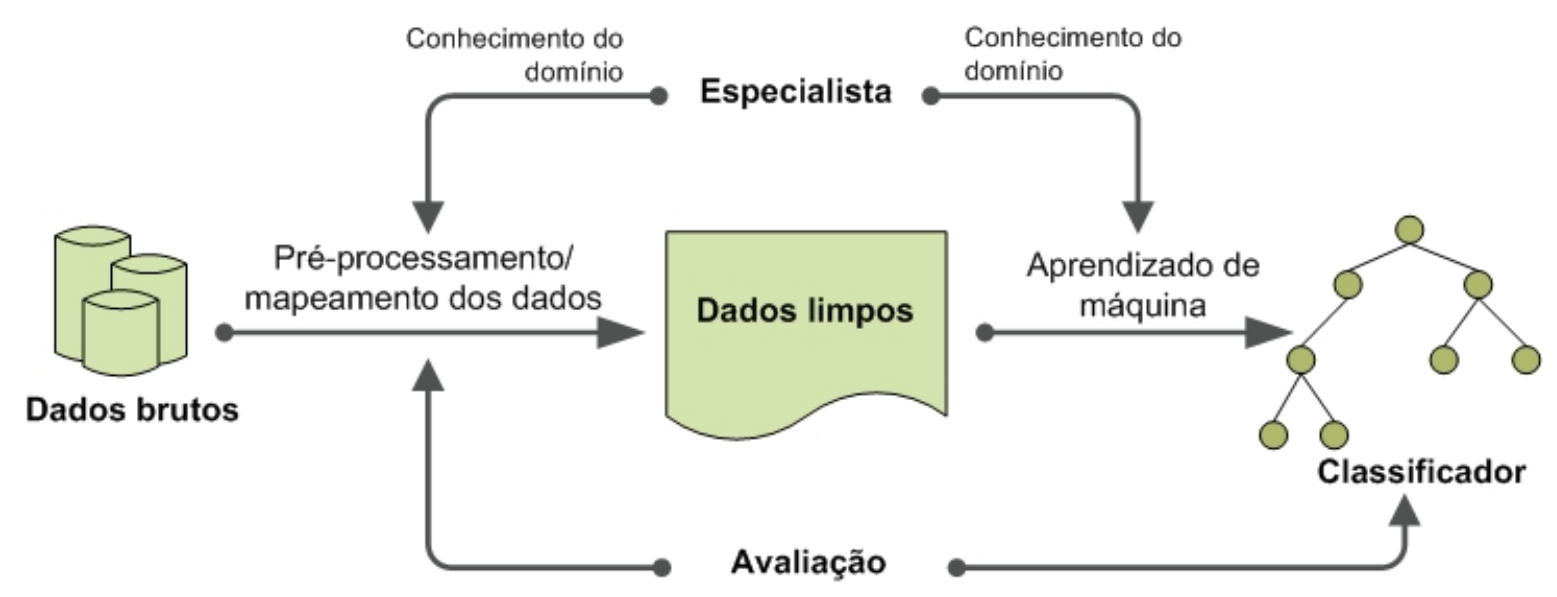

Figura 2.2: Processo de classificação (Monard \& Baranauskas, 2003).

Muitas vezes, o usuário necessita interpretar e compreender o classificador induzido por um sistema de aprendizado supervisionado. De acordo 
com Michalski et al. (1998), os sistemas de aprendizado podem ser classificados em duas grandes categorias, considerando o grau de compreensibilidade proporcionado ao ser humano:

1. sistemas tipo caixa-preta, que desenvolvem sua própria representação do conceito e não fornecem explicações do processo de classificação; e

2. sistemas orientados a conhecimento, que objetivam a criação de estruturas simbólicas que sejam compreensíveis por humanos.

Na primeira categoria, o conceito descrito pela hipótese induzida pode ser considerado como uma "caixa-preta". A segunda categoria é uma visão mais apurada, na qual a "caixa-preta" pode ser aberta e o conceito descrito pela hipótese induzida é facilmente compreensível por humanos. Algoritmos nesta segunda categoria são denominados algoritmos de aprendizado simbólico.

\subsection{Aprendizado Não-Supervisionado}

No aprendizado não-supervisionado, também conhecido como aprendizado por observação e descoberta ou análise exploratória de dados, o conjunto de dados de entrada é composto por exemplos não rotulados, i.e., não há a informação sobre a classe associada a cada exemplo. Nesse caso, são utilizados algoritmos para descobrir padrões nos dados a partir de alguma caracterização de regularidade, sendo esses padrões denominados clusters. Assim, a tarefa consiste em agrupar uma coleção de exemplos segundo alguma medida de similaridade de modo que exemplos pertencentes ao mesmo cluster devem ser mais similares entre si e menos similares aos exemplos que constituem outros clusters.

Os algoritmos e ferramentas de clustering utilizam, usualmente, a tabela atributo-valor para representar o conjunto de exemplos a ser analisado. Porém, nesse caso, a coluna que representa o atributo classe não existe Classe (Y) na Tabela 2.1. Como alternativa à tabela atributo-valor, pode-se também utilizar outra estrutura, conhecida como matriz de similaridade Tabela 2.2 . Essa matriz, constituída de $N$ linhas e $N$ colunas, contém em suas células o valor da similaridade entre cada par de exemplos, de acordo com um índice ou medida de similaridade pré-definido. As células da diagonal principal podem ser ignoradas, uma vez que a similaridade entre um exemplo e ele mesmo é sempre a máxima possível.

Outra distinção importante está relacionada aos conceitos de clusters (AM não-supervisionado) e classes (AM supervisionado). Esses conceitos 


\begin{tabular}{c|ccccc}
\hline \hline Exemplos & $E_{1}$ & $E_{2}$ & $E_{3}$ & $\ldots$ & $E_{N}$ \\
\hline$E_{1}$ & - & $\operatorname{sim}\left(E_{1}, E_{2}\right)$ & $\operatorname{sim}\left(E_{1}, E_{3}\right)$ & $\ldots$ & $\operatorname{sim}\left(E_{1}, E_{N}\right)$ \\
$E_{2}$ & $\operatorname{sim}\left(E_{2}, E_{1}\right)$ & - & $\operatorname{sim}\left(E_{2}, E_{3}\right)$ & $\ldots$ & $\operatorname{sim}\left(E_{2}, E_{N}\right)$ \\
$E_{3}$ & $\operatorname{sim}\left(E_{3}, E_{1}\right)$ & $\operatorname{sim}\left(E_{3}, E_{2}\right)$ & - & $\ldots$ & $\operatorname{sim}\left(E_{3}, E_{N}\right)$ \\
$\vdots$ & $\vdots$ & $\vdots$ & $\vdots$ & - & $\vdots$ \\
$E_{N}$ & $\operatorname{sim}\left(E_{N}, E_{1}\right)$ & $\operatorname{sim}\left(E_{N}, E_{2}\right)$ & $\operatorname{sim}\left(E_{N}, E_{3}\right)$ & $\ldots$ & - \\
\hline \hline
\end{tabular}

Tabela 2.2: Matriz de similaridade utilizada pelos algoritmos de clustering.

não agrupam ou representam necessariamente os mesmos exemplos do conjunto de dados. Eventualmente, é possível que dois ou mais clusters agrupem exemplos que representam uma mesma instância de um determinado conceito (a classe dos exemplos em aprendizado supervisionado), no entanto, clusters e classes são diferentes, como ilustrado na Figura 2.3.

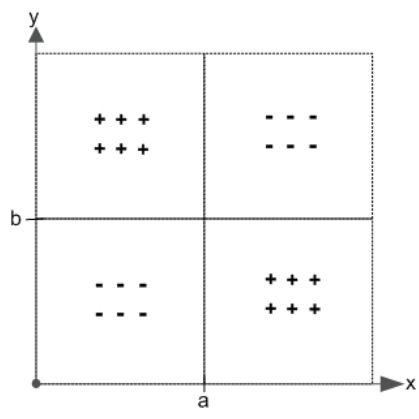

(a)

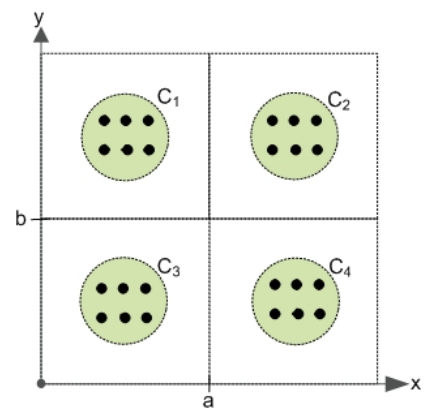

(b)

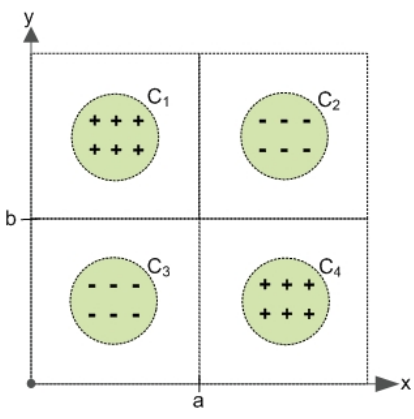

(c)

Figura 2.3: Clusters versus classes: (a) conjunto de treinamento, (b) clusters encontrados e (c) clusters diferentes que representam o mesmo conceito (Martins, 2003).

O caso 2.3(a) ilustra um conjunto de exemplos de treinamento rotulados com a classe "+" e “-”. Após submeter esses exemplos a um algoritmo de aprendizado supervisionado que induz o conceito utilizando uma árvore de decisão - ilustrado no caso 2.3(c) com partições $y=b$ e $x=a-$, as regras induzidas seriam do tipo:

$$
\begin{aligned}
& \text { se } x<a \text { e } y<b \text { então classe “-" } \\
& \text { se } x \geq a \text { e } y \geq b \text { então classe "-" } \\
& \text { se } x<a \text { e } y \geq b \text { então classe “+" } \\
& \text { se } x \geq a \text { e } y<b \text { então classe “+" }
\end{aligned}
$$

Entretanto, quando não se conhece a classe, os exemplos de treinamento poderiam ser vistos pelo algoritmo de clustering como mostrado na Figura 2.3(b), i.e., apenas como pontos no espaço de busca que podem ser agrupados de acordo com algum critério de similaridade. Nesse caso, o algoritmo de clustering encontraria 4 (quatro) clusters distintos $-C_{1}, C_{2}, C_{3}$ e $C_{4}$. Porém, quando supervisionado, esse conjunto de treinamento representa apenas duas instâncias de um determinado conceito, representadas 
pelas classes “+” (clusters 1 e 4) e “-” (clusters 2 e 3) na Figura 2.3(c). Evidentemente, seria interessante, após encontrados esses quatro clusters, ter algum procedimento que permita descobrir que existem duas instâncias de um conceito, uma delas "+" representada pelos exemplos pertencentes aos clusters 1 e 4, e a outra “-”, pelos exemplos pertencentes aos clusters 2 e 3. Para atingir tal objetivo é necessária a interpretação dos clusters por um especialista, a fim de tentar extrair o significado conceitual de cada cluster e identificar possíveis "fusões" conceituais.

Em tarefas de aprendizado não-supervisionado, objeto de estudo deste trabalho, usualmente é realizado um grande esforço para interpretação dos resultados. Essa etapa de interpretação, assim como todas as etapas executadas na realização do processo de clustering, são apresentadas no Capítulo 3.

\subsection{Aprendizado Semi-Supervisionado}

Uma das maiores restrições do aprendizado supervisionado é a necessidade de um conjunto de dados com uma quantidade expressiva de exemplos rotulados para a indução de um bom classificador, o que nem sempre acontece em aplicações reais. Obter esses exemplos rotulados pode não ser uma tarefa trivial, pois muitas vezes o processo é manual, lento, altamente custoso e envolve especialistas do domínio da aplicação. Desse modo, é difícil, quando não impossível, encontrar conjuntos de dados com vários exemplos rotulados. Para contornar essas limitações, o modo de aprendizado semisupervisionado faz uso de poucos exemplos rotulados e muitos exemplos não rotulados, os quais encontram-se facilmente disponíveis. A idéia básica desses algoritmos é rotular um maior número de exemplos dos quais a classe não é conhecida com a finalidade de melhorar a performance de algoritmos de aprendizado supervisionado (Matsubara, 2004).

A maioria dos algoritmos propostos para o aprendizado semi-supervisionado consistem em uma variação dos algoritmos de aprendizado de máquina tradicionais. Muitos desses algoritmos tentam obter, de alguma maneira, um ganho sobre os poucos exemplos rotulados. Normalmente, esse ganho é obtido com algum método de escolha dos exemplos a serem rotulados. Esse método é de vital importância para os algoritmos semi-supervisionados, pois, uma vez que um "erro" for introduzido ao rotular um novo exemplo, esse erro pode se propagar nas próximas iterações, acumulandose e tendo como conseqüência um aumento no erro do classificador induzido sobre os exemplos rotulados pelo algoritmo semi-supervisionado. 


\subsection{Considerações Finais}

Neste capítulo foram apresentados alguns conceitos do aprendizado de máquina, que são comumente utilizados para a construção de sistemas de aprendizado para aquisição de conhecimento de maneiras automáticas ou semi-automáticas. Para a construção desses sistemas, o desenvolvedor deve considerar a estratégia de aprendizado que será utilizada pelo sistema, pois cada estratégia apresenta um grau de complexidade de inferência. A disponibilidade e características dos dados que serão utilizados na tarefa de aprendizado é outra característica que deve ser considerada para a construção desses sistemas, pois essas características determinam qual modo de aprendizado é mais adequado para aplicação.

No próximo capítulo são apresentados os conceitos e técnicas empregados no clustering, técnica de aprendizado não-supervisionado amplamente utilizada para o análise exploratória de dados. O clustering, mais especificamente a abordagem hierárquica, é a técnica de aprendizado de maior interesse para o desenvolvimento deste trabalho. 



\section{Agrupamento de Dados}

\subsection{Considerações Iniciais}

O clustering tem sido freqüentemente utilizado em tarefas de exploração de dados e extração de padrões. A aplicação do clustering para detecção de características e segmentação de imagens é muito comum, mas há também outros domínios nos quais o clustering é muito utilizado, como a detecção de características em expressões gênicas, seqüencias de proteínas e outras aplicações em bioinformática. Os resultados obtidos por meio dessa técnica de aprendizado de máquina não-supervisionado são altamente dependentes da escolha de parâmetros como as medidas de similaridade e métodos de agrupamentos utilizados. Esses e outros conceitos envolvidos na realização dos clustering são apresentados neste capítulo.

\subsection{Abordagens de Clustering}

Como mencionado, o resultado obtido por meio dos algoritmos de clustering é um conjunto de agrupamentos de dados, no qual cada agrupamento é denominado cluster. Pode-se caracterizar um cluster como sendo um agrupamento composto de um número não fixo de objetos (exemplos) similares de acordo com uma medida de similaridade. Diversas definições de cluster são encontradas na literatura e algumas das mais utilizadas são (Everitt, 1993):

Definição 1: um cluster é um conjunto de entidades semelhantes, e entidades pertencentes a clusters diferentes não são semelhantes.

Definição 2: um cluster é um agrupamento de pontos no espaço de teste de tal maneira que a distância entre quaisquer dois pontos em um mesmo 
cluster é menor que a distância entre qualquer ponto desse cluster e um outro ponto qualquer não pertencente a ele.

Definição 3: clusters podem ser descritos como regiões conectadas de um espaço multi-dimensional contendo uma alta densidade relativa de pontos, separadas de outras regiões por uma região contendo uma baixa densidade relativa de pontos.

Os algoritmos de clustering podem ser classificados considerando diferentes aspectos. Uma classificação bastante aceita é fornecida por Jain et al. (1999), na qual os algoritmos são classificados de acordo com o método adotado para definir os clusters: particionais, grade, densidade e hierárquicos. A seguir são apresentadas essas abordagens e também as abordagens de sobreposição (clumping), redes auto-organizáveis e conceitual. Os algoritmos de clustering hierárquico implementam os conceitos de maior interesse deste trabalho. Portanto, a descrição da abordagem hierárquica é apresentada com maiores detalhes em relação às outras.

Clustering Particional ou de Otimização: o objetivo da abordagem de otimização é formar agrupamentos ótimos sobre os dados, dividindo iterativamente o conjunto de exemplos em $k$-partições mutuamente exclusivas, as quais devem maximizar uma função critério pré-definida. Nessa abordagem, todos os exemplos são utilizados para o cálculo da distância entre os agrupamentos, o que pode torná-la computacionalmente inviável, uma vez que realiza uma busca exaustiva pela melhor distribuição das partições. Uma alternativa para solucionar esse problema é utilizar apenas um exemplo como representante do cluster para o cálculo da similaridade, usualmente representado pelo centro do cluster. Dessa maneira, a complexidade para o cálculo da função critério torna-se linear e possibilita a aplicação eficiente do particionamento (Berkhin, 2002).

Um problema associado ao clustering de otimização é a necessidade de informar com antecedência o número de clusters desejados. Além disso, apresenta alta variância, pois a seleção dos exemplos representantes (sementes iniciais) afeta, significativamente, o resultado do clustering e pode fazer com que a solução vá em direção a um máximo local da função de avaliação. Para minimizar esse efeito negativo, usualmente os algoritmos são executados diversas vezes com exemplos iniciais diferentes, e, então, a melhor solução é atribuída ao resultado do processo de clustering (Berry \& Linoff, 2002). Os algoritmos k-means (Hamerly \& Elkan, 2002; Kanungo et al., 2002) e 
k-medoids (Zhang \& Couloigner, 2005) são os representantes mais utilizados dessa abordagem.

Clustering Baseado em Grade: essa abordagem define uma grade para o espaço de exemplos e realiza todas as operações nesse espaço quantizado. Em termos gerais, essa abordagem é capaz de encontrar clusters de formatos arbitrários, não apresenta alta sensibilidade aos outliers e é muito eficiente para grandes conjuntos de dados. Exemplos de algoritmos que seguem essa abordagem são CLIQUE (Agrawal et al., 1998), MAFIA (Nagesh et al., 1999), OptiGrid (Hinneburg \& Keim, 1999) e STING (Wang et al., 1997).

Clustering Baseado em Densidade: essa abordagem assume que os clusters são regiões de alta densidade separadas por regiões com baixa densidade no espaço de exemplos. A idéia dessa abordagem é que cada exemplo do cluster deve manter uma vizinhança com um número mínimo de vizinhos dentro de uma esfera com raio $R$. Os exemplos que possuem uma vizinhança com densidade mínima, e estão numa distância menor que $R$, pertencem ao mesmo cluster. Existem diversos algoritmos que seguem essa abordagem, por exemplo, os algoritmos DENCLUE (Hinneburg \& Keim, 1998), DBSCAN (Ester et al., 1996), OPTICS (Ankerst et al., 1999) e Wave-cluster (Sheikholeslami et al., 1998).

Clustering Com Sobreposição (Clumping): um agrupamento exclusivo é uma partição do conjunto de exemplos, no qual cada exemplo pertence exclusivamente a um único cluster. O resultado desse agrupamento pode ser dito crisp, quando a relação entre os exemplos e os agrupamentos resume-se em pertencer ou não a um dado cluster. $\mathrm{Na}$ abordagem de agrupamento não exclusivo (com sobreposição ou clumping), pode-se associar um exemplo a vários clusters. Nesse caso, a cada exemplo é atribuído um grau de pertinência em relação aos clusters encontrados. Assim, um exemplo pode estar em mais de um agrupamento, com probabilidades diferentes. O AutoClass (Cheeseman \& Stutz, 1996) é um dos algoritmos que implementam essa idéia. Na Figura 3.1 é ilustrada a representação de agrupamentos com sobreposição, na qual o exemplo $E_{1}$ pertence simultaneamente aos clusters $C_{1}$ e $C_{2}$.

Redes Auto-Organizáveis: as redes auto-organizáveis, também conhecidas como redes SOM - Self Organizing Map (Kohonen, 1990; Haykin, 1999) —, são freqüentemente utilizadas para a tarefa de clustering e visualização. As redes SOM são redes neurais artificiais não- 


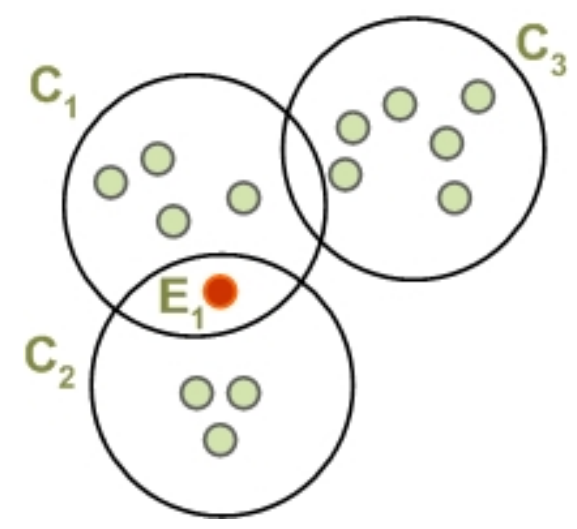

Figura 3.1: Representação de agrupamentos com sobreposição.

supervisionadas cujos neurônios são organizados em um reticulado bidimensional, onde cada neurônio está conectado a todas as entradas da rede. A cada exemplo de entrada apresentado à rede, os neurônios atualizam seus pesos e ativam uma região diferente do reticulado determinando a localização espacial de uma vizinhança topográfica de neurônios excitados, centrada no neurônio mais semelhante ao exemplo apresentado.

O objetivo da rede SOM é encontrar um conjunto de neurônios de referência e associar cada exemplo do conjunto de dados ao neurônio de referência mais próximo. O resultado consiste de um conjunto de neurônios que definem implicitamente os clusters. Dois algoritmos bastante conhecidos que implementam redes auto-organizáveis são SOTA (Herrero et al., 2001) e SomPack (Kohonen et al., 1996).

Clustering Conceitual: algoritmos de clustering baseados apenas em similaridade não utilizam conhecimento semântico na formação dos clusters. Na construção dos agrupamentos, esses algoritmos utilizam medidas de similaridade que tratam todos os atributos indistintamente. Entretanto, certos atributos podem ser mais importantes do que outros para a construção de bons agrupamentos. O uso de medidas de similaridade numérica apresenta outras desvantagens, pois essas medidas consideram apenas as propriedades locais, sem analisar qualquer contexto que poderia caracterizar melhor o conjunto de exemplos (Fisher \& Langley, 1986; Stepp \& Michalski, 1986).

Na abordagem de clustering conceitual, o resultado depende do objetivo da classificação e dos conceitos disponíveis ao sistema para caracterização das coleções de exemplos. A premissa básica dessa abordagem é que os exemplos devem ser organizados em clusters que tenham algum significado conceitual simples e que seja útil do ponto de vista da aplicação. Desse modo, exemplos de um mesmo cluster não são 
similares somente segundo alguma medida de similaridade definida matematicamente, mas também segundo um mesmo significado conceitual descrito pelo cluster (Bhatia \& Deogun, 1998; Mishra et al., 2004).

Clustering Hierárquico: essa abordagem, assim como as outras, constrói os agrupamentos de modo que exemplos pertencentes ao mesmo cluster possuem alta similaridade e exemplos pertencentes à clusters diferentes possuem baixa similaridade. Entretanto, uma distinção entre essa abordagem e as demais é que o resultado obtido não é constituído apenas de uma partição do conjunto de dados inicial, mas sim de uma hierarquia que descreve um particionamento diferente à cada nível analisado.

Um conjunto de dados, geralmente, contém diversos clusters e esses clusters, por sua vez, são compostos de sub-clusters. Os sub-clusters podem ainda ser formados a partir do agrupamento de outros clusters menores (sub-sub-clusters), e assim sucessivamente. Na Biologia, por exemplo, os reinos são divididos em filos, que são sub-divididos em sub-filos, os quais são divididos em famílias, sub-famílias, gêneros e espécies. Essa sucessão de níveis e sub-níveis constitui naturalmente uma hierarquia (Duda et al., 2000). Dessa maneira, é necessária a utilização de uma representação formal para a hierarquia de clusters obtida a partir dos dados. O dendograma é a estrutura mais freqüentemente utilizada para representar essa hierarquia, que consiste de um tipo especial de estrutura de árvore, na qual os nós pais agrupam os exemplos representados pelos nós filhos. Outras estruturas são também utilizadas para representar a hierarquia de agrupamentos, como diagramas de Venn e banner. Essas estruturas são apresentadas na Seção 3.4.

A hierarquia de agrupamentos pode ser descrita por meio de uma seqüência de partições de $N$ amostras em $k$ clusters, em que o nível 1 (um) corresponde a um cluster contendo todos os exemplos do conjunto de dados e o último nível corresponde a um conjunto de clusters unitários (folhas), nos quais cada exemplo constitui um cluster. Um agrupamento hierárquico agrupa os dados de modo que se dois exemplos são agrupados em algum momento, nas próximas iterações eles continuam fazendo parte do mesmo grupo, mesmo se forem agrupados em outros clusters mais gerais, caracterizando assim uma hierarquia de clusters. Essa técnica permite analisar os clusters em diferentes níveis de granularidade, pois cada nível do dendograma descreve um conjunto diferente de agrupamentos. 
Duas estratégias podem ser utilizadas para implementação de algoritmos de clustering hierárquico:

1. Aglomerativa (botton-up); e

2. Divisiva (top-down).

Na primeira, cada exemplo é considerado um cluster unitário. Em seguida, pares desses clusters são iterativamente agrupados de acordo com um indice de similaridade, até que todos os exemplos pertençam a apenas um cluster. Por outro lado, a abordagem divisiva é iniciada com apenas um agrupamento contendo todos os exemplos e procede dividindo o conjunto de exemplos em clusters cada vez menores, até que cada exemplo pertença exclusivamente a um cluster ou até que se alcance o critério de parada, freqüentemente o número de clusters desejados (Murtagh, 1983).

Na literatura, trabalhos relacionados ao clustering hierárquico, geralmente, referenciam a abordagem aglomerativa, não mostrando muito interesse pelos métodos divisivos. Mesmo os pacotes de software que implementam algoritmos de clustering dificilmente incluem algoritmos divisivos. O principal aspecto que influencia esse fato é a complexidade computacional desses métodos. Algoritmos aglomerativos são quadráticos em relação ao número de exemplos do conjunto de entrada, i.e., $O\left(N^{2}\right)$, mas ainda assim muitas vezes aplicáveis. A complexidade dos algoritmos divisivos, por outro lado, cresce exponencialmente em relação ao tamanho do conjunto de entrada, o que torna proibitiva sua aplicação sobre conjuntos de dados com pouco mais que algumas centenas de exemplos (Kaufman \& Rousseeuw, 1990b).

Um aspecto positivo do clustering hierárquico é a flexibilidade em relação à analise dos diferentes níveis de granularidade ou densidade dos agrupamentos. Diversos conjuntos de dados reais possuem a propriedade de que, em geral, as estruturas intrínsecas não podem ser caracterizadas por parâmetros globais de densidade ou por funções matemáticas que não consideram os diferentes níveis de granularidade dos clusters. Em alguns casos, os parâmetros e densidade teriam que variar para cada cluster com valores muito diferentes para que os algoritmos pudessem identificar os clusters com densidade distintas. Considere, por exemplo, o conjunto de dados apresentado na Figura 3.2. Nesse caso, não seria possível identificar, simultaneamente, os clusters A, B, C1, C2 e C3 utilizando valores de densidade globais, mas sim os clusters A, B e C ou C1, C2 e C3, no último caso considerando os clusters A e B como ruído ou outliers. Sob esse aspecto, o cluste- 
ring hierárquico é uma alternativa para identificar corretamente essas estruturas, pois com a análise em diferentes níveis da hierarquia é possivel observar agrupamentos com densidades distintas.

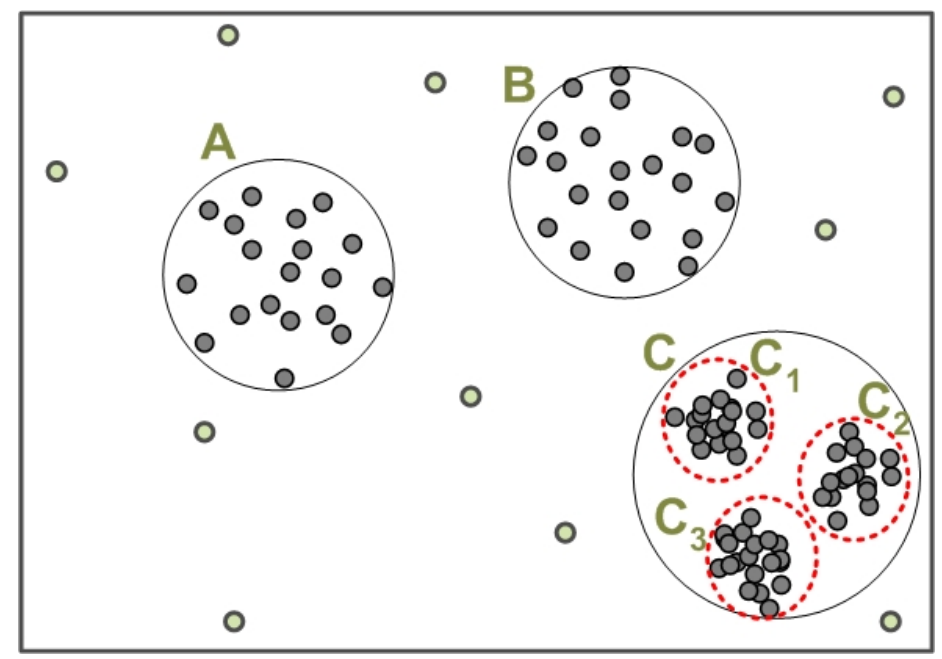

Figura 3.2: Clusters com diferentes densidades (Ankerst et al., 1999).

Deve ser observado que nenhuma abordagem é melhor ou pior que outra, mas simplesmente diferentes e indicadas para aplicações distintas. Assim, antes de escolher uma abordagem para a realização do clustering ou implementação de novos algoritmos, deve-se ter consciência do objetivo que se pretende alcançar e verificar a adequabilidade de cada abordagem a essa aplicação. Um fator negativo associado ao clustering em geral, é que os resultados obtidos por meio dessa técnica são de difícil interpretação, o que torna necessária uma maior interação com um especialista do domínio, bem como o desenvolvimento de metodologias que facilitem a compreensão dos agrupamentos encontrados. Em toda aplicação de descoberta de conhecimento existem algumas etapas que devem ser realizadas para que o processo seja bem sucedido. As etapas realizadas para a exploração dos dados quando a técnica selecionada é o clustering são descritas na próxima seção.

\subsection{Etapas do Processo de Clustering}

Várias etapas devem ser realizadas no processo de clustering, entre elas o pré-processamento dos dados, seleção da medida de similaridade, execução do algoritmo de clustering, avaliação dos resultados e interpretação dos clusters identificados. Essas etapas são descritas a seguir. 


\subsubsection{Pré-processamento}

A preparação e a transformação dos dados devem ser realizadas nesta etapa. Como mencionado anteriormente, os algoritmos de clustering agrupam exemplos baseados em indices de similaridade entre pares de exemplos. Quando os exemplos estão representados por meio da tabela atributovalor, seus atributos podem assumir tipos diferentes: binário, discreto ou contínuo. Atributos binários podem assumir exatamente dois valores, por exemplo sim e não ou 1 e 0 , indicando presença ou ausência de uma determinada característica. Atributos discretos possuem, freqüentemente, um conjunto finito e pequeno de valores possíveis, meses do ano e dias da semana, por exemplo. Os atributos contínuos, por outro lado, podem assumir qualquer valor real dentro de um intervalo pré-definido (Jain \& Dubes, 1988).

Além dos tipos dos atributos, o clustering é influenciado pela escala, a qual indica a significância relativa dos valores dos atributos. A escala dos atributos pode ser qualitativa (nominal ou ordinal) ou quantitativa (intervalo de valores ou proporção). Essas características são descritas a seguir.

\section{- Gualitativa}

- Nominal: os valores são apenas nomes diferentes. Exemplos: CEP, cores, sexo.

- Ordinal: os valores refletem uma ordem. Exemplos: hierarquia militar, avaliações qualitativas como frio, morno e quente.

\section{- Guantitativa}

- Intervalo: a diferença entre os valores é significativa, isto é, existe uma unidade de medida. Exemplos: temperatura $\left(90^{\circ}\right.$ Célsius $^{1}$ é diferente de $90^{\circ}$ Fahrenheit $^{2}$ ), a duração de um evento em minutos ou segundos.

- Proporção: os números têm um significado absoluto. Isto significa que existe um zero absoluto junto com uma unidade de medida, de modo que a proporção tenha significado. Exemplos: altura, salário e distância.

Os tipos e escalas de atributos foram sumarizados por Jain \& Dubes (1988) e são apresentados na Figura 3.3.

\footnotetext{
${ }^{1} \mathrm{O}$ Célsius $\left({ }^{o} \mathrm{C}\right)$ é uma unidade de temperatura proposta em 1742, assim denominada em homenagem ao seu criador, o astrônomo sueco Anders Célsius.

${ }^{2}$ Fahrenheit é uma escala de temperatura proposta por Gabriel Fahrenheit em 1724.
} 


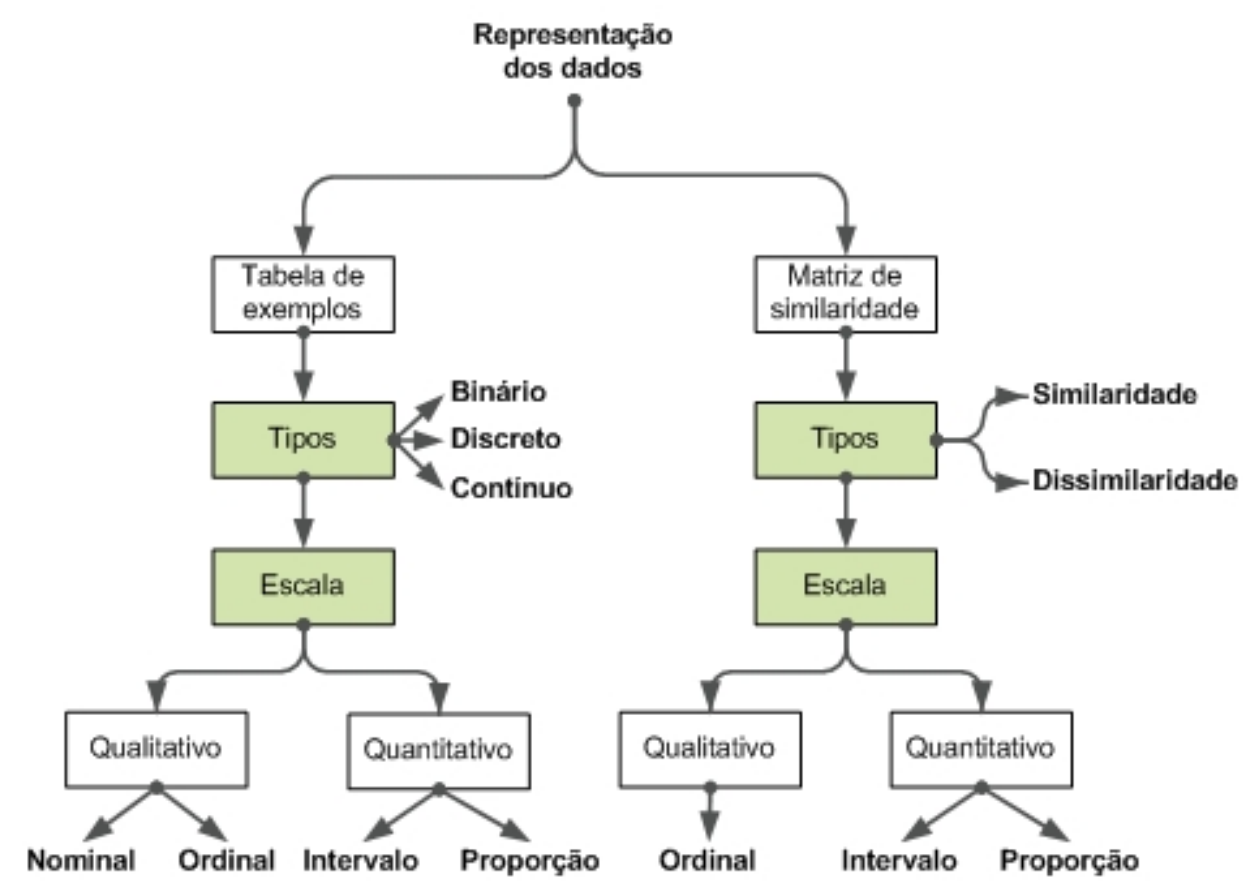

Figura 3.3: Tipos e escalas de atributos (Jain \& Dubes, 1988).

A preparação dos dados para o clustering muitas vezes requer algum tipo de normalização, que considera a medida de similaridade a ser aplicada. Por exemplo, a distância Euclidiana (Seção 3.3.2) é um índice usualmente utilizado para medir a similaridade entre exemplos, mas implicitamente atribui maior importância aos atributos que podem assumir valores em um intervalo maior que aqueles com menor intervalo de valores. Desse modo, manter os atributos dentro de uma faixa de valores comum pode minimizar esse problema.

Outro aspecto importante é a base ou sistema de coordenadas em que os dados estão representados. Freqüentemente, assume-se que os dados já estão numa base adequada para a aplicação de um algoritmo de clustering. No entanto, a análise mais rigorosa do domínio da aplicação, das características disponíveis e das transformações que podem ser aplicadas aos dados, propicia a obtenção de resultados significativamente melhores. Considere como exemplo o agrupamento do conjunto de dados ilustrado na Figura 3.4, na qual os elementos (exemplos do conjunto de dados) formam um cluster curvilíneo com distância da origem aproximadamente constante. Utilizando uma representação em coordenadas cartesianas, muitos algoritmos de clustering encontrariam dois um mais clusters. Entretanto, se fossem utilizadas coordenadas polares para representar os exemplos, a solução de um único cluster poderia ser obtida (Jain et al., 1999).

A dimensionalidade dos exemplos é outra característica que deve ser considerada na fase de preparação dos dados. O clustering é uma tarefa de exploração de dados que deve ser apoiada por técnicas de visualização com 


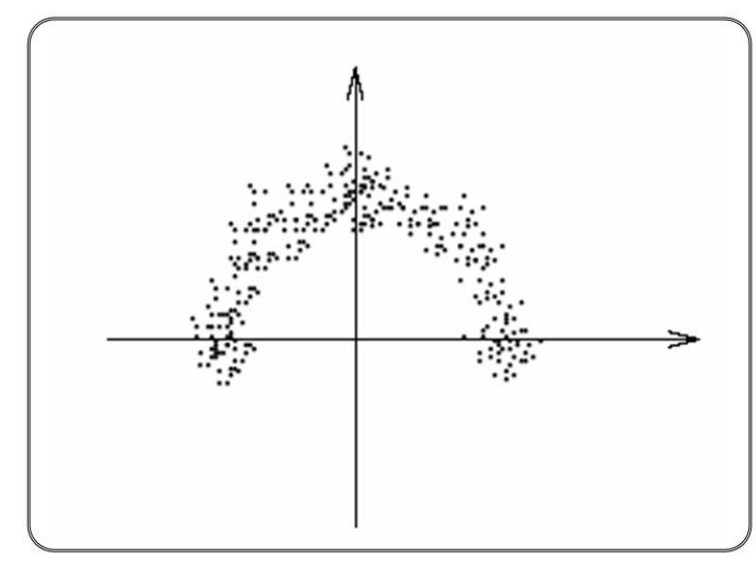

Figura 3.4: Cluster curvilíneo (Jain et al., 1999).

o intuito de facilitar a interpretação dos resultados. A maneira mais direta de visualização é dispor os dados em um espaço bi-dimensional $\mathbb{R}^{2}$ ou tridimensional $\mathbb{R}^{3}$, representando os exemplos agrupados por meio de pontos nesse espaço. Entretanto, dados com mais de três dimensões $\left(\mathbb{R}^{n}\right.$ para $\left.n>3\right)$ não podem ser diretamente visualizados ou projetados precisamente em um espaço de duas ou três dimensões. A representação de sub-conjuntos dos atributos no $\mathbb{R}^{2}$ ou $\mathbb{R}^{3}$ pode ser de grande ajuda para o entendimento dos dados, mesmo quando $n>3$. Além disso, um número menor de atributos reduz substancialmente o tempo de execução dos algoritmos. Desse modo, métodos de seleção de atributos são empregados com o objetivo de selecionar apenas os atributos que melhor descrevem e discriminam o conjunto de dados e suas estruturas latentes, o que conseqüentemente reduz a dimensionalidade dos dados, melhora a eficiência dos algoritmos em relação ao tempo de execução, e, em alguns casos, pode melhorar os resultados obtidos (Liu \& Motoda, 1998; Lee, 2005).

\subsubsection{Seleção da Medida de Similaridade}

Nesta etapa devem ser determinadas as medidas de similaridade utilizadas no processo de construção dos clusters, as quais devem ser cuidadosamente selecionadas considerando as características do conjunto de dados, como o tipo e escala dos atributos. Foram propostas diversas medidas para o cálculo da similaridade, entre as quais estão as medidas de distância, de correlação e de associação. Quando o conjunto de dados é composto por atributos numéricos (quantitativos), as medidas de distância podem ser aplicadas para o cálculo da similaridade entre os exemplos. $\mathrm{O}$ problema com a aplicação dessas medidas ocorre quando os exemplos são descritos por atributos qualitativos, pois, nesse caso, se não existir uma ordenação conceitual dos valores desses atributos, não é possivel calcular 
a similaridade entre os exemplos por meio das medidas de distância. Uma estratégia geralmente utilizada nesses casos para o cálculo da similaridade, é aplicar o coeficiente de correspondência, que verifica se os atributos de exemplos diferentes apresentam o mesmo valor ou diferem. Assim, se os valores dos atributos são iguais, então a similaridade para aquele atributo é 1 (um), caso contrário é 0 (zero). Desse modo, cada medida de similaridade representa uma perspectiva, dependendo das características dos dados. As medidas de distância e de correlação requerem atributos contínuos, enquanto que as medidas de associação são utilizadas para atributos discretos. Uma revisão de vários tipos de medidas de similaridade pode ser encontrada em (Jain \& Dubes, 1988) e (Everitt, 1993).

É importante observar que quando uma medida de distância é utilizada para o cálculo da similaridade entre exemplos, tem-se na verdade o oposto da similaridade, pois quanto maior o valor calculado (maior distância), menor o grau de semelhança entre os exemplos envolvidos no cálculo, e, quanto menor a distância, maior a similaridade. Desse modo, para obter a similaridade por meio das medidas de distância é necessário calcular o complemento da distância ${ }^{3}$, i.e., $\operatorname{sim}\left(E_{i}, E_{j}\right)=1-\operatorname{dist}\left(E_{i}, E_{j}\right)$, onde $\operatorname{sim}\left(E_{i}, E_{j}\right)$ representa a similaridade entre os exemplos $E_{i}$ e $E_{j}$ e $\operatorname{dist}\left(E_{i}, E_{j}\right)$, a distância entre esses exemplos.

Diversos índices de proximidade foram propostos para o cálculo da similaridade entre exemplos, os quais devem satisfazer as seguintes condições:

i. $\operatorname{dist}\left(E_{i}, E_{j}\right) \geq 0, \forall(i, j)$ (positividade)

ii. $\operatorname{dist}\left(E_{i}, E_{j}\right)=0$ se e somente se $E_{i}=E_{j}$ (identidade)

iii. $\operatorname{dist}\left(E_{i}, E_{j}\right)=\operatorname{dist}\left(E_{j}, E_{i}\right)$ (simetria)

Para que um índice de proximidade seja considerado uma métrica, este deve satisfazer, além das três propriedades anteriores, a propriedade de desigualdade triangular:

iv. $\operatorname{dist}\left(E_{i}, E_{j}\right) \leq \operatorname{dist}\left(E_{i}, E_{q}\right)+\operatorname{dist}\left(E_{q}, E_{j}\right), \forall(i, j, q)$

Algumas medidas de distância, correlação e associação são apresentadas a seguir.

\footnotetext{
${ }^{3}$ Para o cálculo do complemento deve ser utilizado o valor máximo possível para a distância entre dois exemplos no conjunto de dados. Se o cálculo da distância resulta sempre em um valor entre 0 (zero) e 1 (um), então o complemento é obtido a partir da subtração $\operatorname{sim}\left(E_{i}, E_{j}\right)=1-\operatorname{dist}\left(E_{i}, E_{j}\right)$, caso contrário, $\operatorname{sim}\left(E_{i}, E_{j}\right)=\operatorname{maxdist}-\operatorname{dist}\left(E_{i}, E_{j}\right)$.
} 


\subsubsection{Medidas de Distância}

Considerando os atributos dos exemplos como dimensões de um espaço multi-dimensional, a descrição de cada exemplo corresponde a um ponto nesse espaço. Assim, há diversas maneiras de calcular a distância. Por exemplo, para encontrar a distância entre dois pontos em um plano, basta encontrar o comprimento do segmento de reta que os une. Já no caso de encontrar a distância entre duas cidades, isso não seria adequado, uma vez que a superfície do solo é irregular. Nesse caso, uma medida de distância mais adequada seria encontrar o comprimento do segmento da curva que liga as duas cidades.

A seguir são apresentados alguns exemplos de métricas de distância, onde $E_{i}=\left(x_{i 1}, x_{i 2}, \ldots, x_{i M}\right)$ e $E_{j}=\left(x_{j 1}, x_{j 2}, \ldots, x_{j M}\right)$ são exemplos descritos pelos respectivos valores dos $M$ atributos.

Manhattan/city-block: essa medida, também conhecida como distância$L_{1}$, pode ser definida como a distância entre dois pontos no espaço Euclidiano, com um sistema de coordenadas cartesianas fixo, como sendo a soma dos comprimentos das projeções dos segmentos de reta entre os pontos dos eixos das coordenadas, i.e., é a soma das diferenças absolutas dos valores dos atributos. Por exemplo, no espaço $\mathbb{R}^{2}$ a distância de Manhattan entre o ponto $p_{1}$ com coordenadas $\left(x_{1}, y_{1}\right)$ e o ponto $p_{2}$ com coordenadas $\left(x_{2}, y_{2}\right)$ é $\left|x_{1}-x_{2}\right|+\left|y_{1}-y_{2}\right|$. De maneira mais geral, essa medida é definida pela Equação 3.1:

$$
\operatorname{dist}\left(E_{i}, E_{j}\right)=\sum_{l=1}^{M}\left|x_{i l}-x_{j l}\right|
$$

É assim chamada pois em várias cidades é praticamente impossível estabelecer uma rota entre dois pontos através de uma reta, devido ao fato das cidades serem freqüentemente subdivididas em quadras com prédios, conforme ilustrado na Figura 3.5.

Euclidiana: essa medida de distância, definida pela Equação 3.2, é provavelmente a mais utilizada em clustering. Ela expressa a distância geométrica Euclidiana entre os exemplos em um espaço multi-dimensional.

$$
\operatorname{dist}\left(E_{i}, E_{j}\right)=\sqrt{\sum_{l=1}^{M}\left(x_{i l}-x_{j l}\right)^{2}}
$$

Uma alternativa à essa medida é a distância Euclidiana quadrada, definida pela Equação 3.3, semelhante à anterior mas sem extrair a 


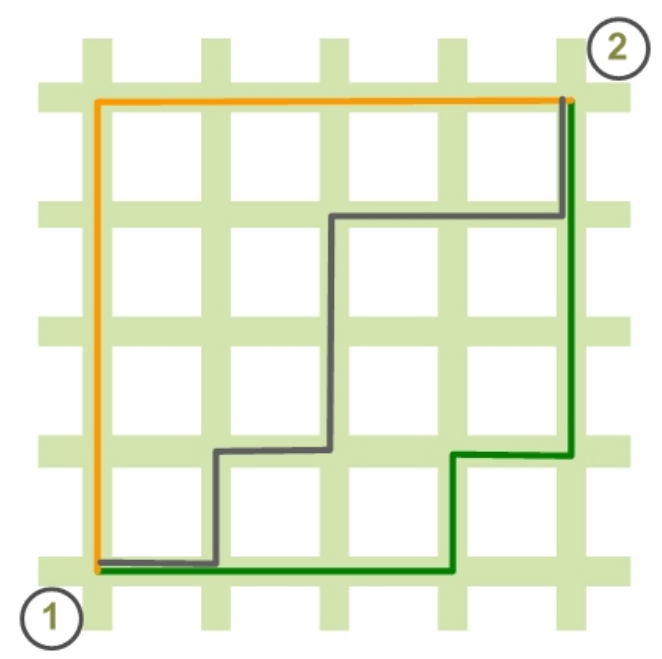

Figura 3.5: Distância de Manhattan: as três rotas apresentam o mesmo comprimento.

raiz quadrada. A grande vantagem dessa medida é a diminuição do tempo computacional para efetuar o seu cálculo.

$$
\operatorname{dist}\left(E_{i}, E_{j}\right)=\sum_{l=1}^{M}\left(x_{i l}-x_{j l}\right)^{2}
$$

Chebyshev ou distância supremum: essa medida, definida pela Equação 3.4, é a máxima diferença absoluta entre os valores dos atributos. Ela é apropriada para casos nos quais dois exemplos são considerados diferentes caso possuam qualquer atributo diferente.

$$
\operatorname{dist}\left(E_{i}, E_{j}\right)=\max _{l=1}^{M}\left|x_{i l}-x_{j l}\right|
$$

Mahalanobis: a distância de Mahalanobis é definida pela Equação 3.5, onde Cov é a matriz de covariância dos valores dos atributos. Essa distância incorpora a correlação entre atributos e os padroniza de modo que suas médias sejam 0 (zero) e variância 1 (um). A idéia básica dessa medida é associar diferentes pesos à diferentes atributos com base em seus valores de variância e correlação linear entre pares de exemplos (Webb, 2005).

$$
\operatorname{dist}\left(E_{i}, E_{j}\right)=\sum_{l=1}^{M} \sum_{t=1}^{M}\left(E_{i l}-E_{j l}\right) \operatorname{Cov}^{-1}\left(E_{i t}-E_{j t}\right)
$$

Minkowsky: a definição dessa medida é dada pela Equação 3.6. Minkowsky estabelece uma maneira genérica para calcular a distância entre dois pontos no espaço $n$-dimensional $\left(\mathbb{R}^{n}\right)$ de acordo com o valor do 
parâmetro $r$, o qual determina a medida utilizada.

Aggarwal et al. (2001) discutem a adequabilidade da medida de Minkowsky para conjuntos de dados com grandes dimensões. Além disso, sugerem que valores de $r=1$ ou 2 são mais relevantes que valores de $r \geq 3$. Nesse trabalho, são apresentadas também algumas evidências teóricas e empíricas de que os resultados dessas medidas podem degradar rapidamente ao serem aplicadas sobre conjuntos de dados com alta dimensão e altos valores de $r$. A partir desse estudo, observou-se que valores de $r$ menores produzem resultados melhores, o que intuitivamente indica que a distância de Manhattan $(r=1)$ é preferivel à distancia Euclidiana ( $r=2$ ), e assim sucessivamente. A partir da análise dessa tendência, os autores também sugerem que os valores de $r$ entre zero e um $(0<r<1)$ podem gerar resultados mais significativos.

$$
\operatorname{dist}\left(E_{i}, E_{j}\right)=\left(\sum_{l=1}^{M}\left|x_{i l}-x_{j l}\right|^{r}\right)^{\frac{1}{r}}
$$

Como mencionado, quando $r=1$, a medida Minkowsky é conhecida como distância de Manhattan/city-block (Equação 3.1), e quando $r=$ 2, ela é conhecida como distância Euclidiana (Equação 3.2). Conforme o aumento do valor de $r$, a figura geométrica formada pelos pontos eqüidistantes do ponto central aproximam-se de um quadrado. Para $r \rightarrow \infty$, esses pontos formam exatamente um quadrado, conforme ilustrado na Figura 3.6.

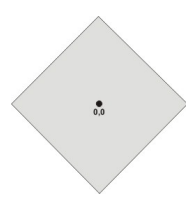

(a)

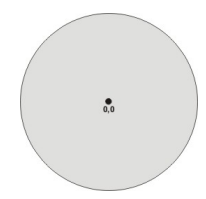

(b)

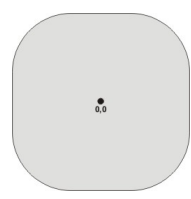

(c)

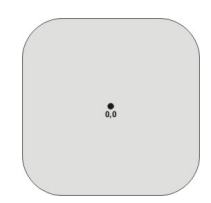

(d)

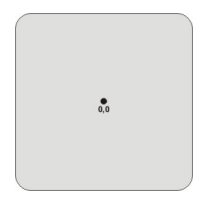

(e)

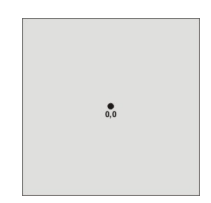

(f)

Figura 3.6: Efeito da variação de $r$ na métrica de Minkowsky. (a) $r=1$, (b) $r=2$, (c) $r=3$, (d) $r=4$, (e) $r=20$ e (f) $r \rightarrow \infty$ (Sanches, 2003).

Uma pergunta que surge com relação às possiveis métricas de distância é: qual métrica escolher para calcular a similaridade?

Não existe uma regra geral que define qual métrica de distância deve ser utilizada em determinada situação. A escolha ideal para um determinado problema se dá, geralmente, após a realização de vários testes com diferentes métricas. Entretanto, uma ressalva pode ser feita caso seja conhecido o formato do cluster esperado. Nesse caso, a distância mais apropriada será 
aquela que apresentar, para pontos eqüidistantes da origem, um formato semelhante ou parecido com aquele formato esperado.

\subsubsection{Medidas de Correlação}

Uma medida de similaridade entre exemplos pode ser o coeficiente de correlação, o qual é também medido utilizando os valores dos diversos atributos considerando o padrão desses valores e não a magnitude. As medidas de similaridade baseadas em correlação são consideradas semi-métricas, pois não satisfazem a propriedade de desigualdade triangular.

Diversas maneiras de se obter a correlação entre os dados foram desenvolvidas. Algumas delas são apresentadas a seguir:

Correlação de Pearson: esse coeficiente, também chamado de coeficiente de correlação produto-momento, mede o grau da correlação e a direção dessa correlação entre duas variáveis. Esse coeficiente assume apenas valores entre -1 e 1 . Quando igual a 1 (um), significa que há uma correlação perfeita entre as duas variáveis analisadas. Se igual a -1 , significa que há uma correlação inversa, i.e., se uma das variáveis aumenta a outra diminui. Finalmente, se igual a 0 (zero), significa que não há dependência linear entre as variáveis. Esse coeficiente é calculado por meio da Equação 3.7:

$$
\operatorname{cor}\left(E_{i}, E_{j}\right)=\frac{1}{M} \sum_{l=1}^{M}\left(\frac{x_{i l}-\bar{x}_{i}}{\sigma_{i}}\right)\left(\frac{x_{j l}-\bar{x}_{j}}{\sigma_{j}}\right)
$$

onde $\bar{x}_{i}$ e $\bar{x}_{j}$ representam as médias dos valores dos atributos dos exemplos $E_{i}$ e $E_{j}$, respectivamente e, $\sigma_{i}$ e $\sigma_{j}$ seus desvios padrão.

A similaridade entre exemplos, calculada por meio de índices de correlação, tem o mesmo valor resultante do cálculo da correlação, i.e., $\operatorname{sim}\left(E_{i}, E_{j}\right)=\operatorname{cor}\left(E_{i}, E_{j}\right)$. Por outro lado, a distância entre os exemplos $E_{i}$ e $E_{j}$ calculada por meio de um coeficiente de correlação, é dada pelo seu complemento: $\operatorname{dist}\left(E_{i}, E_{j}\right)=1-\operatorname{cor}\left(E_{i}, E_{j}\right)$.

É importante observar que o coeficiente de Pearson centraliza automaticamente os dados subtraindo sua média, e os normaliza dividindo por seus respectivos desvios padrão. Em algumas situações essa normalização pode ser útil, por outro lado, acarreta na perda de informação.

Correlação de Pearson absoluto: o valor absoluto do coeficiente de correlação de Pearson resulta em um valor entre 0 (zero) e 1 (um), que indica se há ou não correlação entre os dados, mas não informa se a correla- 
ção é positiva ou negativa. Assim, a similaridade entre dois exemplos é obtida a partir da Equação 3.8:

$$
\operatorname{sim}\left(E_{i}, E_{j}\right)=\left|\operatorname{cor}\left(E_{i}, E_{j}\right)\right|
$$

onde $\operatorname{cor}\left(E_{i}, E_{j}\right)$ é o coeficiente de correlação de Pearson, definido pela Equação 3.7.

Correlação de Pearson não-centralizado: em alguns casos é preferível utilizar o coeficiente de correlação não-centralizado, que é definido pela Equação 3.9, onde $\operatorname{cor}_{U}$ é o coeficiente de correlação de Pearson nãocentralizado. Esse coeficiente é equivalente ao cosseno do ângulo entre dois vetores.

$$
\operatorname{cor}_{U}\left(E_{i}, E_{j}\right)=\frac{1}{M} \sum_{l=1}^{M}\left(\frac{x_{i l}}{\sigma_{i}^{(0)}}\right)\left(\frac{x_{j l}}{\sigma_{j}^{(0)}}\right)
$$

onde

$$
\sigma_{i}^{(0)}=\sqrt{\frac{1}{M} \sum_{l=1}^{M} x_{i l}^{2}}
$$

e

$$
\sigma_{j}^{(0)}=\sqrt{\frac{1}{M} \sum_{l=1}^{M} x_{j l}^{2}}
$$

A similaridade é calculada a partir da Equação 3.12:

$$
\operatorname{sim}\left(E_{i}, E_{j}\right)=\operatorname{cor}_{U}\left(E_{i}, E_{j}\right)
$$

Correlação de Pearson não-centralizado e absoluto: de maneira análoga à correlação absoluta de Pearson, pode-se também utilizar a correlação absoluta não-centralizada. Nesse caso, a similaridade é calculada por meio da Equação 3.13:

$$
\operatorname{sim}\left(E_{i}, E_{j}\right)=\left|\operatorname{cor}_{U}\left(E_{i}, E_{j}\right)\right|
$$

Geometricamente, o valor absoluto do coeficiente de correlação nãocentralizado é igual ao cosseno do menor ângulo entre os dois exemplos analisados. 
O coeficiente de correlação de Spearman e o coeficiente de Kendall's $\tau$, descritos a seguir, são duas medidas de similaridade não paramétrica baseadas no coeficiente de correlação de Pearson, porém mais robustas em relação à presença de outliers.

Correlação de Spearman: o processo para o cálculo desse coeficiente de correlação inicia por meio da substituição de cada valor dos atributos dos exemplos por seus índices relativos a sua magnitude, i.e., se o valor do atributo $x_{i 1}$ é menor que o valor do atributo $x_{i 2}$, então seus índices são, respectivamente, 1 e 2. Em seguida, a correlação de Pearson é calculada sobre os vetores a partir desses índices ao invés de utilizar os valores dos atributos originais. A notação utilizada para esse coeficiente é $\operatorname{cor}_{S}\left(E_{i}, E_{j}\right)$. Como ilustração, considere os exemplos:

$$
E_{1}=\{2.3,6.7,4.5,20.8\} \text { e } E_{2}=\{2.1,5.9,4.4,4.2\} .
$$

O primeiro passo para o cálculo é substituir seus valores pelos seus respectivos índices:

$$
E_{1}=\{1,3,2,4\} \text { e } E_{2}=\{1,4,3,2\}
$$

A partir desses índices, é, então, calculado o coeficiente de correlação de Pearson definido pela Equação 3.7 na página 33. A similaridade é obtida de maneira análoga ao caso da correlação de Pearson, tal como apresentada na Equação 3.14:

$$
\operatorname{sim}\left(E_{i}, E_{j}\right)=\operatorname{cor}_{S}\left(E_{i}, E_{j}\right)
$$

onde $\operatorname{cor}_{S}\left(E_{i}, E_{j}\right)$ é o coeficiente de correlação de Spearman.

Kendall's $\tau$ : esse coeficiente é muito semelhante ao coeficiente de correlação de Spearman, mas ao invés de utilizar os índices dos atributos em relação a todos os atributos do mesmo exemplo, apenas os índices relativos em cada par de exemplos são aplicados para o cálculo da correlação. Para isso, considere todos os pares de atributos dos exemplos envolvidos no cálculo, tal que, dois pares de atributos são concordantes se:

$$
\begin{gathered}
x_{i l}<x_{i(l+1)} \text { e } x_{j l}<x_{j(l+1)} \\
\text { ou } \\
x_{i l}>x_{i(l+1)} \text { e } x_{j l}>x_{j(l+1)}
\end{gathered}
$$


e são discordantes se:

$$
\begin{gathered}
x_{i l}<x_{i(l+1)} \text { e } x_{j l}>x_{j(l+1)} \\
\text { ou } \\
x_{i l}>x_{i(l+1)} \text { e } x_{j l}<x_{j(l+1)}
\end{gathered}
$$

Utilizando os exemplos $E_{1}=\{2.3,6.7,4.5,20.8\}$ e $E_{2}=\{2.1,5.9,4.4,4.2\}$, essas relações podem ser representadas de maneira resumida em uma tabela - Tabela 3.1. A partir dessa tabela, observa-se que há oito pares concordantes e quatro pares discordantes. Denominando $n c_{\tau} \mathrm{o}$ número de pares concordantes e $n d_{\tau}$ o número de pares discordantes, tem-se $n c_{\tau}=8$ e $n d_{\tau}=4$. O coeficiente de Kendall's $\tau$ é definido pela Equação 3.15:

\begin{tabular}{c|c|c|c|c}
\hline \hline- & $(2.3,2.1)$ & $(6.7,5.9)$ & $(4.5,4.4)$ & $(20.8,4.2)$ \\
$(2.3,2.1)$ & - & $<<$ & $<<$ & $<<$ \\
$(6.7,5.9)$ & $>>$ & - & $>>$ & $<>$ \\
$(4.5,4.4)$ & $>>$ & $<<$ & - & $<>$ \\
$(20.8,4.2)$ & $>>$ & $><$ & $><$ & - \\
\hline \hline
\end{tabular}

Tabela 3.1: Ranques dos atributos utilizados na correlação de Kendall's $\tau$. As células com símbolos iguais indica a concordância entre os par de atributos, enquanto que símbolos diferentes representa um par discordante.

$$
\tau\left(E_{i}, E_{j}\right)=\frac{n c_{\tau}-n d_{\tau}}{M(M-1) / 2}
$$

A similaridade entre dois exemplos pode ser definida pela Equação 3.16:

$$
\operatorname{sim}\left(E_{i}, E_{j}\right)=\tau\left(E_{i}, E_{j}\right)
$$

\subsubsection{Medidas de Associação}

Medidas de associação são utilizadas para comparar exemplos cujas características são descritas por meio de atributos com somente dois valores discretos. Por exemplo, valores de um atributo poderiam ser 1 (um) ou 0 (zero), e uma medida de associação poderia verificar o grau de concordância entre cada par de exemplos. Uma maneira mais simples de mensurar a associação seria considerar a percentagem de vezes que ocorre uma concordância, ambos casos 1 (um) ou ambos 0 (zero) para cada atributo.

As medidas de associação são, em geral, derivadas a partir de uma tabela de contingência, semelhante à apresentada na Tabela 3.2, onde:

$a_{11}$ : número de atributos com valor 1 para ambos os exemplos,

$a_{00}$ : número de atributos com valor 0 para ambos os exemplos, 
$a_{01}$ : número de atributos com valor 0 para o exemplo $E_{i}$ e valor 1 para o exemplo $E_{j}$,

$a_{10}$ : número de atributos com valor 1 para o exemplo $E_{i}$ e valor 0 para o exemplo $E_{j}$.

$$
\begin{array}{cccc} 
& & \multicolumn{2}{c}{E_{j}} \\
& & 1 & 0 \\
\cline { 3 - 4 } E_{i} & 1 & a_{11} & a_{10} \\
& 0 & a_{01} & a_{00} \\
\cline { 3 - 5 }
\end{array}
$$

Tabela 3.2: Coeficientes utilizados no cálculo de medidas de associação.

Diversas medidas de associação podem ser calculadas a partir dessa tabela de contingência para dois vetores binários. Dois índices comumente utilizados são definidos como:

1. Coeficiente simples de correspondência - Equação 3.17:

$$
c c\left(E_{i}, E_{j}\right)=\frac{a_{00}+a_{11}}{a_{00}+a_{10}+a_{01}+a_{11}}
$$

2. Coeficiente de Jaccard - Equação 3.18:

$$
J\left(E_{i}, E_{j}\right)=\frac{a_{11}}{a_{10}+a_{01}+a_{11}}
$$

A diferença entre os dois índices está relacionada com o valor de $a_{00}$, uma vez que é considerado apenas no coeficiente simples de correspondência. No segundo caso, coeficiente de Jaccard, é considerado que a correspondência dos valores 0-0 é menos importante que a dos valores 1-1, pois, em muitas aplicações, o valor 1 (um) para os atributos indica presença da característica descrita por esse atributo, enquanto o valor zero indica ausência da característica.

\subsubsection{Avaliação de Clusters}

Neste estágio, o conjunto de exemplos deve ser submetido para a execução do clustering por meio de algum algoritmo para a construção de um modelo que apresenta os exemplos que pertencem a cada clusters.

Com o modelo criado, deve-se prosseguir para a avaliação dos clusters. Essa tarefa é realizada para determinar o grau de significância dos resultados obtidos pelo algoritmo de clustering. O fato de não haver uma classe definida para os dados em tarefas de aprendizado não-supervisionados, acarreta na utilização de heurísticas e suposições para a identificação das 
estruturas embutidas nesses dados, que são avaliadas e validadas considerando a qualidade dos clusters encontrados pelos diversos algoritmos, i.e., por meio da análise de índices que medem a adequabilidade da estrutura encontrada em termos das probabilidades dos clusters serem corretos. A adequabilidade dos clusters extraídos refere-se ao fato de representarem corretamente a informação ou a habilidade de recuperarem padrões que reflitam os conceitos intrínsecos ao conjunto de dados.

A validação do clustering, em geral, é realizada com base em índices estatísticos que julgam, de uma maneira quantitativa, as estruturas encontradas no conjunto de dados. A maneira pela qual um índice é aplicado para validar um agrupamento é dada pelo critério de validação. Assim, um critério de validação expressa a estratégia utilizada para validar uma estrutura de agrupamento, enquanto que um índice é um valor estatístico pelo qual a validade é testada. Existem três tipos de critérios para investigar a validade de um agrupamento (Halkidi et al., 2002a,b):

\section{Critérios relativos;}

2. Critérios internos; e

\section{Critérios externos.}

Os critérios relativos têm como objetivo encontrar o melhor agrupamento que um algoritmo pode obter sob certas suposições e valores para seus parâmetros, ou o algoritmo mais apropriado para os dados e estruturas analisadas. A maneira mais comum de aplicação de um índice com um critério relativo, por exemplo, consiste do cálculo do seu valor para vários agrupamentos que estão sendo comparados, obtendo-se uma seqüência de valores. O melhor agrupamento é determinado pelo valor que se destaca nessa seqüência, como o valor máximo, mínimo ou inflexão na curva do gráfico construído com a seqüência.

Os critérios internos e externos são baseados em testes estatísticos e têm um alto custo computacional. Seu objetivo é medir o quanto o resultado obtido confirma uma hipótese pré-especificada. Nesse caso, são utilizados testes de hipótese para determinar se uma estrutura obtida é apropriada para os dados. O mesmo índice pode ser utilizado em um critério interno ou externo, embora as distribuições de referência do índice sejam diferentes (Jain \& Dubes, 1988). O que distingüe a utilização de um índice em cada um dos critérios é a maneira como o índice é aplicado.

Por exemplo, uma maneira de mensurar a qualidade do dendograma construído por um algoritmo de clustering hierárquico é aplicar um índice de validação interna conhecido como coeficiente de correlação cophenético (Everitt, 1993). Para isso, deve-se saber o valor de similaridade que 
ocasionou a junção de cada par de clusters. Esse informação, conhecida como similaridade cophenética, é facilmente obtida a partir do dendograma resultante da aplicação do algoritmo sobre os dados. A correlação cophenética de um dendograma é definida como a correlação linear entre as matrizes de similaridade utilizada para construir o dendograma e a matriz de similaridade cophenética (Webb, 2005). Se o dendograma é válido, a matriz de similaridade cophenética deve ter alta correlação com a matriz de similaridade original, indicando que o dendograma obtido representa corretamente as estruturas latentes no conjunto de dados.

O cálculo do coeficiente de correlação cophenético ${ }^{4}$ resulta em um valor entre 0 (zero) e 1 (um). Segundo esse índice, um dendograma reflete as estruturas embutidas no dados quando esse valor é próximo de 1 (um). Esse coeficiente de correlação é definido pela Equação 3.19, onde $\operatorname{sim}\left(E_{i}, E_{j}\right)$ e $\operatorname{coph}\left(E_{i}, E_{j}\right)$ são respectivamente os elementos da matriz de similaridade original do conjunto de dados e da matriz de similaridade cophenética obtida a partir do dendograma construído pelo algoritmo de clustering hierárquico. Os valores $\mu_{\text {sim }}$ e $\mu_{\text {coph }}$ são as médias da matriz de similaridade e matriz cophenética, respectivamente. Mais detalhes de como construir a matriz de similaridade cophenética e efetuar o cálculo desse coeficiente de correlação podem ser obtidos em (Metz \& Monard, 2006b).

$$
\operatorname{coph}=\frac{\sum_{i<j}\left(\operatorname{sim}\left(E_{i}, E_{j}\right)-\mu_{\operatorname{sim}}\right)\left(\operatorname{coph}\left(E_{j}, E_{j}\right)-\mu_{\text {coph }}\right)}{\left(\sum_{i<j}\left(\operatorname{sim}\left(E_{i}, E_{j}\right)-\mu_{\text {sim }}\right)^{2}\left(\operatorname{coph}\left(E_{i}, E_{j}\right)-\mu_{\text {coph }}\right)^{2}\right)^{\frac{1}{2}}}
$$

\subsubsection{Interpretação de Clusters}

Esta etapa refere-se ao processo de examinar os clusters encontrados pelo algoritmo para tentar descobrir significados relacionados ao domínio da aplicação. A atribuição de conceitos aos agrupamentos é parte fundamental do processo de descoberta de conhecimento. Porém, é uma tarefa complexa que exige a participação do especialista do domínio na análise dos agrupamentos para que ele identifique os conceitos que, eventualmente, cobrem ou explicam os exemplos contidos em um mesmo cluster. Assim, o especialista pode avaliar subjetivamente os clusters encontrados para descobrir a existência de algum significado prático, e/ou diferenças, considerando os padrões representados em cada cluster.

Pode ser difícil interpretar o resultado encontrado pelos algoritmos, pois não apresentam descrições conceituais simples, mas apenas um conjunto de agrupamentos dos dados, descritos freqüentemente por meio de valores estatísticos e índices de similaridade. Essa limitação sugere que novas téc-

\footnotetext{
${ }^{4}$ Cophenetic correlation coefficient.
} 
nicas e ferramentas sejam utilizadas para tentar auxiliar o especialista no entendimento dos conceitos descritos pelos clusters. Para que o conhecimento extraído seja útil à aplicação, os padrões devem ser de fácil interpretação. Em (Martins, 2003) é proposta uma metodologia que faz uso de técnicas de aprendizado supervisionado para guiar a tarefa de explicação de clusters. A idéia básica é utilizar algoritmos de aprendizado supervisionado com o objetivo de descobrir e interpretar, com auxílio do especialista, os padrões encontrados pelos algoritmos de clustering sobre os dados não rotulados.

A metodologia proposta para auxiliar a tarefa de interpretação de clusters de maneira semi-automática, ilustrada na Figura 3.7, consiste em uma seqüência de estágios que compreende tanto algoritmos de aprendizado não-supervisionado quanto algoritmos de aprendizado supervisionado. Essa metodologia é composta das seguintes etapas:

1. Clustering um conjunto de dados não rotulados, no formato atributovalor - Tabela 2.1 -, é submetido a um algoritmo de clustering. $\mathrm{O}$ algoritmo utilizado é responsável por descobrir os clusters presentes nesse conjunto de dados.

2. Rotulamento do conjunto de exemplos o resultado obtido pelo algoritmo na etapa um é processado para que os dados do conjunto original, ou um sub-conjunto desses dados, sejam rotulados com um nome que identifica o cluster ao qual foram atribuídos durante o processo de clustering. Com isso, é criado um novo conjunto de dados com uma dimensão adicional, no qual o cluster é utilizado como o atributo classe.

3. Indução o conjunto de dados gerado na etapa dois possui as características necessárias para serem utilizados nessa etapa como entrada para algoritmos de aprendizado supervisionado, e, assim, obter uma descrição simbólica dos clusters identificados pelo algoritmo de clustering. Como o interesse é tentar explicar para o usuário/especialista os clusters previamente encontrados, a linguagem de descrição de conceitos utilizada pelo algoritmo de aprendizado supervisionado deve ser uma linguagem simbólica de fácil entendimento, tal como regras ou árvores de decisão.

4. Interpretação o conhecimento do especialista do domínio é de fundamental importância para a interpretação conceitual dos clusters, agora descritos utilizando um formalismo simbólico e portanto de mais fácil entendimento. Com a interpretação do especialista, é possível ter uma 
explicação para os dados pertencentes a cada cluster encontrado pelo algoritmo de aprendizado não-supervisionado.

Caso os resultados não sejam satisfatórios, o usuário/pesquisador pode decidir repetir o processo utilizando configurações diferentes dos agrupamentos encontrados ${ }^{5}$, alterar o algoritmo de agrupamento e/ou o indutor.

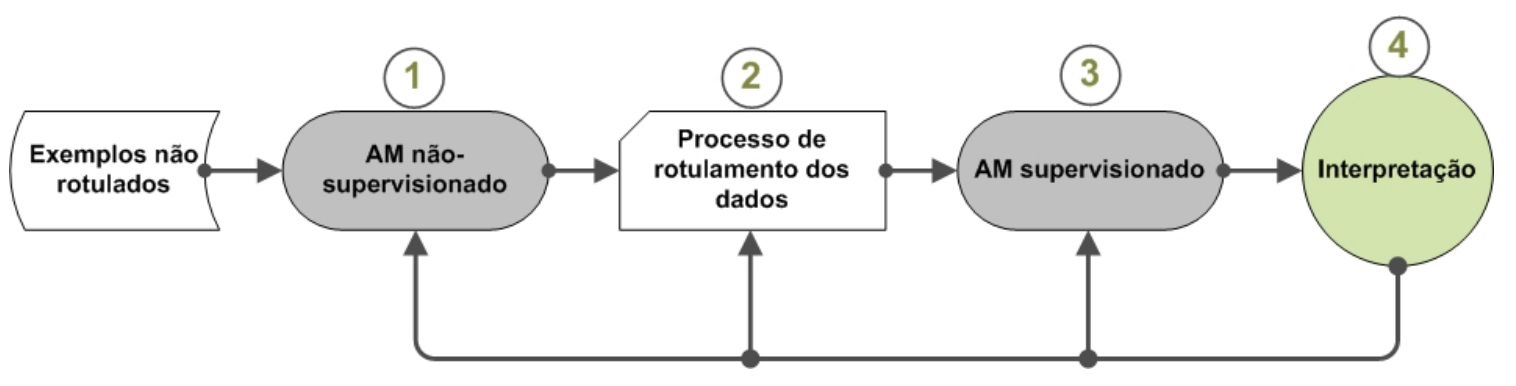

Figura 3.7: Metodologia para interpretação de clusters (Martins, 2003).

É importante observar que um algoritmo de clustering sempre encontrará clusters em um conjunto de dados, independentemente dos conceitos por eles representados. No entanto, os clusters nem sempre descrevem um agrupamento adequado ou estão relacionados com os objetivos da aplicação. Ainda, os clusters não representam, necessariamente, uma descrição conceitual relacionada a uma "classe". Dessa maneira, dois ou mais clusters podem agrupar exemplos que se referem a um mesmo conceito.

A metodologia para interpretação de clusters construídos por algoritmos de clustering hierárquico, proposta neste trabalho, está baseada nessa idéia, porém apresenta várias características diferentes, como descrito na Seção 5.6.

\subsection{Representação do Clustering Hierárquico}

Os resultados obtidos a partir do processo de mineração de dados devem estar representados por meio de uma linguagem de fácil entendimento para simplificar a análise e compreensão do conhecimento extraído. Nesta seção, são descritas algumas das representações mais usualmente utilizadas em tarefas de aprendizado por meio do clustering. São discutidos pontos positivos e negativos de cada representação, e, também, identificados os algoritmos que as utilizam.

No clustering hierárquico, foco do nosso trabalho, os resultados são descritos simbolicamente por alguma estrutura que permite observar a seqüência com que os agrupamentos foram criados. Diversas representações po-

\footnotetext{
${ }^{5}$ Por exemplo, rotulando exemplos que pertencem a clusters diferentes com a mesma classe a fim de verificar/melhorar o aspecto conceitual.
} 
dem ser utilizadas, mas o aspecto fundamental em cada uma delas é que seja possivel identificar a hierarquia dos agrupamentos, em quais clusters estão distribuídos os exemplos, em que iteração do processo um determinado exemplo foi agrupado e qual o grau de similaridade que resultou no agrupamento. Outras informações também são desejáveis, por exemplo, a média de similaridade interna e externa de cada cluster, a densidade dos agrupamentos e uma medida de qualidade global do clustering.

Os métodos de clustering hierárquico, tanto divisivos como aglomerativos, constroem uma estrutura que descreve uma hierarquia de agrupamentos sobre os dados. Um algoritmo hierárquico é, então, a especificação de ações que resultam nessa estrutura.

Uma forma simples para representar o clustering é utilizar a notação de conjuntos. Dados os $N$ exemplos inicias do conjunto $E=\left\{E_{1}, E_{2}, \ldots, E_{N}\right\}$, uma partição $P$ sobre o conjunto de dados inicial divide $E$ em sub-conjuntos $P=\left\{P_{1}, P_{2}, \ldots, P_{k}\right\}$ tal que:

$$
\begin{gathered}
P_{i} \cap P_{j}=\emptyset, \quad \forall(i, j), i=1,2, \ldots k ; j=1,2, \ldots k e i \neq j \\
E=P_{1} \cup P_{2} \cup P_{3} \cup \ldots \cup P_{k}
\end{gathered}
$$

A partir dessa notação, diz-se que uma partição $P^{\prime}$ está aninhada a uma partição $P$ se todo componente de $P^{\prime}$ é um conjunto próprio de algum componente em $P$, i.e., $P$ é formado pelo agrupamento dos componentes de $P^{\prime}$. Por exemplo, se o clustering $P$ com três clusters e o clustering $P^{\prime}$ com cinco clusters são definidos da seguinte maneira:

$$
\begin{gathered}
P=\left\{\left\{E_{1}, E_{2}, E_{3}\right\},\left\{E_{4}, E_{5}, E_{6}, E_{7}\right\},\left\{E_{8}\right\}\right\} \\
P^{\prime}=\left\{\left\{E_{1}\right\},\left\{E_{2}, E_{3}\right\},\left\{E_{4}, E_{5}\right\},\left\{E_{6}, E_{7}\right\},\left\{E_{8}\right\}\right\}
\end{gathered}
$$

então $P^{\prime}$ está inserido em $P$ e ambos representam o clustering sobre o conjunto de dados $E$.

Ainda que essa representação descreva a estrutura hierárquica dos clusters, por ela não é possivel identificar o grau de similaridade dos agrupamentos. Além disso, não é simples analisar os resultados quando o conjunto de dados contém muitos exemplos. Para tentar facilitar a interpretação do clustering, pode-se utilizar outra representação, também baseada em conjuntos, na qual cada conjunto é formado de outros conjuntos menores Figura 3.8. Essa representação, conhecida como diagrama de Venn, revela a estrutura hierárquica e facilita a interpretação de dados bi-dimensionais, mas também não apresenta a similaridade dos clusters e não pode ser diretamente utilizada para conjuntos de dados multi-dimensionais. Por esse motivo, outras representações são mais utilizadas, como banner e o dendograma, descritas a seguir. 


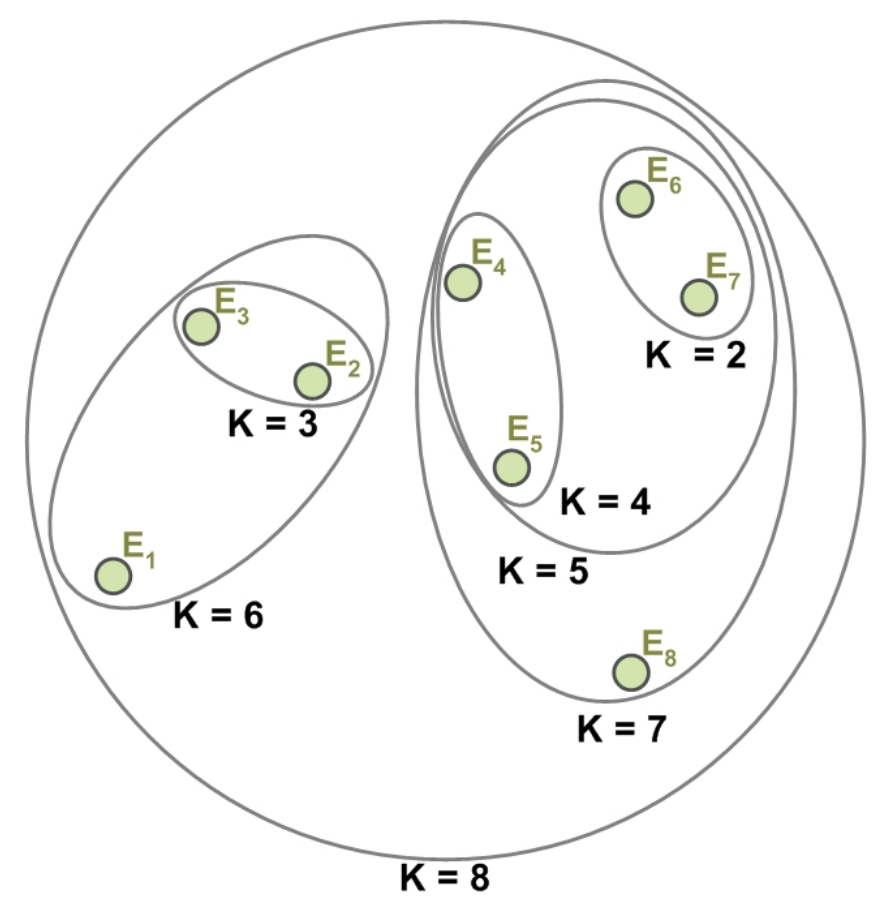

Figura 3.8: Clustering representado por meio do diagrama de Venn.

A representação da hierarquia por meio do banner é utilizada nos algoritmos AGNES - Agglomerative Nesting (Kaufman \& Rousseeuw, 1990a), DIANA — Divisive Analysis (Kaufman \& Rousseeuw, 1990b) e MONA - Monothetic Analysis (Kaufman \& Rousseeuw, 1990d). O banner é ilustrado na Figura 3.9 . Os asteriscos (*) indicam ligações entre objetos (clusters ou exemplos) e as listas de identificadores contêm repetições do rótulo desses objetos. Assim, no nível $2(\mathrm{~L}=2)$ inicia uma seqüência de três linhas. A primeira composta por $6+6+6+\ldots$ que é simplesmente a repetição do rótulo do exemplo $E_{6}$ separado pelo caractere “+”. Da mesma maneira, a lista de caracteres composta por $7+7+7+\ldots$ na terceira linha denota o exemplo $E_{7}$. A segunda linha, composta por uma seqüência de asteriscos, indica que houve um agrupamento entre os exemplos $E_{6}$ e $E_{7}$ a partir daquele nível. Os próximos dois agrupamentos ocorrem com os exemplos $E_{2}$ e $E_{3}$ no terceiro nível $(\mathrm{L}=3)$ e com os exemplos $E_{4}$ e $E_{5}$ no quarto nível $(\mathrm{L}=4)$, e assim sucessivamente até que todos estejam agrupados num único cluster. Observe que o banner deve ser lido sempre da esquerda para a direita (Metz \& Monard, 2006a).

O dendograma é a representação mais utilizada em algoritmos de clustering hierárquico, pois além da seqüência de agrupamentos, apresenta também a similaridade com que os clusters são formados. Os algoritmos CURE - Clustering Using Representatives (Guha et al., 1998), BIRCH Balanced Iterative Reducing and Clustering Using Hierarchies (Zhang et al., 1996), CHAMELEON - A Hierarchical Clustering Algorithm Using Dynamic Modeling (Karypis et al., 1999) e ROCK - Robust Clustering Using Links (Guha 


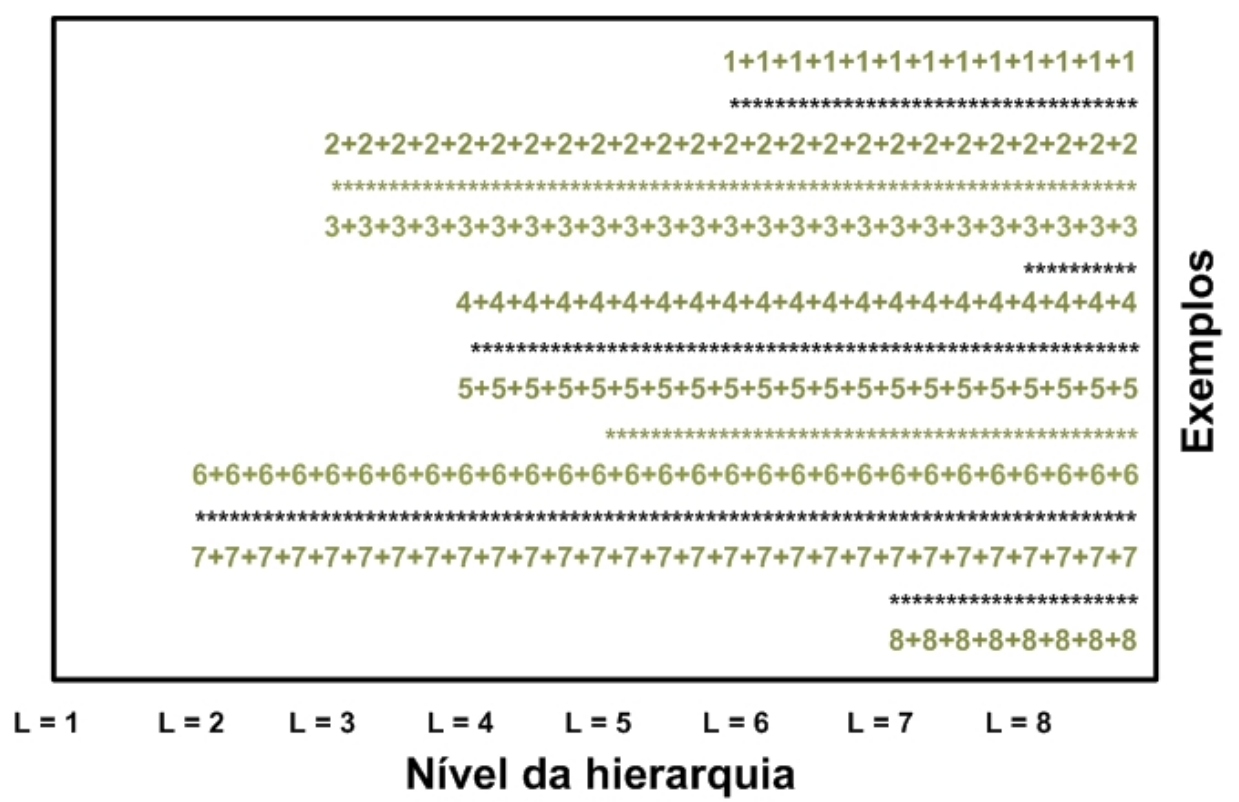

Figura 3.9: Clustering representado por meio do banner.

et al., 2000), fazem uso dessa representação.

Essa estrutura é uma árvore com $N$ folhas e altura $N-1$, na qual os exemplos são dispostos no eixo horizontal, enquanto que o eixo vertical indica a distância (ou a similaridade) com que os agrupamentos são criados. O primeiro nível do dendograma corresponde a um cluster contendo todos os $N$ exemplos do conjunto de dados; o segundo nível corresponde à divisão do cluster presente no primeiro nível, o que resulta em outros dois clusters. Cada um desses clusters contém um parte dos exemplos que estavam agrupados pelo único cluster do nível anterior. O nível $N$ corresponde a um conjunto de clusters unitários (folhas), no qual cada exemplo constitui um cluster. Para a construção dessa estrutura a partir da abordagem aglomerativa, os clusters presentes em um nível são agrupados e passam a fazer parte de outros clusters maiores e mais gerais, representados pelos nós ancestrais na árvore, até que toda a hierarquia seja construída. Desse modo, o dendograma não é apenas um conjunto de agrupamentos, mas uma estrutura com toda a hierarquia dos agrupamentos gerados sobre o conjunto de exemplos inicial. Em conseqüência, essa forma de representação possibilita ao pesquisador escolher o nivel de corte do dendograma que corresponde ao conjunto de clusters mais apropriado para a aplicação.

Para montar um dendograma gráfico são desenhados arcos, na forma de $\sqcap$, que representam os agrupamentos entre os clusters. A altura de cada arco indica a distância (ou similaridade) que resultou no agrupamento dos clusters aos quais suas extremidades estão conectadas. Considere como exemplo o dendograma ilustrado na Figura 3.10, o qual foi construído sobre um conjunto de dados composto de oito exemplos $\left\{E_{1}, E_{2}, \ldots E_{8}\right\}$. Na primeira 
iteração do algoritmo de clustering, um arco com altura aproximadamente 20 é desenhado no dendograma para representar o agrupamento dos exemplos $E_{6}$ e $E_{7}$. Na segunda iteração, os exemplos $E_{2}$ e $E_{3}$ são agrupados com distância aproximadamente 30. Analogamente, o arco que representa o agrupamento do exemplo $E_{1}$ com o cluster composto pelos exemplos $E_{2}$ e $E_{3}$ tem altura aproximadamente 70 .
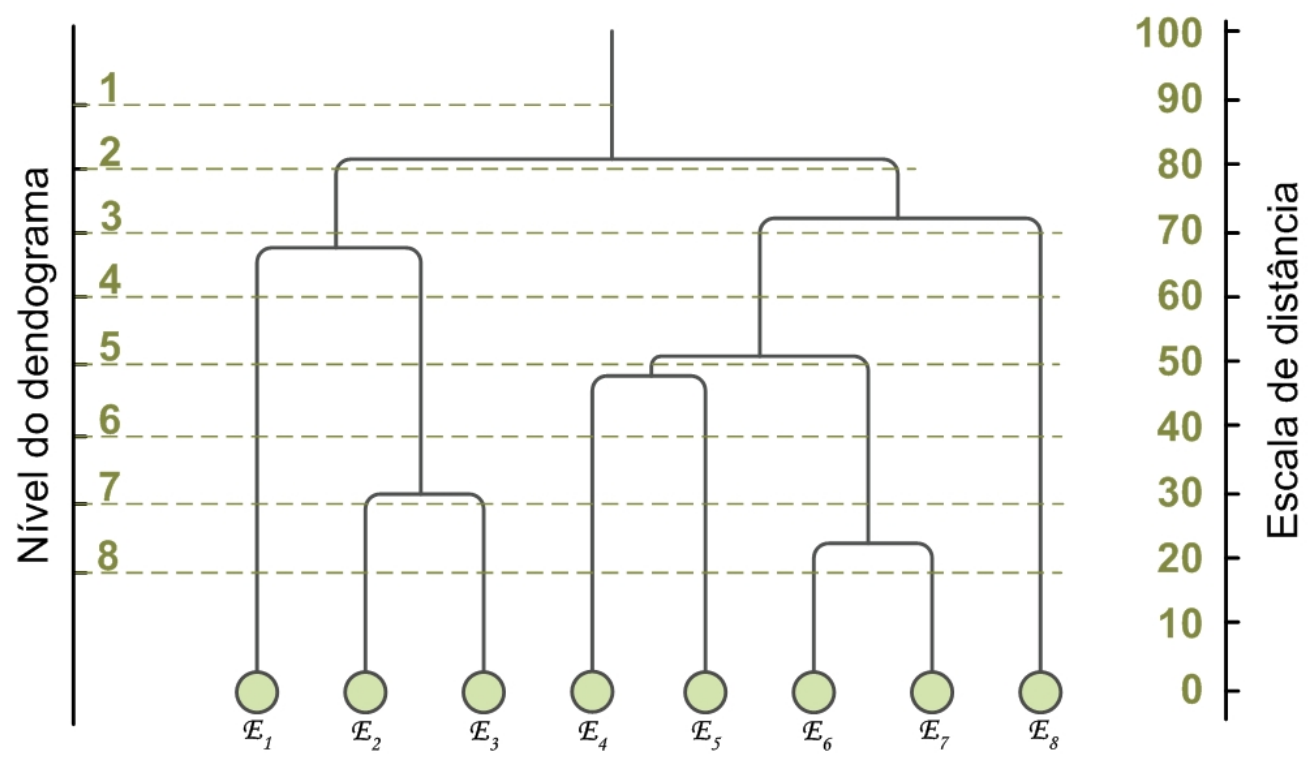

Figura 3.10: Clustering representado por meio do Dendograma.

Segundo a literatura, espera-se que bons clusters sejam compactos de modo que seus elementos apresentem alta similaridade, enquanto que a similaridade com os elementos de outros clusters seja a menor possível. Uma maneira de verificar essa compactação é analisar a altura dos arcos que agrupam os cluster, pois quanto menor a altura, mais compactos serão os clusters. Por outro lado, a junção entre clusters distintos deve apresentar pouca similaridade, conseqüentemente, o arco que os une deve ser maior em relação aos arcos que unem seus sub-clusters. Um arco com altura aproximadamente igual a altura dos arcos que formam seus sub-clusters não representa uma divisão natural dos clusters que ele agrupou. Por outro lado, a diferença expressiva entre a altura de um arco e os arcos formados anteriormente a ele, é um indicador de que os clusters agrupados são totalmente distintos e que provavelmente não representam o mesmo conceito. Essa diferença na altura dos arcos indica a separação ou junção natural de clusters. Um bom exemplo para ilustrar essas características é apresentado na Figura 3.11, na qual são mostrados dois dendogramas obtidos por meio da execução de algoritmos de clustering hierárquico diferentes mas com a mesma medida de distância e sobre o conjunto de dados bupa, descrito na Seção 6.2 .

Observe que no caso 3.11(a), os arcos iniciais que unem os clusters são 


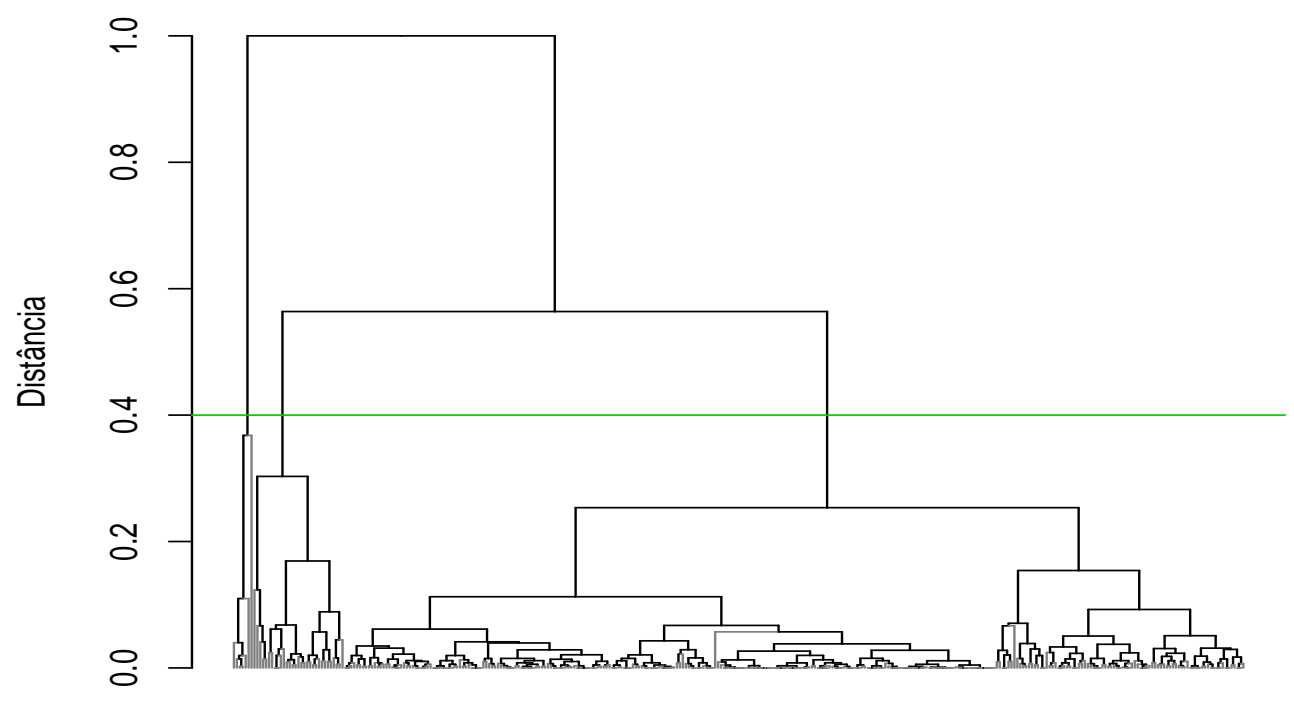

Exemplos

(a) Dendograma obtido a partir do conjunto de dados bupa por meio do algoritmo Complete Link e medida de distância de Manhattan.

\section{Dendograma}

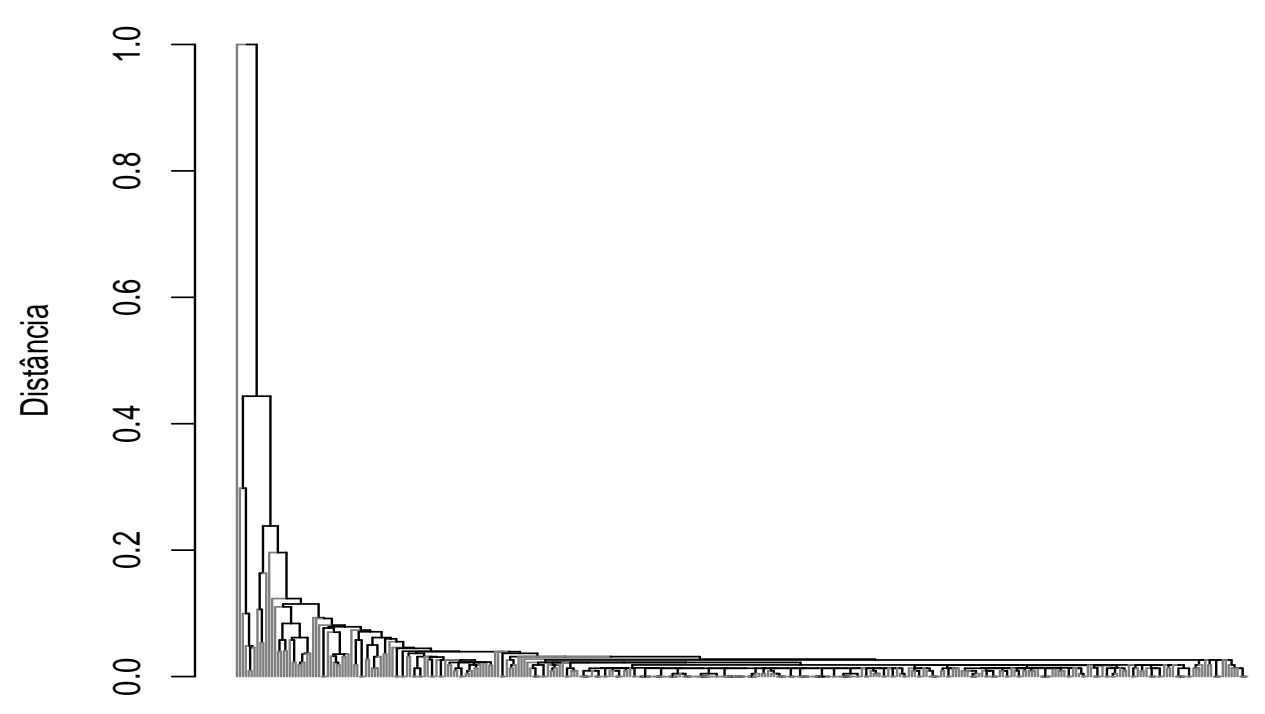

\section{Exemplos}

(b) Dendograma obtido a partir do conjunto de dados bupa por meio do algoritmo Single Link e medida de distância de Manhattan.

Figura 3.11: Comparação de dendogramas. 
muito pequenos, o que indica distância próxima a zero. Conforme o número de iterações aumenta, esses clusters são agrupados em clusters maiores com distâncias maiores, conseqüentemente, originando em arcos mais altos. Porém, as diferenças significativas entre as alturas dos arcos aparecem apenas nas últimas junções. Com isso, é fácil perceber a presença de clusters nesses dados e determinar onde deve ser cortado o dendograma. No caso 3.11(b), por outro lado, não há diferenças significativas no tamanho dos arcos que representam os agrupamentos, dificultando a escolha para o corte do dendograma.

É importante observar que dendogramas gerados a partir de métricas de similaridade e métodos de agrupamento diferentes, devem ser analisados de maneira diferente. Um dendograma obtido a partir da execução de um algoritmo Complete Link, por exemplo, deve apresentar valores de distância maiores entre clusters grandes, ao passo que um dendograma gerado por meio do algoritmo Single Link tende à apresentar valores de distância menores para os mesmos clusters - Capítulo 4. Essa diferença impacta, também, nos critérios de avaliação do clustering. No exemplo anterior, Figura 3.11, o coeficiente de correlação cophenético (apresentado na Seção 3.3.3) para o dendograma 3.11(a) é de 0,64, enquanto que o mesmo coeficiente para o dendograma 3.11(a) tem valor igual a 0,88 .

A variabilidade desse coeficiente de correlação ocorre devido à tendência que os diferentes algoritmos possuem para calcular a distância entre clusters distintos. Como pode ser observado a partir desses dendogramas, o coeficiente de correlação cophenético beneficia, em geral, os dendogramas construídos pelo algoritmo Single Link, pois a distância entre os clusters calculada por esse algoritmo é, em geral, menor que a distância calculada pelo algoritmo Complete Link.

Alguns trabalhos na literatura (Everitt, 1993; Jain \& Dubes, 1988) afirmam que valores acima de 0,80 para esse coeficiente é indicativo de um bom dendograma, a partir do qual pode ser extraída a estrutura natural dos clusters presentes no conjunto de dados. Mas, como pode ser observado nesses exemplos, essa afirmação nem sempre é verdadeira, pois nesses casos o dendograma que apresenta o menor valor para o coeficiente cophenético, Figura 3.11(a), é o dendograma com melhor separação entre os clusters.

Essa observação leva à conclusão de que apenas o valor desse coeficiente de correlação não é suficiente, na nossa opinião, para identificar os melhores dendogramas obtidos em diferentes experimentos, sendo ainda necessária a inspeção visual dos dendogramas construídos pelo algoritmo de clustering. Outras representações para o clustering também podem ser utilizadas, como Johnson-type, IciclePlot e Ward-type, descritos em (Metz \& 
Monard, 2006a), mas nesses casos não é possivel utilizar o coeficiente de correlação cophenético para a validação do resultado.

Para implementação da hierarquia de agrupamentos obtida pelos algoritmos hierárquicos, podem ser utilizadas diversas estruturas de dados, como a de matriz bidimensional ou as estruturas Parent Array (Karypis, 2003) e Pointer Representation (Sibson, 1973). Essas estruturas também estão descritas em (Metz \& Monard, 2006a), onde foi realizado um levantamento das diversas estruturas de dados e de representação utilizadas por algoritmos de clustering hierárquico. Esse estudo foi utilizado na elaboração do projeto de implementação do módulo de clustering hierárquico do DISCOVER, descrito no Capítulo 5.

As duas últimas estruturas são muito mais econômicas que a estrutura de matriz, pois a complexidade de espaço dessas estruturas é linear em relação ao número de exemplos, respectivamente, $2 \times(2 N-1)$ e $3 \times(N-1)$, i.e., $\Theta(N)$. A complexidade de espaço da estrutura de matriz, por outro lado, é quadrática, $\Theta\left(N^{2}\right)$. Considere por exemplo um conjunto de dados com 100 exemplos. A matriz quadrada necessita de 10.000 posições de memória, ao passo que as estruturas de Parent Array e Pointer Representation necessitam de aproximadamente $4 \%$ desse espaço de memória. Por outro lado, a estrutura de matriz é mais eficiente em termos de tempo de acesso aos dados. Desse modo, a escolha da estrutura para implementação do clustering deve considerar os aspectos de complexidade, tanto de tempo quanto de espaço.

\subsection{Considerações Finais}

Para a realização de experimentos por meio do clustering, o pesquisador deve conhecer os diversos conceitos que compõem essa técnica de aprendizado de máquina não-supervisionado. Além disso, é necessário que o objetivo da aplicação seja bem definido assim como as características dos dados que serão utilizados para análise, de modo que se possa selecionar com precisão a melhor abordagem, o melhor algoritmo de clustering e uma boa configuração dos parâmetros dos algoritmos. Neste capítulo foram apresentadas as características do clustering, entre elas, as abordagens mais utilizadas, as etapas de execução do clustering, as medidas de similaridade freqüentemente utilizadas e os critérios de validação de clustering.

É importante lembrar que o especialista de domínio desempenha um papel fundamental na etapa de interpretação dos clusters identificados no processo de clustering. Para facilitar a compreensão dos clusters, é interessante que existam metodologias automáticas, ou mesmo semi-automáticas, 
que auxiliem o especialista nessa tarefa. Outro fator importante é que a representação dos agrupamentos construídos seja de fácil entendimento e disponha do máximo de informação possível. Com isso, a realização do clustering se torna mais simples e a extração de conhecimento mais proveitosa, simplificando o processo e aumentando as chances de descobrir conhecimento novo e útil à aplicação. 



\section{Capitulo}

\section{Ferramentas e Algoritmos de Clustering Hierárquico}

\subsection{Considerações Iniciais}

Diversos algoritmos e ferramentas para o clustering foram desenvolvidos e estão disponíveis para uso. Muitos são de domínio público e podem ser encontrados via Internet. Neste capítulo são apresentados os algoritmos clássicos utilizados em clustering hierárquico e diversos outros algoritmos que foram desenvolvidos a partir desses algoritmos clássicos, bem como algumas ferramentas e bibliotecas para execução dessa tarefa.

\subsection{Algoritmos de Clustering Hierárquico}

Como mencionado, a tarefa de clustering é altamente dependente dos parâmetros, medidas de similaridade e métodos utilizados pelo algoritmo. Em essência, algoritmos diferentes que utilizam a mesma medida de similaridade e método de agrupamento deveriam apresentar os mesmos resultados se aplicados sobre um mesmo conjunto de dados. Essa observação é válida se considerarmos que a cada iteração os mesmos pares de clusters são selecionados para o agrupamento. No entanto, os algoritmos freqüentemente utilizados em aplicações práticas implementam outros recursos e heurísticas que, além de acarretarem resultados distintos, em alguns casos, melhoram a adequação do modelo obtido ao problema em questão.

Esses recursos vão desde técnicas para redução do conjunto de dados (seleção aleatória e particionamento do conjunto de dados), estruturas de dados para otimizar o cálculo da similaridade entre agrupamentos, como as árvores métricas R-Tree (Guttman, 1984) e Kd-Tree (Bentley, 1975), conceitos da teoria de grafos e diversas outras estratégias. 
Um algoritmo de clustering hierárquico aglomerativo executa, basicamente, os seguintes passos:

1. Seleção do par de clusters com a maior semelhança;

2. Criação de um novo cluster que agrupa o par de clusters selecionado no passo 1;

3. Decremento do número de clusters restantes; e

4. Avaliação da condição de parada: voltar ao passo 1 enquanto o número de clusters for maior que um.

Para implementar um algoritmo que execute esses passos, várias estratégias diferentes podem ser utilizadas. Em geral, o que diferencia os diversos algoritmos dessa família é o método ou estratégia utilizada para identificar os pares de clusters mais semelhantes, e, também, algumas heurísticas que podem ser utilizadas com o objetivo de melhorar os resultados. Nesse contexto, diversos algoritmos foram propostos: Single Link, Complete Link, Average Link, Centroid-based e Ward. Esses algoritmos, descritos a seguir, são freqüentemente referenciados como os algoritmos clássicos da literatura de clustering hierárquico.

Single Link é um dos algoritmos de clustering hierárquico mais simples, descrito inicialmente por Sneath (1957) e Johnson (1967). Esse método utiliza a técnica do vizinho mais próximo - (Nearest Neighbor Technique), na qual a distância entre dois clusters é determinada pela distância do par de exemplos mais próximo, sendo cada exemplo pertencente a um desses clusters, conforme ilustrado na Figura 4.1.

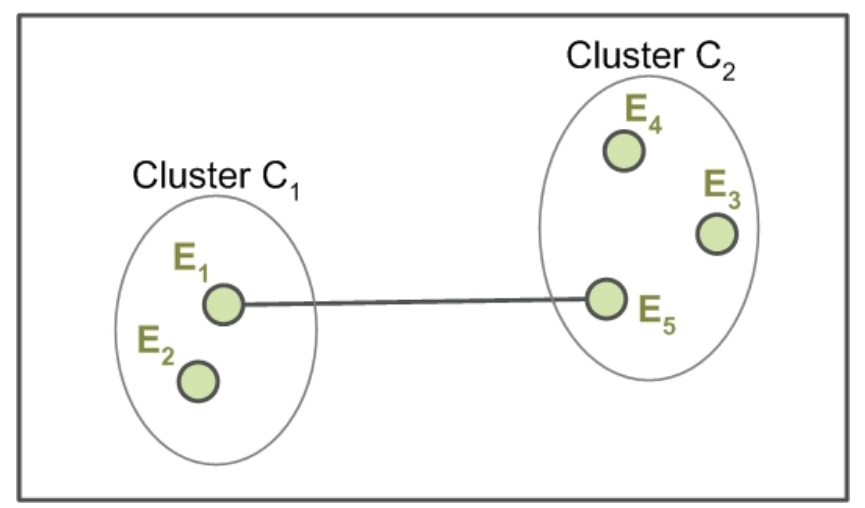

Figura 4.1: Single Link: menor distância entre dois clusters. Assim, $\operatorname{dist}\left(C_{1}, C_{2}\right)=\min \operatorname{dist}\left(E_{i}, E_{j}\right) ; E_{i} \in C_{1}, E_{j} \in C_{2}$.

Alguns algoritmos que implementam essa estratégia são descritos por Sibson (1973) e Rohlf (1973, 1978). 
Para entender melhor como funciona essa estratégia, considere um grafo no qual os exemplos representam os nós e as arestas formam um caminho entre os nós contidos num mesmo sub-grafo (cluster). A junção ou agrupamento de dois sub-grafos corresponde à adição de uma aresta entre o par de nós mais próximo, sendo que cada nó pertence a um cluster diferente. Utilizando a terminologia da teoria dos grafos, esse procedimento, caso seja executado até que todos os sub-grafos estejam conectados, resulta em uma árvore denominada MST - Minimal Spanning Tree (Figura 4.2).

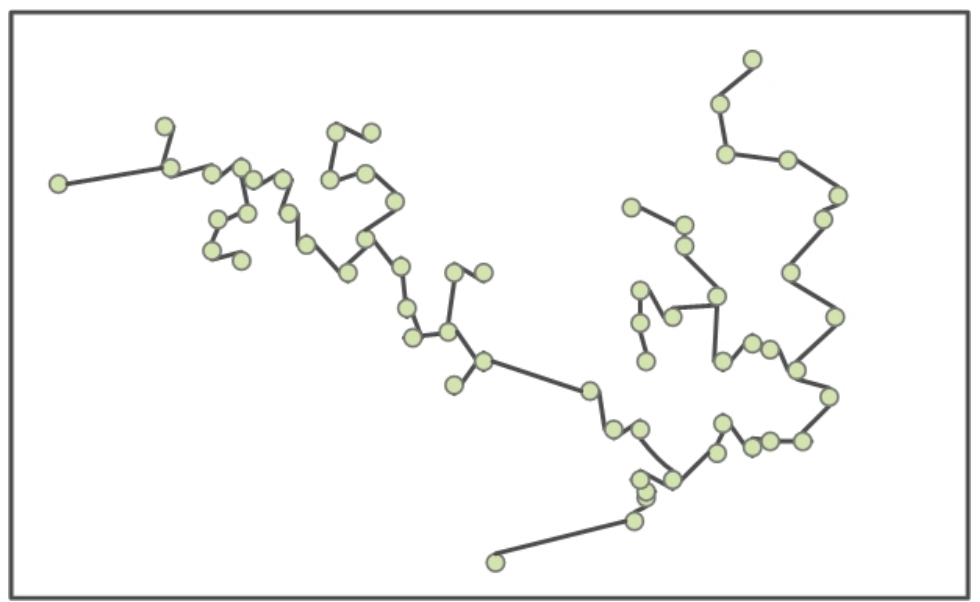

Figura 4.2: Minimal Spanning Tree obtida com a aplicação do método Single Link.

O algoritmo Single Link apresenta um problema, usualmente chamado de chaining effect, que acontece na presença de exemplos localizados entre dois clusters distintos, formando uma ponte e forçando a junção indevida desses clusters.

Complete Link utiliza uma técnica conhecida como Farthest Neighbor ou vizinho mais distante. Ao contrário do algoritmo Single Link, esse algoritmo determina a distância entre dois clusters de acordo com a maior distância entre um par de exemplos, sendo cada exemplo pertencente a um cluster distinto, conforme ilustrado na Figura 4.3. Com isso, tem maior propensão a identificar clusters menos alongados.

Average Link as estratégias de distância mínima e máxima, Single Link e Complete Link respectivamente, representam dois extremos em termos de distância entre clusters. Como todos os procedimentos que envolvem esses extremos, eles tendem a ser altamente sensíveis à presença de outliers. Assim, o uso de uma abordagem intermediária é um caminho natural para amenizar esse problema (Duda et al., 2000).

No algoritmo Average Link, a distância entre dois clusters é definida como a média das distâncias entre todos os pares de exemplos em cada 


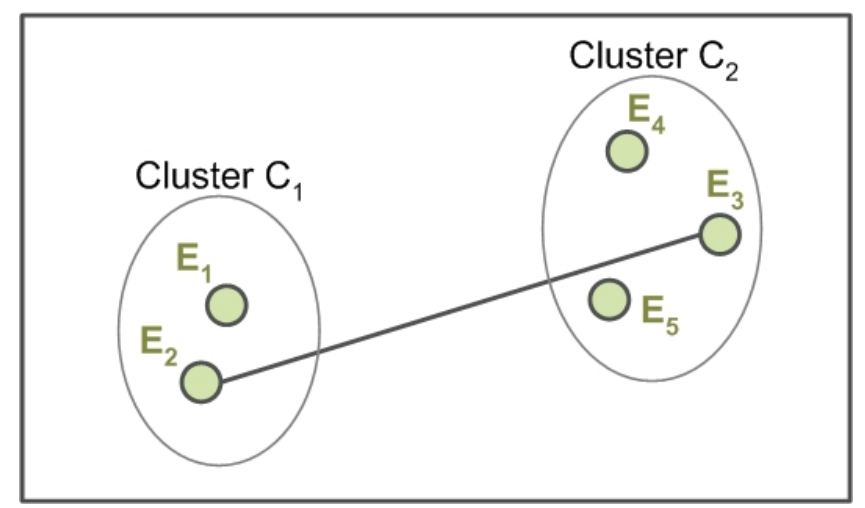

Figura 4.3: Complete Link: maior distância entre dois clusters. Assim, $\operatorname{dist}\left(C_{1}, C_{2}\right)=\max \operatorname{dist}\left(E_{i}, E_{j}\right) ; E_{i} \in C_{1}, E_{j} \in C_{2}$.

cluster, cada par composto por um exemplo de cada cluster, ilustrado na Figura 4.4.

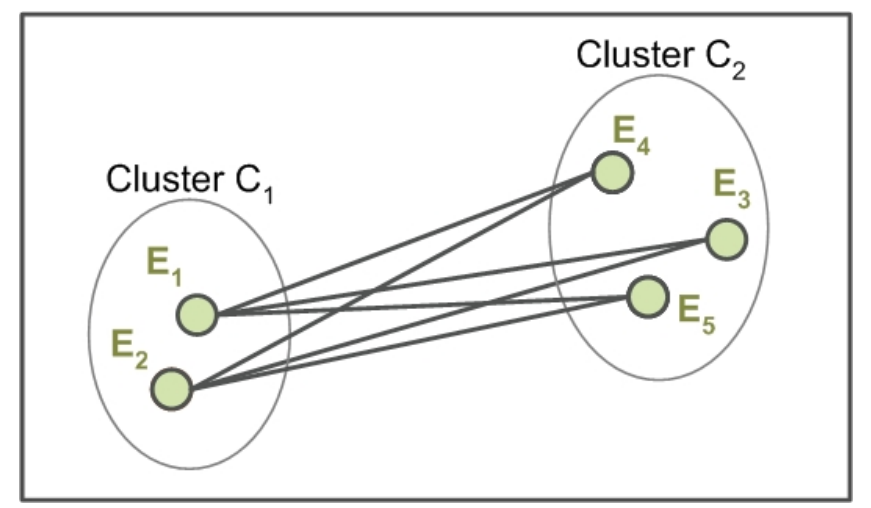

Figura 4.4: Average Link: média das distâncias entre exemplos dois clusters. $\operatorname{dist}\left(C_{1}, C_{2}\right)=\frac{1}{\left|C_{1}\right| \times\left|C_{2}\right|} \sum \operatorname{dist}\left(E_{i}, E_{j}\right) ; E_{i} \in C_{1}, E_{j} \in C_{2}$.

Centroid Link os três métodos descritos anteriormente operam sobre a matriz de similaridade e não necessitam acesso direto aos valores dos atributos dos exemplos, enquanto que o método baseado no centróide deve ter acesso direto aos exemplos. Com esse algoritmo, os grupos identificados são representados por um vetor que armazena a média de cada atributo. Assim, a distância entre os clusters é definida em termos da distância no espaço euclidiano entre o representante de cada cluster.

Uma desvantagem desse método está relacionada ao tamanho dos clusters selecionados para a junção, pois quando são muito diferentes, o centróide do novo cluster será semelhante ao centróide do cluster de maior tamanho, o que acarretará na perda das características do menor cluster.

Ward (Ward, 1963), elaborado de modo que as partições formadas minimizam a perda associada a cada agrupamento, a qual deve ser facil- 
mente quantizada e de simples interpretação. Nesse procedimento, a cada passo, todas as possiveis uniões entre pares de clusters são consideradas e os clusters que apresentam a mínima perda de informação são selecionados para o agrupamento. Essa perda de informação é definida em termos da soma dos erros quadrados.

Como mencionado, os algoritmos descritos anteriormente são considerados os algoritmos clássicos da literatura de clustering hierárquico. Outros algoritmos foram elaborados a partir das idéias implementadas nos algoritmos clássicos, como o AGNES - Agglomerative Nesting (Kaufman \& Rousseeuw, 1990a), o BIRCH - Balanced Iterative Reducing and Clustering Using Hierarchies (Zhang et al., 1996), o CURE - Clustering Using Representatives (Guha et al., 1998), o CHAMELEON - A Hierarchical Clustering Algorithm Using Dynamic Modeling (Karypis et al., 1999), o DIANA - Divisive Analysis (Kaufman \& Rousseeuw, 1990b), o ROCK - Robust Clustering Using Links (Guha et al., 2000) e o MONA - Monothetic Analysis (Kaufman \& Rousseeuw, 1990d), descritos a seguir.

AGNES - Agglomerative Nesting - , proposto por Kaufman \& Rousseeuw (1990a), é um dos algoritmos de clustering hierárquico mais tradicionais. Esse algoritmo constrói um dendograma completo, a partir do qual obtêm-se todos os possíveis conjuntos de clusters identificados. Uma implementação de domínio público desse algoritmo está disponível no ambiente $\mathrm{R}^{1}$ (Team, 2005).

O AGNES, assim como os outros algoritmos aglomerativos, procede com uma série de sucessivas fusões entre clusters. Assim, o par de clusters mais semelhantes é identificado a partir da matriz de similaridade e selecionado para o agrupamento. Quando mais de um par é identificado como mais semelhante, a seleção aleatória entre esses pares é utilizada para determinar qual deles será agrupado na iteração corrente. Com o algoritmo AGNES podem ser utilizados cinco métodos para o agrupamento: Single Link, Complete Link, Ward, UPGMA Unweighted Pair Group Method with Arithmetic Mean, Weighted Average e uma flexibilização desse último baseada na fórmula de atualização de Lance-Willians (Lance \& Willams, 1967).

BIRCH surgiu como uma proposta para o clustering de grandes conjuntos de dados que encontram-se armazenados em memória externa. Para isso, são utilizadas algumas estratégias que minimizam o número de acessos ao disco e mantêm as informações necessárias para a realização do agrupamento em memória principal. A idéia básica desse 
algoritmo é comprimir os exemplos de dados em sub-clusters para que o agrupamento possa ser realizado em memória principal. Com isso, o algoritmo faz apenas uma varredura no conjunto de dados, o que caracteriza uma vantagem em termos de eficiência de tempo de execução. Entretanto, sua performance é prejudicada quando os agrupamentos não possuem tamanhos e formatos uniformes. Além disso, é adequado apenas para conjuntos de dados com atributos quantitativos. A tarefa realizada pelo algoritmo $\mathrm{BIRCH}-$ Balanced Iterative Reducing and Clustering Using Hierarchies - é composta por quatro etapas, ilustradas na Figura 4.5.

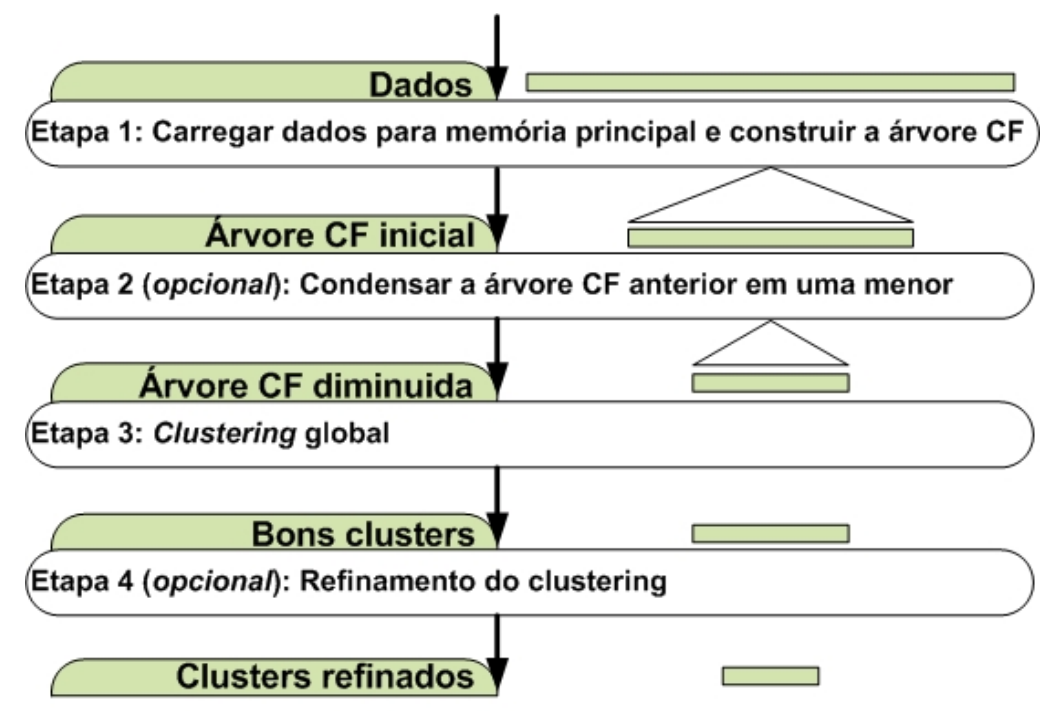

Figura 4.5: Ełapas do algoritmo $\mathrm{BIRCH}$.

O objetivo da primeira etapa é ler todo o conjunto de dados e construir uma árvore em memória principal. Essa árvore (CF) descreve o conjunto de dados da maneira mais detalhada possível de acordo com as limitações de espaço de memória, armazenando em seus nós apenas um resumo de cada cluster, o qual contém informações como o número de exemplos presentes no cluster $\left(\left|C_{i}\right|\right)$, um vetor com a soma linear dos atributos de cada exemplo local $(\overrightarrow{L S})$ e a soma quadrada desses exemplos $(S S)$. Na segunda etapa, a árvore $C F$ é analisada e reestruturada para ocupar menos espaço de memória e otimizar a execução do agrupamento na terceira etapa. Durante a reestruturação da árvore, alguns outliers são eliminados e alguns sub-clusters menores são agrupados em sub-clusters mais gerais, fazendo com que a árvore resultante seja menor. A quarta etapa consiste na atribuição dos exemplos restantes aos clusters encontrados na terceira etapa.

CURE é outra proposta para análise de grandes conjuntos de dados. Diver- 
sos algoritmos representam os clusters por meio de um ponto central, usualmente o centróide. Um problema com esses algoritmos ocorre quando clusters distintos estão muito próximos, apresentam formato não elipsoidal ou tamanhos não uniformes. Por outro lado, outros algoritmos representam os clusters como um grafo, no qual todos os exemplos são considerados para o cálculo da similaridade. Essa abordagem também apresenta algumas desvantagens, discutidas anteriormente na descrição dos algoritmo Single Link e Complete Link, as quais sugerem que essas abordagens não produzem bons resultados quando os clusters não estão bem separados ou os tamanhos não são uniformes (Guha et al., 1998).

Com o objetivo de minimizar esses problemas, o CURE - Clustering Using Representatives - segue uma estratégia intermediária, na qual cada cluster é representado por um número $p$ de exemplos distribuídos de modo que descrevam naturalmente o formato do cluster. Em seguida, esses exemplos são aproximados do centro do cluster por meio de um fator de encolhimento. Após, os $p$ exemplos selecionados são definidos como representantes do cluster, e, então, a distância entre dois clusters é obtida como sendo a distância entre o par de representantes mais próximos (mesma estratégia utilizada no algoritmo Single Link), porém considerando apenas os $p$ exemplos representantes e não todos os exemplos contidos nos clusters.

Para a análise de grandes conjuntos de dados, o CURE realiza a seleção aleatória de uma amostra dos dados e particiona essa amostra em sub-conjuntos para executar o clustering em cada partição desses subconjuntos de dados. Uma vez que as partições tenham passado pelo clustering, esse algoritmo utiliza os múltiplos representantes de cada cluster para definir o agrupamento dos dados restantes. As etapas do algoritmo CURE são apresentadas na Figura 4.6.

CHAMELEON difere dos algoritmos de clustering amplamente utilizados, como BIRCH e CURE, pois esses algoritmos são projetados para encontrar agrupamentos que seguem algum modelo estático. Esses algoritmos falham na identificação dos clusters se a escolha dos parâmetros desse modelo estático não for apropriada, e, eventualmente, se o modelo propriamente dito não é adequado para capturar as características dos clusters embutidos nos dados. Adicionalmente, os formatos e tamanhos dos clusters podem dificultar na criação de bons modelos.

O CHAMELEON - A Hierarchical Clustering Algorithm Using Dynamic Modeling - , por outro lado, mede a similaridade entre dois clusters ba- 


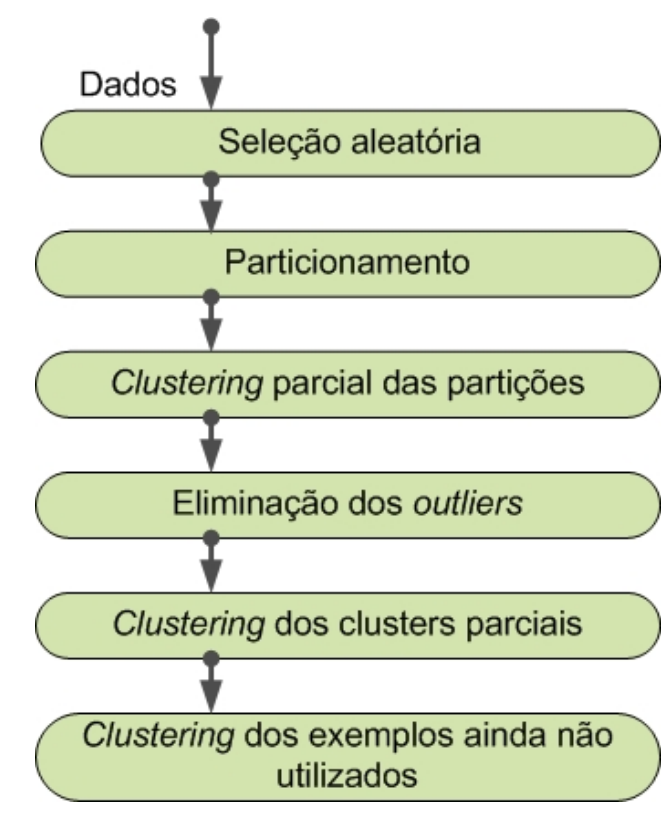

Figura 4.6: Etapas do algoritmo CURE.

seado em modelos dinâmicos. Nesse caso, dois clusters são agrupados somente se a inter-conectividade e a distância entre os dois clusters são comparáveis à inter-conectividade interna e à similaridade interna desses clusters, o que facilita a identificação natural e homogênea dos clusters contidos nos dados (Karypis et al., 1999). Dessa maneira, o CHAMELEON supera as limitações dos modelos estáticos discutidos anteriormente, pois analisa características internas dos clusters no momento do agrupamento.

Esse algoritmo utiliza o conceito de $k$-vizinhos mais próximos ( $k$-Nearest Neighbor - KNN) sobre um grafo esparso que representa o conjunto de dados, no qual cada vértice refere-se a um exemplo e uma aresta entre dois vértices é criada se o exemplo correspondente a um dos dois vértices é um dos $k$ exemplos mais similares do outro vértice. O CHA$M E L E O N$ realiza o processo de clustering em duas etapas. Na primeira etapa, um algoritmo de particionamento de grafos esparsos é aplicado sobre o grafo para particionar o conjunto de dados em um número grande de clusters relativamente pequenos. Na segunda etapa, utiliza um algoritmo de clustering hierárquico aglomerativo para encontrar os clusters finais, agrupando sucessivamente os pequenos clusters encontrados na primeira etapa. Uma visão geral do processo de clustering executado pelo CHAMELEON é apresentada na Figura 4.7 .

Existe uma implementação de domínio público desse algoritmo, a qual faz parte do Cluto - Clustering Toolkit ${ }^{2}$. 


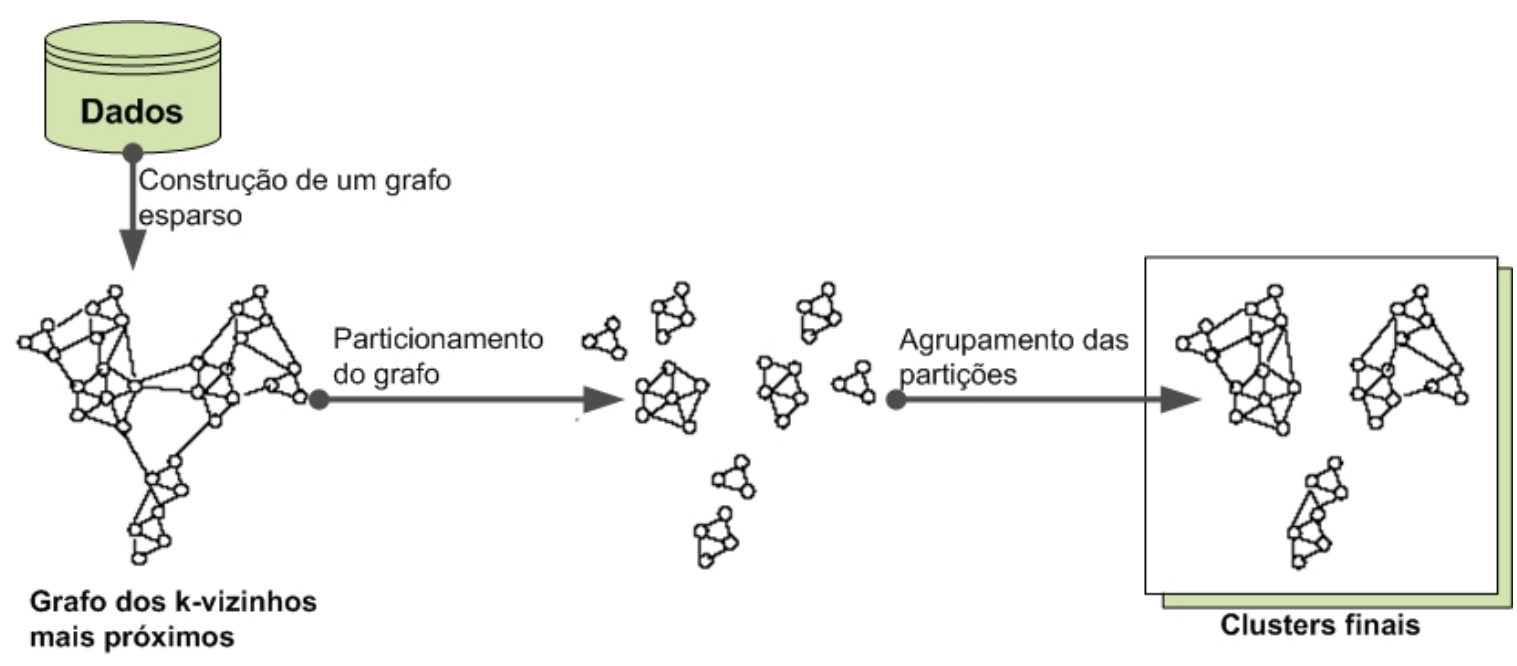

Figura 4.7: Ełapas do algoritmo CHAMELEON.

ROCK grande parte dos algoritmos são aplicáveis a dados com atributos quantitativos e não são apropriados para atributos qualitativos. O algoritmo ROCK - Robust Clustering Using Links, proposto por Guha et al. (2000), sugere uma alternativa à esse problema, utilizando um novo conceito baseado em ligações entre exemplos, ao invés de métricas de distância. Nesse contexto, o conjunto de dados é analisado como um grafo esparso, onde exemplos são os nós do grafo e a aresta entre dois exemplos indica que eles fazem parte de um mesmo subgrafo (cluster). É importante observar que, nesse caso, ligações entre exemplos e arestas no grafo são conceitos distintos; o número de ligações entre um par de exemplos $E_{i}$ e $E_{j}$ é o número de vizinhos comuns desses exemplos, conforme ilustrado na Figura 4.8.

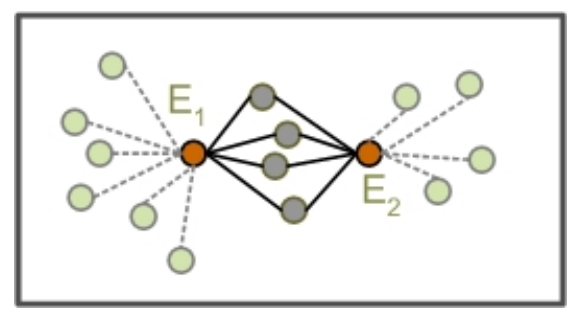

Figura 4.8: llustração do conceito de ligações utilizado pelo algoritmo ROCK: $\operatorname{Link}\left(E_{1}, E_{2}\right)=4$.

Partindo desse princípio, o algoritmo analisa o grau de conectividade dos clusters e seleciona para o agrupamento o par que maximiza a soma das ligações. Uma visão geral do algoritmo ROCK é apresentada na Figura 4.9.

Inicialmente, uma amostra significativa de exemplos é selecionada aleatoriamente a partir dos dados originais. Após, o processo de agrupamento hierárquico que usa o conceito de ligações é aplicado sobre essa 


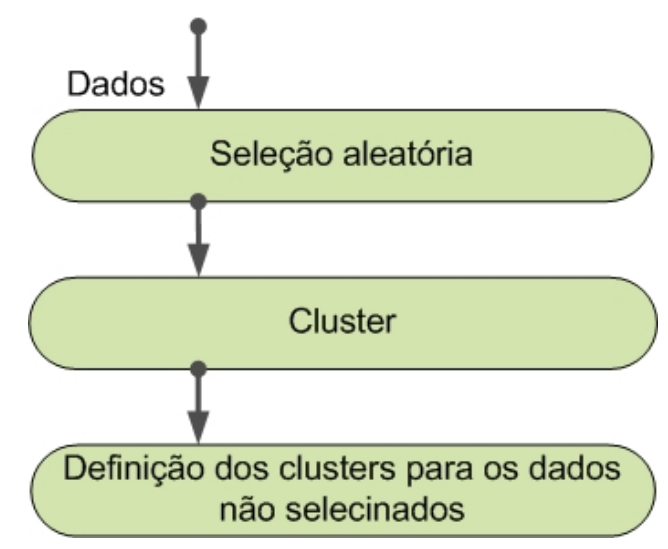

Figura 4.9: Ełapas do algoritmo ROCK.

amostra, e, finalmente, os clusters identificados são utilizados para determinar o grupo ao qual pertence cada exemplo não selecionados na primeira etapa, os quais são atribuídos ao cluster que maximiza o número de ligações.

MONA os algoritmos apresentados anteriormente foram desenvolvidos para operar sobre conjuntos de dados quantitativos ou qualitativos. Entretanto, ao contrário do algoritmo MONA, eles não distingüem atributos qualitativos de binários, os quais podem assumir apenas dois valores que representam presença ou ausência de determinada característica.

A idéia do algoritmo MONA - Monothetic Analysis - é selecionar um dos atributos binários e dividir o conjunto de dados em relação a esse atributo. Assim, são obtidos dois clusters, um com exemplos que possuem valor 1 (presença) para o atributo selecionado e outro cluster com exemplos que possuem valor 0 (ausência) para esse atributo. Em cada cluster gerado, um dos atributos restantes é selecionado e usado para uma nova divisão. Esse processo é repetido até que os clusters restantes sejam unitário ou não haja mais atributos que possam separar os dados em cada cluster. Um atributo utilizado em alguma divisão anterior não pode ser selecionado novamente, pois nesse estágio todos os exemplos pertencentes ao mesmo cluster apresentam o mesmo valor para o atributo que já foi utilizado.

A característica mais importante desse algoritmo é a seleção do atributo para separação dos exemplos. O atributo selecionado é o que maximiza a soma da similaridade com todos os outros atributos, ou seja, o atributo que está mais centralizado no espaço dos exemplos analisados.

DIANA a abordagem divisiva é hierárquica por natureza. A cada passo, algoritmos divisivos particionam um cluster formando dois novos clus- 
ters menores, até que todos os clusters restantes não possam mais ser divididos.

Como todos os algoritmos divisivos, o DIANA - Divisive Analysis proposto por Kaufman \& Rousseeuw (1990b), considera inicialmente que todos os exemplos fazem parte de um único cluster e, então, divide esse cluster em dois clusters menores. Nessa divisão não são consideradas todas as possibilidades, mas é utilizado um procedimento iterativo que otimiza a escolha dos exemplos que serão atribuídos a cada novo cluster. Nesse procedimento, o exemplo menos semelhante a todos os outros é selecionado e utilizado para a criação de um novo cluster. A seleção aleatória é utilizada caso mais de um exemplo esteja apto para ser selecionado. Na seqüência são selecionados outros exemplos que são mais semelhantes ao novo cluster que ao cluster inicial, e esses exemplos são transladados para o novo cluster. Esse processo se repete dividindo a cada iteração o cluster que contém o maior valor de diâmetro, até que restem apenas clusters unitários.

Os algoritmos apresentados nesta seção são, como mencionado anteriormente, os mais comumente utilizados e fazem parte tanto da abordagem aglomerativa como divisiva. Além disso, há algoritmos capazes de operar sobre dados com atributos quantitativos e qualitativos. Esses algoritmos freqüentemente fazem parte de ferramentas e/ou pacotes de software que integram o clustering com as outras técnicas utilizadas no processo de mineração de dados. Nas próximas seções são relacionadas algumas ferramentas para o clustering e uma biblioteca que implementa alguns dos algoritmos apresentados anteriormente.

\subsection{Ferramentas e Bibliotecas de Clustering Hierárquico}

Diversas ferramentas desenvolvidas para a extração de padrões e descoberta de conhecimento estão disponiveis, como o Mineset $^{3}$ (Rathjens, 2000), o IntelliMiner ${ }^{4}$ (IBM, 2000), o WEKA - Waikato Environment for Knowledge Analysis - (Witten \& Frank, 2000), o YALE - Yet Another Learning Environment $^{5}$ - e o Orange (Demsar \& Zupan, 2004). Há também um pacote de software, Cluto (Karypis, 2003), implementado exclusivamente para a execução dos clustering das abordagens particional e hierárquica. Nesse pacote está disponível a implementação do algoritmo CHAMELEON. Além

\footnotetext{
$3_{\text {http }}: / /$ www.sgi.com

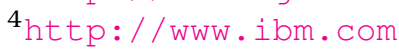

$5_{\text {http: }} / /$ www.yale.cs.uni-dortmund.de
} 
dessas ferramentas, o ambiente estatístico $\mathrm{R}^{6}$ (Team, 2005) também dispõe de implementações de algoritmos de clustering. No pacote Cluster do ambiente R, por exemplo, estão disponíveis os algoritmos AGNES, DIANA e MONA. Além desses, há também o pacote HCluster que implementa um algoritmo de clustering hierárquico. Nesses ambientes de software, existem outras ferramentas que auxiliam na análise de clusters, bem como a criação de gráficos e representação gráfica do dendograma ou banner. Entretanto, ainda que essas representações gráficas auxiliem bastante na interpretação dos clusters, elas não são interativas.

O HCE (Seo, 2005) é uma ferramenta para o clustering com diversas facilidades para visualização e exploração interativa, que permite aos usuários um melhor entendimento das estruturas latentes em dados multi-dimensionais por meio da inspeção visual.

Usualmente, os algoritmos de clustering disponiveis para uso requerem que o número de clusters finais seja informado ou, no caso do clustering hierárquico, que seja determinado o nível no qual o dendograma deve ser cortado para a criação dos clusters. Outros algoritmos implementam estratégias que identificam automaticamente o número de clusters supostamente contidos nos dados. Entretanto, esse resultado pode não ser interessante ao usuário, uma vez que ele tem pouco ou nenhum controle sobre o processo. A interação do usuário com as ferramentas gráficas disponiveis no $\mathrm{HCE}^{7}$ permite determinar o número natural de clusters.

Uma dificuldade encontrada pelos usuários desenvolvedores é o difícil acesso ao código fonte dos algoritmos e ferramentas disponíveis. Esse acesso é desejável, uma vez que permitiria o controle total sobre os algoritmos estudados, as estruturas de dados utilizadas na implementação e as representações internas dos objetos e resultados obtidos, assim como às heurísticas utilizadas pelo desenvolvedor do algoritmo. Sob esse prisma, alguns pesquisadores disponibilizam seus algoritmos e ferramentas com o código fonte em forma de bibliotecas ou módulos. Um exemplo é a biblioteca Cluster $3.0^{8}$, inicialmente proposta por Michael Eisen e implementada por Hoon et al. $(2004,2005)$, a qual foi utilizada no desenvolvimento deste trabalho.

A biblioteca Cluster 3.0 foi desenvolvida no Laboratório de Análise de informações de DNA, no Centro de Genoma Humano do Instituto de Ciências Médicas da Universidade de Tokyo. A biblioteca consiste de uma coleção de rotinas que implementam os algoritmos de clustering freqüentemente referenciados na literatura, como os hierárquicos Centroid Link, Single Link,

\footnotetext{
$6_{\text {http: //www.r-project.org/ }}$

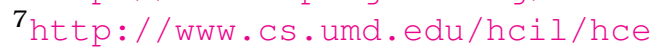

8http://bonsai.ims.u-tokyo.ac.jp/ mdehoon/software/cluster/
} 
Complete Link e Average Link e os particionais $k$-means, $k$-medians e $k$ medoids. Além disso, a biblioteca contém rotinas para a realização do clustering por meio de Redes Auto-Organizáveis (Self-Organizing Maps - SOM) e para identificação de características relevantes por meio da Análise de Componentes Principais (Principal Component Analysis - PCA). Nessa biblioteca, foram implementadas oito medidas de similaridade, das quais seis são baseadas em coeficiente de correlação enquanto que as outras duas são baseadas em distâncias entre pontos no espaço Euclidiano. A biblioteca dispõe ainda de estratégias para atribuição de pesos aos atributos e/ou exemplos, assim como rotinas para tratamento de valores faltantes ou desconhecidos.

\subsection{Considerações Finais}

Neste Capítulo foram descritos os algoritmos clássicos utilizados para execução do processo de clustering hierárquico e vários outros algoritmos referenciados na literatura. Foram apresentadas diversas ferramentas e algumas bibliotecas de domínio público disponiveis via internet que também dispõem, entre outros, da implementação de algoritmos de clustering hierárquico. Após analisar as diversas facilidades fornecidas nessas bibliotecas, decidimos utilizar a biblioteca Cluster 3.0, que dispõe de métodos para a realização do clustering hierárquico, para desenvolver o módulo de clustering hierárquico do DISCOVER, proposto neste trabalho e apresentado no próximo capítulo. 



\section{O Módulo de Clustering Hierárquico do DISCOVER}

\subsection{Considerações Iniciais}

Um problema freqüentemente relacionado às tarefas de análise e exploração de dados é a dificuldade em descobrir padrões com significado útil e de fácil compreensão para a aplicação. Em geral, após a realização do clustering, o que se tem como resultado é um conjunto de clusters que agrupam exemplos segundo alguma medida de similaridade ou distância. Entretanto, em algumas aplicações é importante tentar interpretar o conceito representado pelos clusters. Para isso, é necessário o desenvolvimento de ferramentas que auxiliem o usuário ou especialista na realização dessa tarefa. Com esse objetivo, projetamos e desenvolvemos um módulo de clustering hierárquico que está integrado a um projeto maior, o Discover (Baranauskas \& Batista, 2000; Batista \& Monard, 2003; Prati, 2003), no qual estão disponíveis diversas ferramentas que contemplam todas as etapas do processo de mineração de dados. Essas ferramentas, podem ser acessadas por meio do ambiente DLE - Discover LeARning Environment (Batista \& Monard, 2003), composto pela biblioteca de classes do DISCOVER - Discover OBJECT LIBRARY (DOL) - e pelo gerenciador de experimentos SNIFFER. Com a integração do módulo de clustering ao DISCOVER, o usuário tem acesso à todas as ferramentas disponíveis no ambiente DLE, o que pode facilitar o processo de análise dos clusters e aplicação de metodologias que fazem uso de diferentes técnicas de aprendizado. Com isso, a metodologia de interpretação de clusters, apresentada na Seção 3.3.4, mas adaptada para a abordagem de clustering hierárquica, pode ser facilmente aplicada ao resultado de experimentos realizados no Discover.

Neste Capítulo são apresentadas brevemente algumas características da biblioteca de classes do Discover, do ambiente de gerenciamento de ex- 
perimentos e avaliação experimental SNIFFER, assim como a descrição do projeto e implementação do módulo de clustering hierárquico proposto neste trabalho. Dentre as características apresentadas estão as bibliotecas utilizadas, a descrição dos arquivos de entrada e saída, como são tratados valores faltantes ou desconhecidos e o ambiente de experimentos e análise dos resultados do clustering.

\subsection{A Biblioteca de Classes DOL}

A DOL - Discover Object Library (Batista \& Monard, 2006) é uma biblioteca orientada a objetos baseada em padrões de projeto. As classes dessa biblioteca implementam as tarefas de manipulação e gerenciamento de dados mais comuns, como gerenciamento de diferentes sintaxes de arquivos de dados e atributos, amostragens, métodos de resampling, estatísticas descritivas e normalizações de dados. Essa biblioteca foi implementada com o objetivo de prover funcionalidades para as tarefas de pré-processamento de dados e dar suporte à criação de novos métodos de pré-processamento de dados. Para isso, a DOL foi desenvolvida em uma arquitetura modular na qual cada módulo é constituído de uma ou mais classes que realizam um conjunto bem definido de tarefas. Essa biblioteca possui um módulo central, chamado CORE, que é responsável por manter o conjunto de exemplos utilizado em uma estrutura de dados específica do Discover. Além disso, ela disponibiliza, atualmente, mais de 60 métodos capazes de consultar e manipular essa estrutura. O módulo CoRE é o único que, necessariamente, deve ser carregado por uma aplicação que utiliza a biblioteca, enquanto que os demais módulos são carregados apenas em casos que suas funcionalidades sejam necessárias.

O conjunto de rotinas da biblioteca DOL permite ao desenvolvedor uma forma simples de acesso e manipulação dos dados, os quais podem estar armazenados em arquivos texto ou em tabelas de bancos de dados relacionais. Entre as principais funcionalidades da biblioteca DOL pode-se citar: manipulação de atributos e exemplos, integração com diversos sistemas de aprendizado de máquina, integração com sistemas gerenciadores de bancos de dados, filtros de exemplos e atributos, estatísticas descritivas e correlações, métodos de resampling além de diversos conversores. 


\subsection{O Gerenciador de Experimentos SNIFFER}

Freqüentemente, para avaliar e comparar algoritmos de aprendizado é necessário executar um experimento diversas vezes. Diante de tantas execuções, é muito difícil gerenciar os experimentos manualmente, tornando necessária a automatização dessa tarefa. Por esse motivo, o ambiente computacional SNIFFER (Batista \& Monard, 2003) foi desenvolvido e integrado ao DISCOVER. Com isso, o SNIFFER pode acessar todos os algoritmos e ferramentas disponiveis no ambiente DLE, e, conseqüentemente, propiciar a avaliação e comparação de desempenho de métodos de pré-processamento de dados utilizando diversos sistemas de aprendizado. As principais funcionalidades desse ambiente são o gerenciamento das sintaxes dos diferentes sistemas de aprendizado, aplicação de métodos de resampling, recuperação de taxas de erro, cálculos e comparação de medidas de desempenho.

Uma outra característica importante do SNIFFER é automatizar, sempre que possível, a publicação dos resultados, fornecendo ao usuário uma segurança maior de que os resultados publicados são fiéis aos resultados obtidos nos experimentos. Os resultados dos experimentos envolvem, usualmente, uma grande quantidade de valores numéricos, o que torna muito comum a introdução de erros durante confecção manual de tabelas e gráficos. Como alternativa para solucionar esse problema, o SNIFFER fornece ao usuário relatórios resumidos e detalhados dos resultados obtidos, além de tabular esses resultados em um formato que pode ser utilizado para gerar gráficos com a ferramenta Gnuplot ${ }^{1}$ e tabelas com o processador de textos LAT $\mathrm{X}^{2}$.

O ambiente SNIFFER complementa a biblioteca DOL, pois permite que diferentes indutores proposicionais e métodos de pré-processamento de dados sejam avaliados e comparados experimentalmente de uma forma rápida e segura. Um fator importante que possibilitou essa integração com diferentes técnicas e ferramentas de aprendizado de máquina em um ambiente único, como é o caso do Discover, foi a elaboração de uma sintaxe padrão para a representação dos dados, chamada de DSX - Discover STANDARD SintaX, descrita a seguir.

Outras características do ambiente computacional DLE - DISCOVER LEARNING ENVIRONMENT, como detalhes de arquitetura, projeto e implementação do ambiente, os quais estão fora do escopo deste trabalho, podem ser encontrados em (Batista \& Monard, 2003).

$1_{\text {wwW }}$ gnuplot . org

$2_{\text {http: / /www.tug.org/tetex/ }}$ 


\subsection{Sintaxe de Descrição dos Dados do Discover}

A sintaxe padrão do Discover - DSX - Discover STANDARd SinTAX utiliza arquivos texto para declarar atributos e seus respectivos tipos, e os valores que esses atributos assumem em um conjunto de exemplos. Os nomes dos atributos são declarados em um arquivo de nomes, identificados pela extensão . names. Os valores que esses atributos assumem em cada exemplo do conjunto de dados são declarados em outro arquivo com a extensão . data. Os dois arquivos devem ter o mesmo nome, se diferenciando apenas pela extensão. Assim, um conjunto de exemplos somente está na sintaxe padrão DSX se esses dois arquivos estiverem presentes. A sintaxe dos arquivos de nomes (.names) e dados (. data) é uma extensão do formato utilizado pelo algoritmo $\mathcal{C} 4.5$. Essa extensão tem como principal objetivo adequar o formato dos arquivos com as necessidades do projeto DISCOVER.

A primeira declaração em um arquivo de nomes define qual deve ser o nome do atributo classe, se ele existir. Se o atributo classe não existir, então a palavra nulı deve ser utilizada, indicando que o conjunto de exemplos correspondente é não-supervisionado, i.e., o rótulo da classe do exemplos não é conhecido. Desse modo, esse conjunto de dados pode ser utilizado para aprendizado não-supervisionado.

No caso do atributo classe existir, ele pode ser qualquer atributo presente no conjunto de exemplos. Após a declaração do atributo classe, são declarados os demais atributos com seus identificadores e domínio associado. São válidos os identificadores que são combinações de números, letras e “_” (sublinhado), em qualquer seqüência. Para identificadores mais complexos que envolvem outros caracteres que não sejam os especificados anteriormente (como espaços, letras acentuadas, etc) é necessário colocar o identificador entre aspas. Desse modo, são identificadores válidos: abc, 1, 1a, _1a, “_12a”, “válido”. Para ilustração, considere o conjunto de dados artificial toy - Tabela 5.1 —, com três atributos X_1, X_2 e X_3 cujos valores foram gerados aleatoriamente. Nesse conjunto de dados não há um atributo classe. O arquivo toy . names é mostrado na Tabela 5.2.

\begin{tabular}{ccc}
\hline \hline 1.00, & 1.30, & 2.40 \\
0.80, & 2.10, & 4.20 \\
$\vdots$ & $\vdots$ & $\vdots$ \\
1.10, & 1.90, & 3.30 \\
1.00, & 0.70, & 2.80 \\
\hline \hline
\end{tabular}

Tabela 5.1: Conjunto de dados toy. 


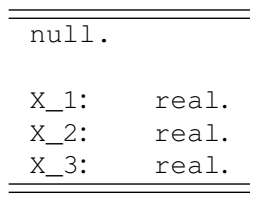

Tabela 5.2: Arquivo toy $\cdot$ names.

$\mathrm{O}$ arquivo de dados correspondente ao arquivo de nomes contém $N$ exemplos, sendo um exemplo por linha. Cada exemplo $E_{i}$ consiste dos valores dos atributos desse exemplo, separados por vírgula. Os valores de cada atributo devem pertencer ao domínio especificado para esse atributo no arquivo de nomes correspondente (.names). Dessa maneira, o "separador de registros" é o caractere de nova linha (representado em muitas linguagens de programação por " $\backslash$ n”) e o separador de campos é a vírgula. Cada valor presente em uma linha está associado a um atributo do arquivo de nomes. Sendo assim, a ordem em que os valores são declarados em uma determinada linha deve ser a mesma na qual os atributos foram declarados no arquivo de nomes. Valores "desconhecidos" são representados por um ponto de interrogação (?) e valores "não-se-aplica" são representados com um ponto de exclamação (!). Os tipos de dados definidos até o momento na sintaxe DSX são: Nominal, Enumerated, Integer, Real, String, Date e Time.

É importante lembrar que com esse formato padrão definido para o DisCOVER, os conjuntos de dados podem ser utilizados tanto em tarefas de aprendizado supervisionado como também em tarefas de aprendizado nãosupervisionado.

\subsection{Descrição do Módulo de Clustering Hierárquico}

Para o desenvolvimento do módulo de clustering hierárquico do DiscoVER foram utilizadas diversas facilidades disponiveis no ambiente computacional DLE - Discover LEARNING ENVIRONMENT, composto pela biblioteca de classes DOL e pelo gerenciador de experimentos SNIFFER.

É importante observar que o módulo de clustering descrito neste trabalho não faz uso direto do SNIFFER, uma vez que dispõe de seu próprio ambiente para execução de experimentos, chamado sHellCluster, o qual permite maior interação com o usuário.

Os algoritmos de clustering disponíveis neste módulo são os implementados na biblioteca Cluster 3.0 - Seção 4.3. Apesar de essa biblioteca dispor de um aplicativo executável para a realização do clustering, optamos por desenvolver outro aplicativo mais simples, o DHCluster - DisCOVER HiERARCHICAL CLUSTER - , que utiliza somente os procedimentos de clustering 
hierárquico da biblioteca Cluster 3.0, ignorando os outros procedimentos disponíveis. Além disso, nessa implementação optamos por simplificar o formato dos arquivos de entrada para a execução do clustering. Nesse sentido, a sintaxe utilizada pelo aplicativo disponível na biblioteca Cluster 3.0 difere da sintaxe adotada pelo DHCluster e, também, da sintaxe DSX. Essas diferenças acarretaram a necessidade de implementação de conversores que pudessem transformar os dados da sintaxe DSX para o formato reconhecido pelo aplicativo DHCluster. Desse modo, os arquivos de dados utilizados pelo usuário devem apresentar o formato descrito pela sintaxe DSX do DISCOVER, e são convertidos automaticamente para o formato reconhecido pelo aplicativo DHCluster, tornando assim, imperceptível ao usuário a utilização de diferentes sintaxes.

A sintaxe definida para os arquivos utilizados pelo aplicativo DHCluster determina que as informações de atributos faltantes sejam armazenadas em um arquivo diferente do arquivo que contém os dados, o qual armazena também informações de pesos atribuídos aos exemplos e atributos. Essa decisão facilita a construção de parsers para a manipulação desses arquivos.

Dois arquivos são utilizados pelo DHCluster: . dat (arquivo de dados) e . mask (arquivo com máscara para atributos faltantes).

No arquivo de dados, a primeira linha contém as pesos dos atributos separados por espaços em branco. As demais linhas do arquivo armazenam informações dos exemplos do conjunto de dados. Cada linha representa um exemplo, cujos atributos são separados por espaços. Além disso, a primeira coluna a partir da segunda linha representa o peso dado para o respectivo exemplo. Na Tabela 5.3 é ilustrado um conjunto de dados com essa sintaxe. O valor padrão para os pesos é 1 (um), indicando que todos os exemplos e atributos são tratados igualmente. Porém, os pesos podem assumir qualquer valor de tipo real.

\begin{tabular}{llll}
\hline \hline 1 & 1 & 1 & \\
1 & 1.00 & 1.30 & 2.40 \\
1 & 0.80 & 2.10 & 4.20 \\
$\vdots$ & $\vdots$ & $\vdots$ & $\vdots$ \\
1 & 1.10 & 1.90 & 3.30 \\
1 & 1.00 & 0.70 & 2.80 \\
\hline \hline
\end{tabular}

Tabela 5.3: Arquivo toy . dat: entrada para o aplicativo DHCluster.

No arquivo . mask — Tabela 5.4 - cada linha corresponde a um exemplo do conjunto de dados e as colunas, separadas por espaços, representam os atributos. Entretanto, nesse caso os valores armazenados não representam os valores dos atributos, mas indicam quais atributos devem ser considerados para o cálculo da similaridade. Assim, o valor 1 (um) indica que esse 
atributo está presente no respectivo exemplo, enquanto que o valor 0 (zero) indica que esse valor não foi informado ou é desconhecido, e, portanto, não deve ser considerado no processo de clustering. É importante observar que na sintaxe DSX existe, também, a possibilidade de utilizar o valor "não-seaplica" para os atributos. Esse valor é convertido para 0 (zero) durante a criação do arquivo . mask do DHCluster, o que indica que eles não serão utilizados, i.e., são valores não conhecidos.

\begin{tabular}{ccc}
\hline \hline 1 & 1 & 1 \\
1 & 1 & 1 \\
$\vdots$ & $\vdots$ & $\vdots$ \\
1 & 1 & 1 \\
1 & 1 & 1 \\
\hline \hline
\end{tabular}

Tabela 5.4: Arquivo toy . mask.

Com o objetivo de melhorar a integração do ambiente DLE com os conversores implementados e o aplicativo DHCluster, e, também, a interação do usuário com o módulo de clustering do DISCOVER, implementamos uma biblioteca (módulo Perl) e um script para execução dos experimentos e análise dos resultados do clustering, o qual agrega outras funcionalidades que auxiliam na execução dos experimentos e avaliação dos resultados (Metz \& Monard, 2006b). Nas próximas Seções são apresentados alguns detalhes das funcionalidades do módulo Cluster.pm e do script sHELLCluster.

\subsubsection{O Módulo cluster.pm}

A necessidade de manipulação dos dados, como a conversão entre formatos, normalizações, seleção de atributos e outras tarefas de pré-processamento para o clustering, motivaram o desenvolvimento de um módulo que pudesse encapsular essas e outras funcionalidades. Assim, diversos procedimentos para preparação de dados e análise do clustering podem ser integrados em um único módulo - Figura 5.1 - permitindo que outras ferramentas façam uso de suas facilidades

Com uma implementação em linguagem Perl (Wall et al., 1996), a criação de scripts torna-se bastante simples, permitindo maior flexibilidade ao desenvolvedor para utilização do módulo de clustering hierárquico do DisCOVER. Além disso, permite que novos algoritmos sejam utilizados, desde que conversores para os respectivos formatos sejam implementados.

Nesse módulo Perl, implementamos procedimentos para a conversão do formato DSX para o formato reconhecido pelo aplicativo DHCluster, leitura e cálculo da matriz de similaridade dos dados, procedimento de conversão da estrutura de dados utilizada para representar o dendograma no formato 


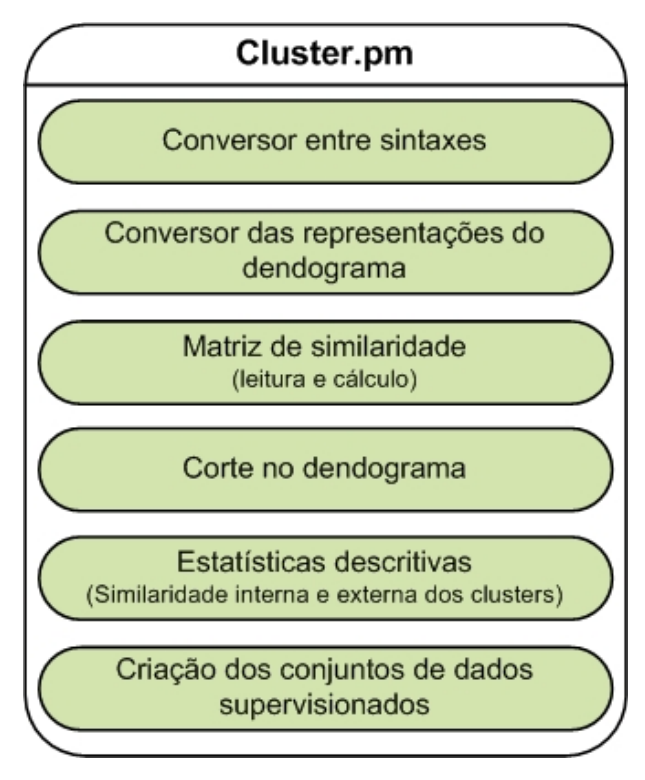

Figura 5.1: Módulo cluster.pm.

adotado nesse módulo, procedimento para o corte horizontal em diferentes níveis da hierarquia do dendograma, estatísticas descritivas sobre os clusters identificados e a criação de arquivos supervisionados nos quais o conjunto de dados é rotulado utilizando os clusters como atributo classe. Uma visão do módulo cluster.pm é apresentada na Figura 5.1.

\subsubsection{Gerenciador de Experimentos e Análise do Clustering}

Para tornar mais interativo o processo de execução de experimentos e análise do clustering hierárquico, implementamos um aplicativo que permite gerenciar esse processo. Esse aplicativo, sHELLCluster, pode ser visto como uma camada sobre o ambiente DLE e o módulo Perl cluster.pm, conforme ilustrado na Figura 5.2. Ele possibilita a realização de experimentos de maneira interativa, por meio da alteração dos parâmetros de execução e análise. Estão disponíveis quatro modos de operação: settings, cluster, int e batch, descritos a seguir:

1. modo settings: são definidos os parâmetros utilizados para execução do clustering e análise dos resultados; além disso, é nesse modo que o conjunto de dados é carregado para a memória.

2. modo cluster: o usuário pode executar o clustering considerando as opções definidas modo settings.

3. modo int: nesse modo de operação é possivel realizar a análise e interpretação dos clusters identificados pelo algoritmo de clustering hierárquico. Um fator que diferencia o clustering hierárquico das outras 


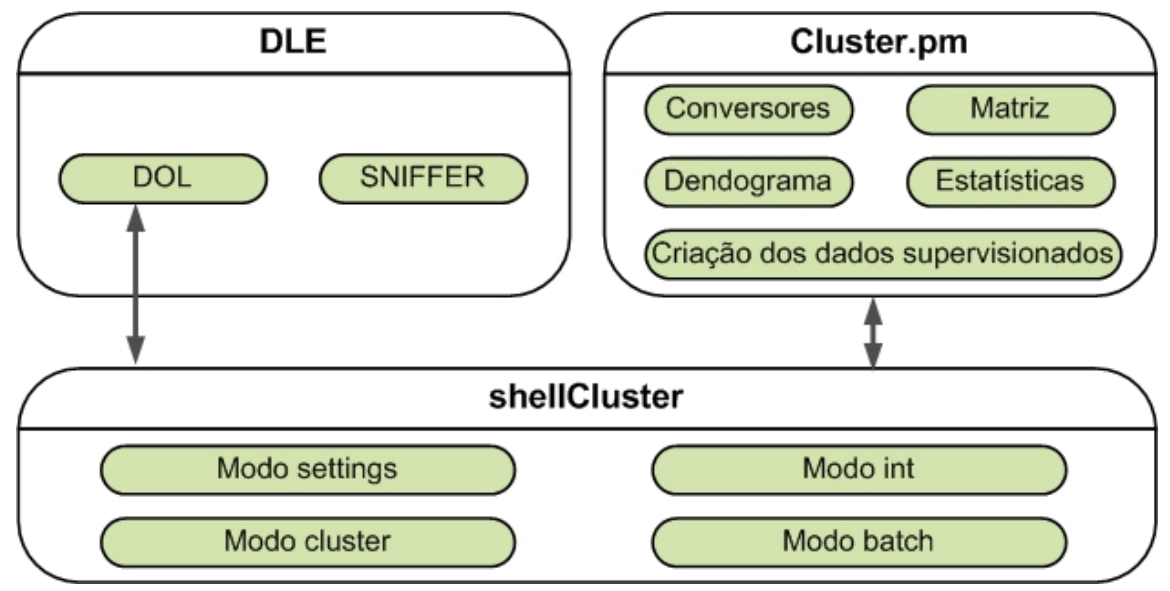

Figura 5.2: Visão geral do ambiente de execução de experimentos SHELLCluster.

abordagens é a maneira com que o resultado pode ser analisado. A flexibilidade em relação à analise dos diferentes níveis de granularidade ou densidade dos agrupamentos faz com que, por meio do clustering hierárquico, seja possível encontrar as estruturas intrínsecas que estão embutidas nos dados. Nesse contexto, um corte horizontal no dendograma em diferentes níveis gera diferentes agrupamentos. Com bases nesses agrupamentos, pode-se tentar descobrir relações ou padrões entre os exemplos que pertencem aos clusters identificados e atribuir conceitos a esses clusters. Nos casos em que não for possível identificar um conceito geral para todo o cluster, pode-se refinar a análise subdividindo o cluster em outros menores. Esse procedimento pode ser realizado nesse modo de operação do sHellCluster. Além do corte no dendograma, esse modo de operação permite a utilização de classificadores para a construção de regras, como os indutores $\mathcal{C} 4.5$ (Quinlan, 1993) e $\mathcal{C N} 2$ (Clark \& Niblett, 1989), que descrevem simbolicamente os clusters.

4. modo batch: esse modo de operação foi implementado para facilitar ao usuário a execução do clustering sobre vários conjuntos de dados de uma única vez. Assim, basta ao usuário definir um arquivo contendo os nomes dos conjuntos de dados e outro arquivo contendo os parâmetros de configuração do clustering para que o sHELLCluster execute os experimentos considerando os parâmetros especificados nos arquivos de configuração.

Uma descrição mais detalhada de cada modo de operação juntamente com a apresentação de cada parâmetro de configuração e comandos de execução pode ser encontrada em (Metz \& Monard, 2006b). 
Uma ilustração do módulo de clustering hierárquico do DisCOVER é apresentada na Figura 5.3. Nesse diagrama, a execução do clustering procede da seguinte maneira: inicialmente o conjunto de dados no formato DSX e os parâmetros para execução do clustering são carregados para a memória, e, então, o conjunto de dados é convertido para o formato reconhecido pelo aplicativo DHCluster, criando os arquivos . dat e .mask. Em seguida, esse novo conjunto de dados é carregado pelo aplicativo sHELLCluster para a memória e o clustering realizado sobre os dados. Esse processo resulta nos arquivos . result e . link que armazenam o dendograma resultante no formato especificado pela estrutura de dados Pointer Representation. Além disso, é criado o arquivo . matrix que armazena a matriz de distâncias utilizada no processo de clustering, caso ela não tenha sido criada anteriormente. Após, o dendograma construído pelo algoritmo de clustering é convertido para a representação utilizada pelo módulo de clustering do DisCOVER. Essa representação é armazenada no arquivo . tree.

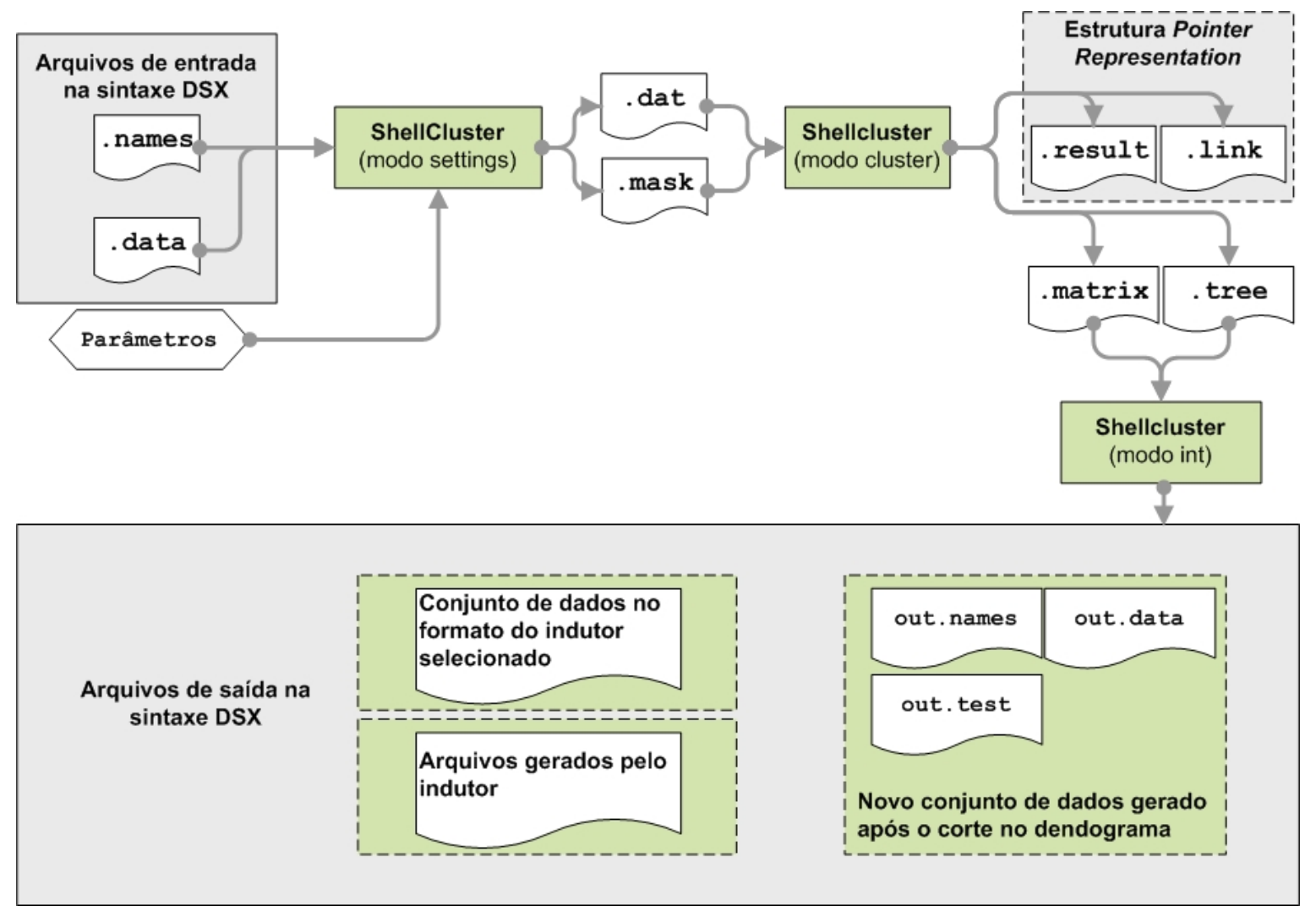

Figura 5.3: Módulo de clustering hierárquico do DISCOVER.

Nesse estágio, o dendograma está disponível para análise. Para isso, é feito um corte horizontal no dendograma, que cria um novo conjunto de dados supervisionado no qual o cluster é utilizado como atributo classe dos exemplos. Em seguida, esse novo conjunto de dados é submetido a um indutor para geração de regras que possam auxiliar no processo de interpretação dos clusters e na atribuição de um significado útil aos clusters 
identificados.

\subsection{Interpretação da Hierarquia de Clusters}

Como mencionado um dos objetivos deste trabalho consiste na interpretação de clusters utilizando a idéia proposta por Martins (2003), descrita na Seção 3.3.4 e ilustrada na Figura 3.7 na página 41, mas utilizando como algoritmo não-supervisionado algoritmos de clustering hierárquico (Metz \& Monard, 2005).

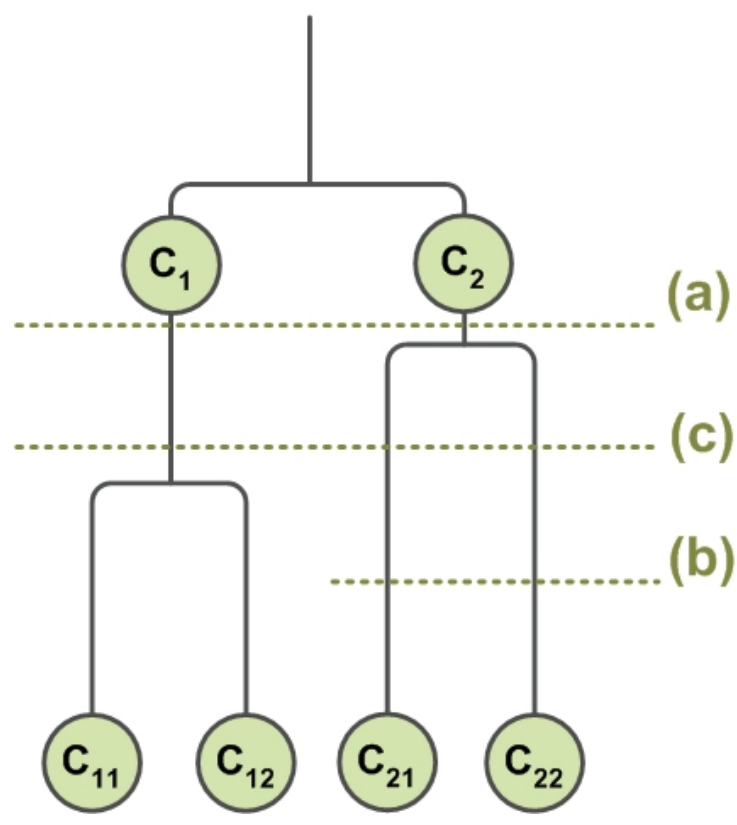

Figura 5.4: Hierarquia de clusters.

Para ilustrar a nossa proposta, considere que a hierarquia de clusters apresentada na Figura 5.4 foi encontrada para um dado conjunto de dados. Ou seja, o conjunto de dados foi agrupado inicialmente em dois clusters nomeados $C_{1}$ e $C_{2}$. Em níveis mais abaixo na hierarquia, o algoritmo identificou os sub-clusters $C_{11}$ e $C_{12}$ que agrupam os exemplos que pertencem ao cluster $C_{1}$. Analogamente, os sub-clusters do cluster $C_{2}, C_{21}$ e $C_{22}$, agrupam os exemplos que pertencem ao cluster $C_{2}$. Após inspecionar a hierarquia, o usuário pode decidir realizar o corte (a), por exemplo. Nesse caso, todos os exemplos no cluster $C_{1}$ e $C_{2}$ são rotulados, respectivamente, com o nome do cluster ao qual pertencem. Com isso, tem-se o conjunto de dados com os exemplos rotulados com dois valores de classe. Esse conjunto de dados rotulado é então utilizado como entrada de algum algoritmo supervisionado para induzir um classificador simbólico. Se a estimativa de erro desse classificador utilizando validação cruzada com 10 partições por exemplo, for baixa, então o usuário pode analisar as regras de conhecimento que 
classificaram os exemplos nos clusters $C_{1}$ e $C_{2}$. Caso a interpretação seja suficiente, o processo termina.

Por outro lado, suponha que o usuário deseja refinar o conhecimento por meio de uma melhor interpretação dos exemplos que pertencem ao cluster $C_{2}$. Nesse caso, ele utilizaria o corte (b) na Figura 5.4, fazendo com que o sub-conjunto de exemplos do cluster $C_{2}$ seja rotulado com o nome dos sub-clusters $C_{21}$ e $C_{22}$ ao qual pertencem, e repetiria o processo. Dessa maneira, em cada iteração da metodologia proposta, o usuário pode refinar a interpretação dos clusters, de uma maneira top-down, incrementando a granularidade da descrição dos clusters, até encontrar (ou não) uma interpretação que o satisfaça. Observe também que no início do processo, o usuário poderia ter decidido efetuar o corte (c) na Figura 5.4. Nesse caso, o conjunto de dados deveria ser rotulado com o nome dos três clusters $C_{1}$, $C_{21}$ e $C_{22}$, aos quais pertence cada exemplo.

No sistema de clustering hierárquico implementado, o usuário tem a disposição o dendograma correspondente para decidir a altura do corte no dendograma.

\subsection{Considerações Finais}

Neste capítulo foi apresentado o projeto de um módulo de aprendizado de máquina não-supervisionado, mais especificamente para a realização do clustering hierárquico, integrado ao projeto Discover, o qual permite a realização de experimentos de maneira semi-automática, com objetivo de interpretar os clusters encontrados.

Com a implementação do módulo de clustering hierárquico descrito neste trabalho e sua integração ao Discover, é possível a realização de experimentos em um ambiente único e padronizado que dispõe de ferramentas de pré e pós-processamento de dados, assim como a integração com outras técnicas de aprendizado. Além disso, a elaboração de um módulo para esse ambiente, considerando os padrões de desenvolvimento adotados, permite que outros algoritmos não-supervisionados sejam integrados de maneira bastante simples, desde que conversores sejam implementados para que as entradas e saídas desses algoritmos também atendam a esses padrões. Com isso, tem-se um sistema de fácil utilização, grande aplicabilidade e com muitas facilidades de expansão. 


\section{Avaliação Experimental com Conjuntos de Dados Naturais}

\subsection{Considerações Iniciais}

Com o objetivo de avaliar cada um dos algoritmos disponíveis no módulo de clustering do DISCOVER e medir a adequabilidade dos clusters aos respectivos dados utilizados, bem como a ilustrar a utilização da metodologia de interpretação de clusters proposta, foram realizados diversos experimentos com conjuntos de dados naturais provenientes do repositório de dados da UCI - University of California at Irvine (Newman et al., 1998). Os conjuntos de dados escolhidos, amplamente utilizados pela comunidade, consistem de dados rotulados, cujo rótulo (classe) não é utilizado no processo de construção dos clusters. A classe dos exemplos é somente utilizada para verificar se os exemplos pertencentes aos clusters encontrados têm alguma relação com os conceitos previamente atribuídos pelo especialista a esse conjunto de exemplos.

\subsection{Descrição dos Conjuntos de Dados}

Foram selecionados do repositório de dados da UCI (Blake \& Merz, 1998), os seguintes cinco conjuntos de dados:

Bupa: o problema tratado nesse conjunto de dados consiste em predizer se um paciente do sexo masculino possui ou não disfunção hepática com base em vários exames sangüíneos e na quantidade de álcool consumida.

German: nesse conjunto de dados, o problema é classificar pessoas, descritas por atributos com o propósito do empréstimo e histórico de crédito, 
como sendo boas ou más pagadoras, apresentando risco de crédito bom ou ruim. Esse conjunto de dados é disponibilizado em dois formatos: um contendo somente atributos simbólicos e outro contendo todos os atributos numéricos. Somente o conjunto de dados com atributos numéricos é utilizado neste trabalho.

Hungaria: esse conjunto de dados tem como objetivo o diagnóstico de doenças cardíacas a partir de dados laboratoriais, clínicos e de eletrocardiograma.

Pima: esse conjunto faz parte de uma base de dados maior que é mantida pelo Instituto Nacional de Diabetes e Doenças Digestivas e Renais nos Estados Unidos. Todas as pacientes são mulheres com pelo menos 21 anos de idade de descendência indígena Pima vivendo próximas a Phoenix, Arizona, EUA. O problema consiste em predizer se uma paciente apresentará um resultado positivo para diabetes, de acordo com os critérios da Organização Mundial de Saúde, a partir de medidas psicológicas e resultados de exames clínicos e laboratoriais.

Vehicle: o objetivo é classificar tipos de veículos, usando um conjunto de atributos extraídos a partir de suas silhuetas.

Um resumo das características desses cinco conjuntos de dados é apresentado na Tabela 6.1. Para cada conjunto são descritos:

- $\mathrm{N}^{o}$. de Exemplos: número de exemplos do conjunto de dados;

- $\mathrm{N}^{o}$. de Atributos: número total de atributos. Neste trabalho todos os conjuntos de dados são compostos somente por atributos numéricos;

- Classes e Classe \%: valores e distribuição das classes;

- Erro da CM: erro cometido no caso de novos exemplos serem classificados como sendo pertencentes à classe majoritária (CM); e

- ?: existência ou não de valores desconhecidos.

Dos cinco conjuntos de dados apenas o conjunto Hungaria contém exemplos com valores faltantes. Esses exemplos não são utilizados nos experimentos, mas apenas os 261 exemplos que apresentam todos os atributos com seus respectivos valores informados. Como mencionado, para a realização dos experimentos neste trabalho, o atributo classe não foi considerado no processo de construção dos clusters. 


\begin{tabular}{|c|c|c|c|c|c|c|}
\hline $\begin{array}{l}\text { Conjunto } \\
\text { de Dados }\end{array}$ & $\mathrm{N}^{o}$. de Exemplos & $\begin{array}{c}\mathrm{N}^{o} \cdot \text { de Atributos } \\
\text { (numéricos) }\end{array}$ & Classes & Classe \% & Erro da CM & ? \\
\hline Bupa & 345 & 6 & $\begin{array}{l}1 \\
2\end{array}$ & $\begin{array}{l}42.03 \% \\
57.97 \%\end{array}$ & $\begin{array}{l}42.03 \% \\
\text { sobre } 2\end{array}$ & não \\
\hline German & 1000 & 24 & $\begin{array}{l}1 \\
2\end{array}$ & $\begin{array}{l}70.00 \% \\
30.00 \%\end{array}$ & $\begin{array}{l}30.00 \% \\
\text { sobre } 1\end{array}$ & não \\
\hline Hungaria & 294 & 13 & $\begin{array}{l}1 \\
2\end{array}$ & $\begin{array}{l}63.95 \% \\
36.05 \%\end{array}$ & $\begin{array}{l}36.05 \% \\
\text { sobre } 1\end{array}$ & $\operatorname{sim}$ \\
\hline Pima & 769 & 8 & $\begin{array}{l}1 \\
2\end{array}$ & $\begin{array}{l}65.02 \% \\
34.98 \%\end{array}$ & $\begin{array}{l}34.98 \% \\
\text { sobre } 1\end{array}$ & não \\
\hline Vehicle & 846 & 18 & $\begin{array}{l}1 \\
2 \\
3 \\
4 \\
\end{array}$ & $\begin{array}{l}25.10 \% \\
25.70 \% \\
25.80 \% \\
23.40 \% \\
\end{array}$ & $\begin{array}{l}74.20 \% \\
\text { sobre } 3\end{array}$ & não \\
\hline
\end{tabular}

Tabela 6.1: Resumo dos conjuntos de dados utilizados nos experimentos.

\subsection{Execução dos experimentos}

Os cinco conjuntos de dados foram submetidos aos três algoritmos de clustering hierárquico, Average Link, Complete Link e Single Link - Seção 4.2. Cada um desses algoritmos foi executado utilizando quatro medidas de similaridade diferentes: distância Euclidiana, distância de Manhattan, correlação de Pearson e correlação de Spearman - Seção 3.3.2 totalizando assim 60 experimentos. Na Tabela 6.2 é mostrado o coeficiente de correlação cophenético para cada um desses experimentos, juntamente com o mínimo e máximo valor desse coeficiente para cada base de exemplos.

\begin{tabular}{|c|c|c|c|c|c|c|}
\hline $\begin{array}{l}\text { Conjunto } \\
\text { de dados }\end{array}$ & $\begin{array}{c}\text { Medida utilizada para } \\
\text { o cálculo da similaridade }\end{array}$ & Aver. Link & Comp. Link & Sing. Link & Mín & Máx \\
\hline \multirow{4}{*}{ Bupa } & Euclidiana & 0.64 & 0.70 & 0.84 & \multirow[b]{4}{*}{0.44} & \multirow{4}{*}{1.00} \\
\hline & Manhattan & 0.61 & 0.64 & 0.88 & & \\
\hline & Cor. Pearson & 0.64 & 0.70 & 1.00 & & \\
\hline & Cor. Spearman & 0.61 & 0.44 & 0.45 & & \\
\hline \multirow{4}{*}{ German } & Euclidiana & 0.54 & 0.52 & 0.99 & \multirow[b]{4}{*}{0.18} & \multirow{4}{*}{$\begin{array}{l}0.99 \\
0.99\end{array}$} \\
\hline & Manhattan & 0.57 & 0.54 & 0.99 & & \\
\hline & Cor. Pearson & 0.86 & 0.85 & 0.94 & & \\
\hline & Cor. Spearman & 0.32 & 0.18 & 0.58 & & \\
\hline \multirow{4}{*}{ Hungaria } & Euclidiana & 0.32 & 0.35 & 0.23 & \multirow[t]{4}{*}{0.23} & \multirow{4}{*}{0.79} \\
\hline & Manhattan & 0.72 & 0.69 & 0.79 & & \\
\hline & Cor. Pearson & 0.68 & 0.57 & 0.56 & & \\
\hline & Cor. Spearman & 0.50 & 0.39 & 0.61 & & \\
\hline \multirow{4}{*}{ Pima } & Euclidiana & 0.43 & 0.44 & 0.28 & \multirow{4}{*}{$\begin{array}{l}0.28 \\
0.28\end{array}$} & \\
\hline & Manhattan & 0.45 & 0.46 & 0.50 & & \\
\hline & Cor. Pearson & 0.37 & 0.28 & 0.48 & & \\
\hline & Cor. Spearman & 0.76 & 0.75 & 0.63 & & 0.76 \\
\hline \multirow{4}{*}{ Vehicle } & Euclidiana & 0.42 & 0.32 & 0.55 & \multirow{4}{*}{0.20} & \multirow[t]{4}{*}{0.55} \\
\hline & Manhattan & 0.37 & 0.39 & 0.52 & & \\
\hline & Cor. Pearson & 0.25 & 0.25 & 0.20 & & \\
\hline & Cor. Spearman & 0.46 & 0.40 & 0.36 & & \\
\hline
\end{tabular}

Tabela 6.2: Coeficiente cophenético dos 60 experimentos realizados com conjuntos de dados naturais.

Como mencionado na Seção 3.3.3, o coeficiente de correlação cophenético, cujo valor encontra-se no intervalo fechado 0 e 1 , indica que o dendograma reflete as estruturas embutidas nos dados quando esse valor é 
próximo de 1. Uma primeira observação, considerando o mínimo e máximo valor desse coeficiente para cada base de dados, é que ele varia bastante dependendo do algoritmo e da medida de similaridade utilizada. O máximo valor 1 do coeficiente de correlação cophenético foi somente atingido com o conjunto de dados Bupa pelo algoritmo Single Link e correlação de Spe-

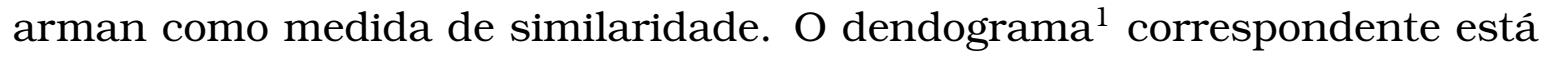
ilustrado na Figura 6.1. Entretanto, como pode ser observado, esse dendograma pode ser considerado um dendograma "degenerado", no sentido que todos os exemplos, exceto um, encontram-se no mesmo cluster. Observando os 60 dendogramas correspondentes a cada experimento ${ }^{2}$, comprovamos que o coeficiente de correlação cophenético não reflete, na nossa opinião, a "melhor" estrutura de clusters.

Deve ser observado que uma "boa" estrutura de clustering hierárquico para tentar interpretar os clusters encontrados utilizando a metodologia proposta, é aquela que possui nos niveis superiores clusters que agrupam um número razoável de exemplos, para assim poder utilizar algoritmos de aprendizado simbólico supervisionado com intuito de interpretar os clusters. Caso contrário, enfrenta-se um problema de desbalanceamento (Batista et al., 2005, 2004; Prati, 2006), que seria difícil e ser tratado com dados não-supervisionados. Assim, decidimos analisar visualmente, para cada base de dados, os 12 dendogramas obtidos em cada experimento e escolher o mais adequado para continuar a análise.

O melhor dendograma construído para cada conjunto de dados foi selecionado para a análise mais detalhada. Para a base de dados Bupa, o melhor dendograma, ilustrado na Figura 6.2, foi obtido pelo algoritmo Complete Link utilizando como medida de similaridade a distância de Manhattan. Nesse dendograma é possível reconhecer três clusters considerando o corte a uma distância igual a 0.4. Pode ser observado que o primeiro cluster (à esquerda no dendograma) é constituído de poucos exemplos $(2.03 \%$ do total - Tabela 6.3) com baixa similaridade entre eles (a altura dos arcos que agrupam os sub-clusters contidos nesse cluster é praticamente igual a 0.4.) O segundo cluster também contém poucos exemplos $(8.98 \%$ do total), com a similaridade interna um pouco melhor que a do cluster anterior. Finalmente, é possível observar que a maioria dos exemplos $(88.99 \%$ do total) encontram-se no terceiro cluster e possuem boa similaridade. Considerando que o conjunto de dados supervisionado Bupa foi rotulado com somente duas classes, com proporção de $42.03 \%$ e $57.97 \%$ - Tabela 6.1 -

\footnotetext{
${ }^{1}$ Os dendogramas foram construídos utilizando rotinas implementadas no ambiente estatístico R, por meio de scripts para geração de gráficos (Voltolini, 2005).

${ }^{2}$ todos os resultados experimentais estão disponíveis no o endereço eletrônicohttp:// www.icmc.usp.br/ metzz/experimentos.html
} 


\section{Dendograma}

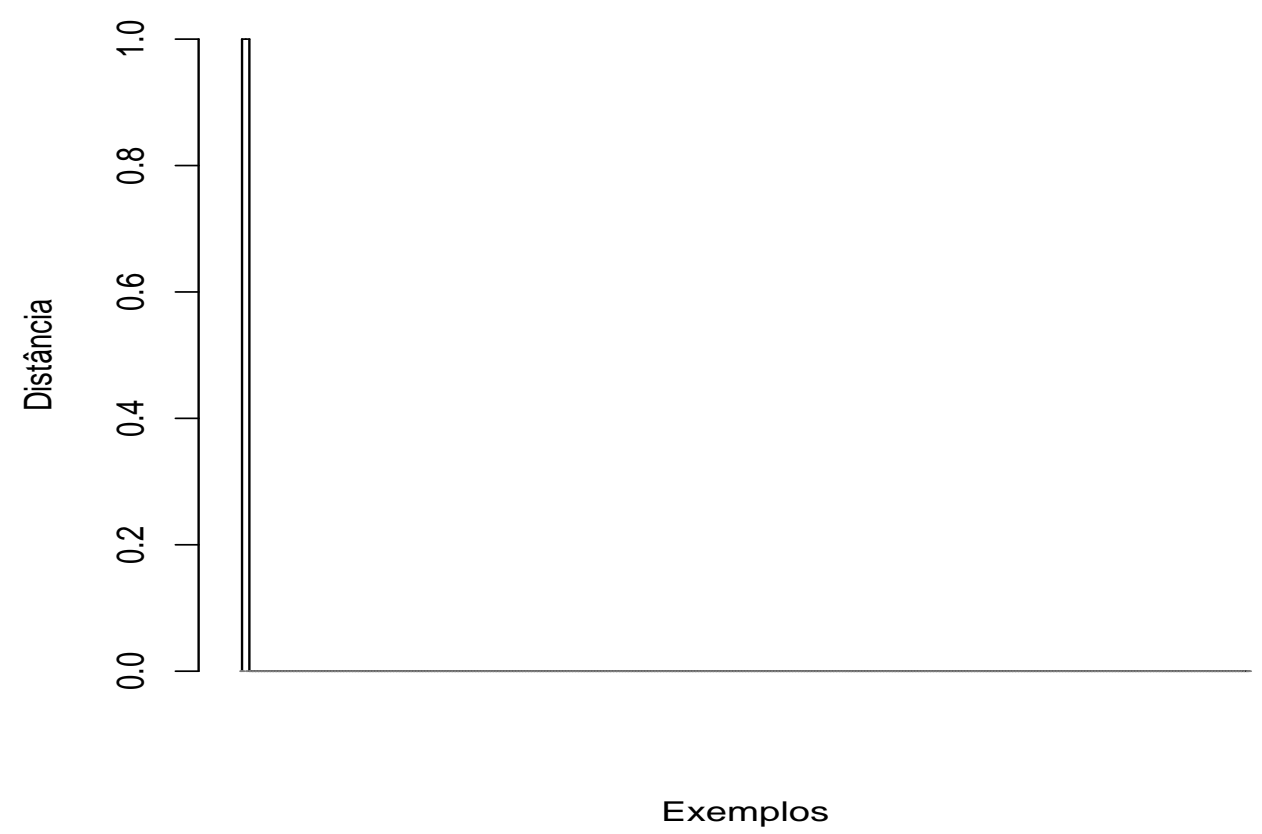

Figura 6.1: Dendograma obtido por meio do algoritmo Single Link utilizando a medida de correlação de Spearman sobre o conjunto de dados Bupa.

, é possível verificar que os clusters encontrados não estão relacionados com a classe atribuída a esses exemplos, mas representam alguma outra característica desses dados.

Para a base de dados German, o melhor dendograma foi obtido pelo algoritmo Average Link utilizando como medida de similaridade a distância de Manhattan - Figura 6.3. Os dois clusters identificados a partir do corte com altura 0.3 nesse dendograma, dividem os exemplos na proporção de $20 \%$ e $80 \%$. A distância interna média dos dois clusters é significativamente menor que a distância externa, o que demonstra a consistência desses dois clusters. Por outro lado, apesar de apresentarem proporção próxima das classes do conjunto de dados supervisionado (70\% para classe 1 e 30\% para classe 2 - Tabela 6.1), não representam os mesmos conceitos das classes. Esse fato foi concluído a partir de uma análise mais detalhada desses clusters. Verificou-se que dos 700 exemplos classificados como classe 1, 79.29\% (555 exemplos) estão agrupados no cluster maior (à direita no dendograma) e representam $69.38 \%$ do total de exemplos presentes nesse cluster. Por outro lado, $81.67 \%$ dos exemplos classificados como classe 2 também fazem parte do cluster maior. Isso demonstra que os exemplos das duas classes estão distribuídos nos dois clusters, e, portanto, eles não podem de fato representar o mesmo conceito da classe. Essas informações de distribuição dos exemplos entre clusters e classes estão apresentadas 


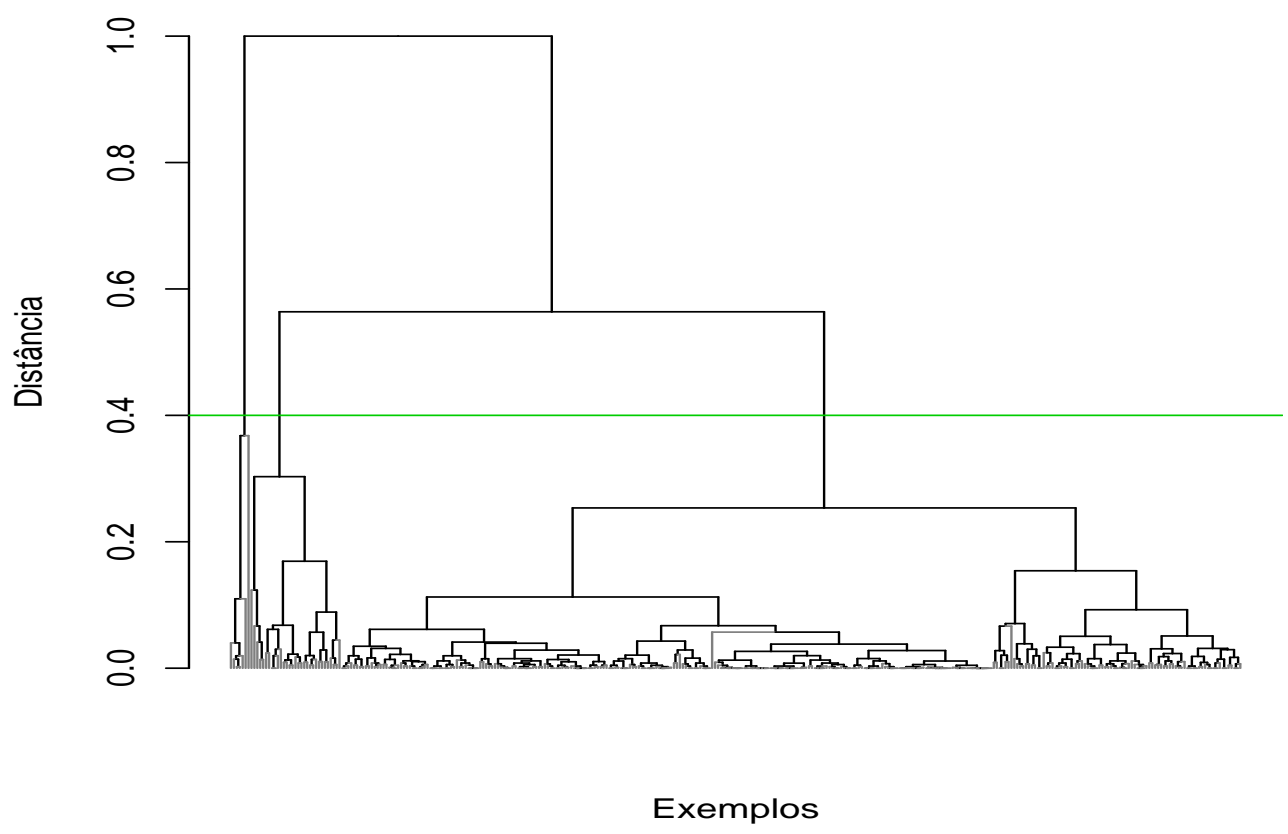

Figura 6.2: Dendograma obtido por meio do algoritmo Complete Link utilizando a medida de distância de Manhattan sobre o conjunto de dados Bupa.

na Tabela 6.3, na qual, as colunas referentes às classes 3 e 4 são utilizadas apenas para o conjunto de dados Vehicle, pois somente esse conjunto de dados foi classificado em 4 (quatro) classes. Os outros são classificados apenas com classes 1 e 2 . A coluna $\Sigma$ refere-se ao número total de exemplos em cada cluster.

\begin{tabular}{|c|c|c|c|c|c|c|c|}
\hline \multirow{2}{*}{$\begin{array}{l}\text { Conjunto } \\
\text { de Dados }\end{array}$} & \multirow{2}{*}{$\begin{array}{l}\text { Ident. } \\
\text { Cluster }\end{array}$} & \multicolumn{4}{|c|}{ Classe } & \multicolumn{2}{|c|}{ Exemplos } \\
\hline & & 1 & 2 & 3 & 4 & $\Sigma$ & \%Exemplos \\
\hline \multirow[t]{3}{*}{$\overline{\text { Bupa }}$} & C684 & 131 & 176 & - & - & 307 & $88.99 \%$ \\
\hline & C685 & 11 & 20 & - & - & 31 & $08.98 \%$ \\
\hline & C686 & 3 & 4 & - & - & 7 & $02.03 \%$ \\
\hline proporção da classe & & $42.03 \%$ & $57.97 \%$ & & & & \\
\hline \multirow[t]{2}{*}{ German } & C1997 & 145 & 55 & - & - & 200 & $20.00 \%$ \\
\hline & C1998 & 555 & 245 & - & - & 800 & $80.00 \%$ \\
\hline proporção da classe & & $70.00 \%$ & $30.00 \%$ & & & & \\
\hline \multirow[t]{3}{*}{ Hungaria } & C515 & 140 & 25 & - & - & 165 & $63.22 \%$ \\
\hline & C517 & 0 & 2 & - & - & 2 & $00.76 \%$ \\
\hline & C518 & 27 & 67 & - & - & 94 & $36.02 \%$ \\
\hline proporção da classe & & $63.98 \%$ & $36.02 \%$ & & & & \\
\hline \multirow[t]{2}{*}{ Pima } & C1534 & $\overline{4448}$ & $\overline{215}$ & $\overline{-1}$ & $\overline{-1}$ & 2663 & $86.22 \%$ \\
\hline & C1535 & 54 & 52 & - & - & 106 & $13.78 \%$ \\
\hline proporção da classe & & $65.28 \%$ & $34.72 \%$ & & & & \\
\hline \multirow[t]{3}{*}{ Vehicle } & C1685 & 0 & 0 & 26 & 0 & 26 & $03.07 \%$ \\
\hline & C1687 & 139 & 137 & 47 & 1 & 324 & $38.30 \%$ \\
\hline & C1688 & 73 & 80 & 145 & 198 & 496 & $58.63 \%$ \\
\hline proporção da classe & & $25.06 \%$ & $25.65 \%$ & $25.77 \%$ & $23.52 \%$ & & \\
\hline
\end{tabular}

Tabela 6.3: Distribuição dos exemplos entre clusters e classes.

Para a base de dados Hungaria, o melhor dendograma, ilustrado na Fi- 


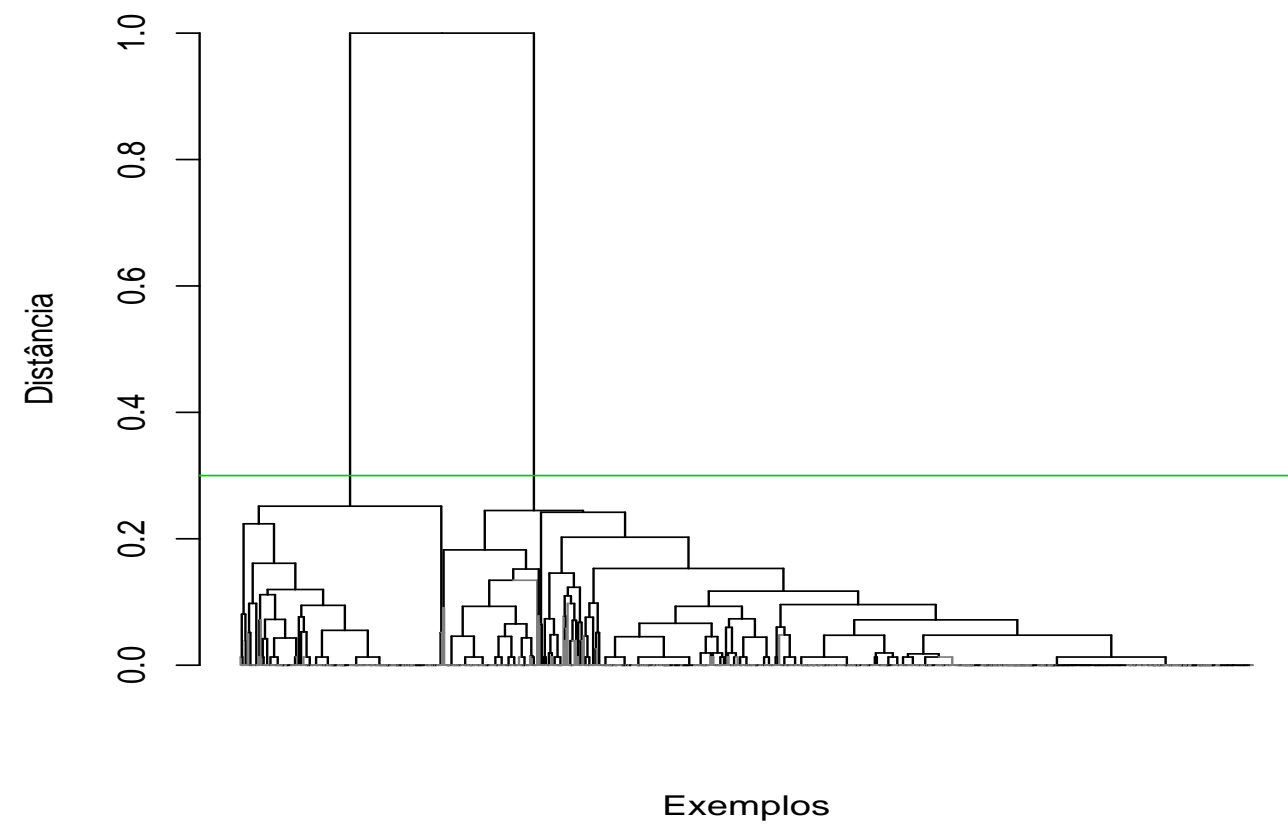

Figura 6.3: Dendograma obtido por meio do algoritmo Average Link utilizando a medida de distância de Manhattan sobre o conjunto de dados German.

gura 6.4, foi obtido pelo algoritmo Average Link utilizando como medida de similaridade a distância de Manhattan. Como mencionado, para a execução do clustering sobre esse conjunto de dados, os exemplos com atributos faltantes ou desconhecidos foram eliminados. Com essa alteração, a distribuição dos exemplos em relação ao atributo classe passou a ser de $62.45 \%$ para classe 1 e $37.55 \%$ para classe 2 . De maneira análoga aos experimentos realizados com os conjuntos de dados Bupa e German, o corte feito a altura 0.42 nesse dendograma resulta em três clusters, com distribuição de exemplos respectivamente $0.76 \%, 36.02 \%$ e $63.22 \%$. Já a distribuição desses exemplos nos clusters considerando o atributo classe do conjunto de dados supervisionado após a remoção dos exemplos com atributos desconhecido, é de $62.45 \%$ para classe 1 e $37.55 \%$ para classe 2 - Tabela 6.3 .

A partir da análise desses clusters, observa-se que os exemplos agrupados no menor cluster (nesse caso 2 exemplos) podem ser considerados outliers, uma vez que os valores médios de distância interna e externa desse cluster são muito altos se comparados com os mesmos valores dos outros clusters. Excluindo-se esses exemplos do conjunto de dados, a média de distância externa dos outros clusters (o cluster central e o cluster à direita no dendograma) aumentaria consideravelmente. Em conseqüência, a separação entre esses clusters provavelmente não seria tão clara quanto essa apresentada nesse dendograma. Com isso, o corte deveria ser feito conside- 


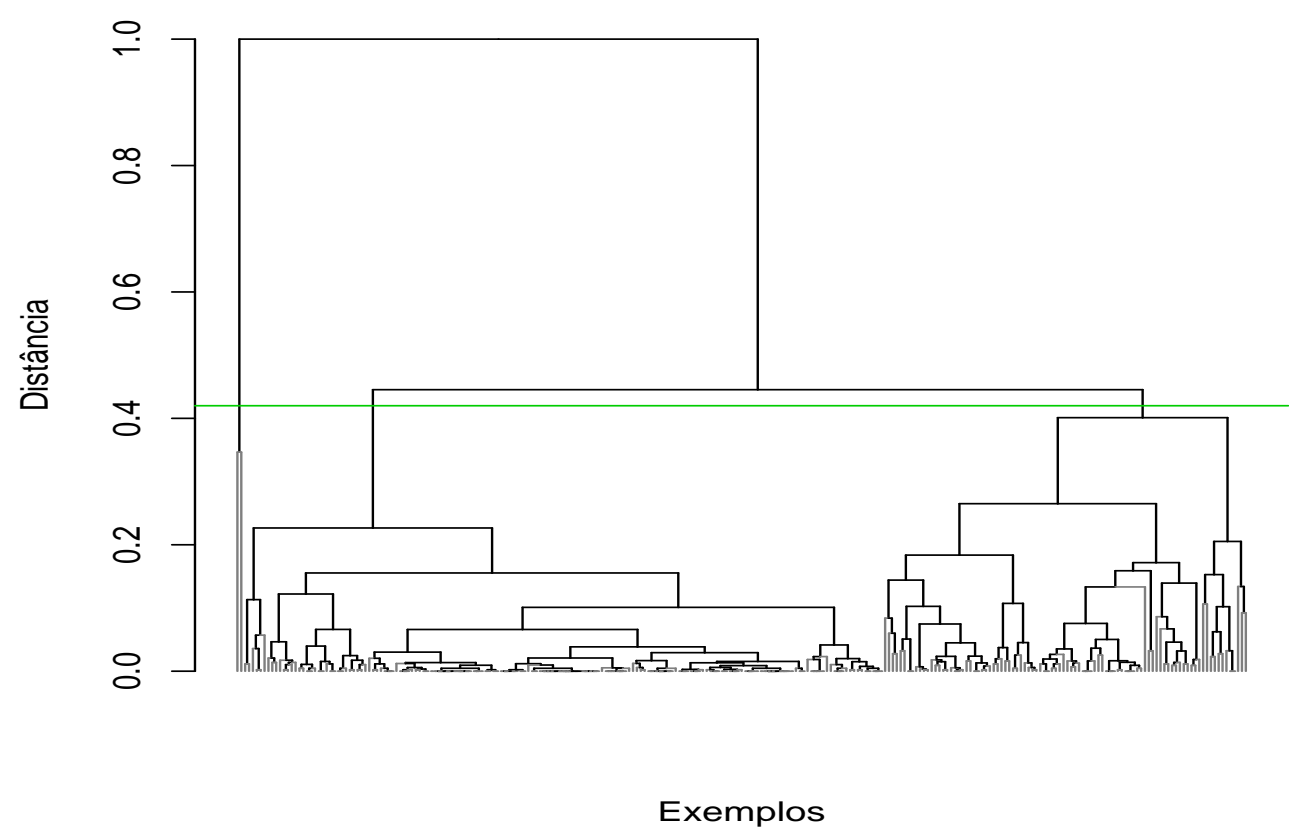

Figura 6.4: Dendograma obtido por meio do algoritmo Average Link utilizando a medida de distância de Manhattan sobre o conjunto de dados Hungaria.

rando outro valor de distância (altura), o que levaria à provável identificação de outros clusters.

Considerando-se apenas o dendograma apresentado na Figura 6.4, observa-se que os três clusters identificados não representam o mesmo conceito do atributo classe do conjunto de dados supervisionado. Apesar disso, com uma análise mais detalhada sobre os dois clusters que contêm o maior número de exemplos, percebe-se que $83.83 \%$ dos exemplos classificados como classe 1 estão presentes no cluster maior (à direita no dendograma) e representam $84.85 \%$ do total de exemplos desse cluster. O cluster central, por outro lado, contém apenas $16.17 \%$ dos exemplos da classe 1, correspondentes à $28.72 \%$ do total de exemplos agrupados nesse cluster. Os outros $71.28 \%$ de exemplos desse cluster foram classificados no conjunto de dados supervisionado como sendo classe 2, e representam $71.28 \%$ dos exemplos dessa classe. Assim, percebe-se que apesar de exemplos de classes diferentes estarem presentes nesses dois clusters, cada cluster tem um número significativo de exemplos de uma das classes e um número relativamente pequeno de exemplos da outra classe.

Para a base de dados Pima, o melhor dendograma foi obtido pelo algoritmo Complete Link utilizando como medida de similaridade a distância Euclidiana, ilustrado na Figura 6.5. Nesse dendograma, observa-se claramente a existência de dois clusters distintos, nos quais a média de distância 
interna é relativamente baixa se comparada com a distância externa entre os dois clusters. O cluster à esquerda no dendograma agrupa $13.78 \%$ dos exemplos, enquanto que $86.22 \%$ estão agrupados no cluster à direita. A distribuição de exemplos entre as duas classe que rotulam o conjunto de dados supervisionado Pima é de 65.28\% e 34.72\% - Tabela 6.3 - Nesse caso, os dois clusters contém um número significativo de exemplos classificados em cada uma das classes. Com isso, observa-se novamente que, apesar de existirem claramente dois clusters identificados nesse dendograma, eles também não representam os mesmos conceitos que as classes do conjunto de dados supervisionado, mas sim algum outro padrão que descreve os exemplos.

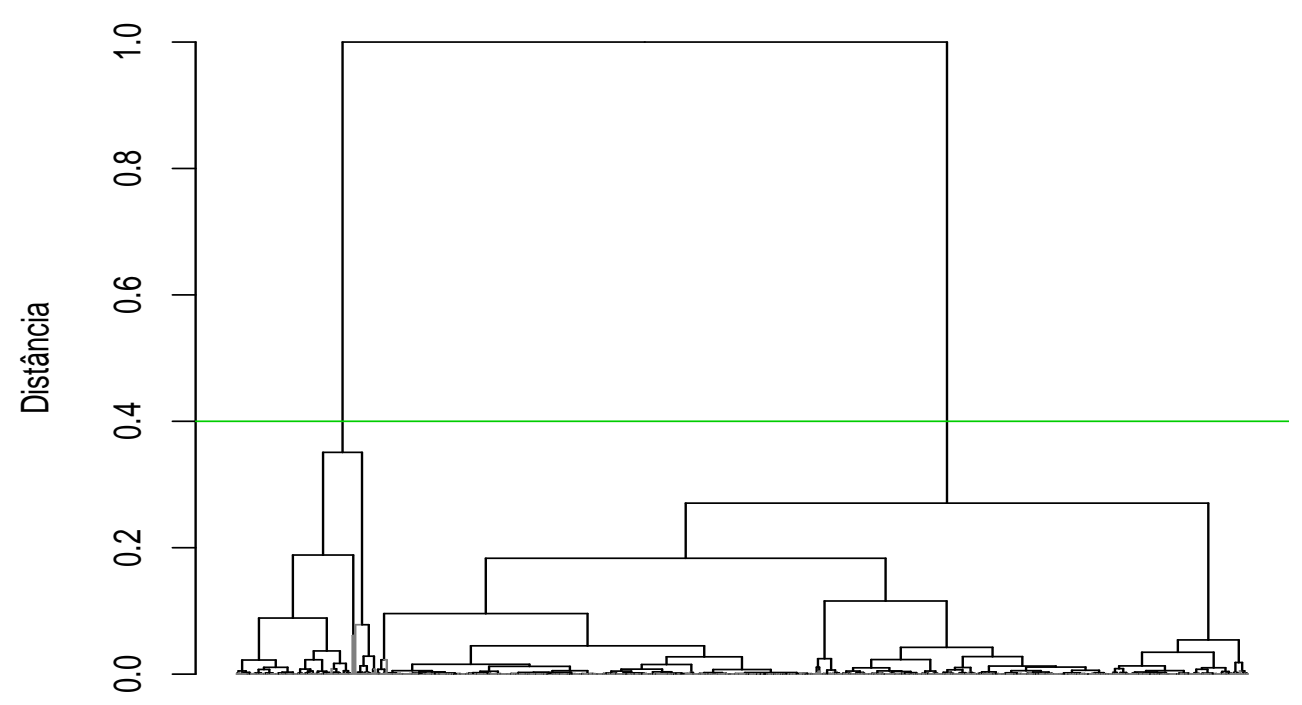

Exemplos

Figura 6.5: Dendograma obtido por meio do algoritmo Complete Link utilizando a medida de distância Euclidiana sobre o conjunto de dados Pima.

Para a base de dados Vehicle, o melhor dendograma, ilustrado na Figura 6.6, foi obtido pelo algoritmo Average Link utilizando como medida de similaridade a distância Euclidiana. Assim como nos experimentos anteriores, esse dendograma também mostra claramente a presença de clusters bem definidos, nesse caso três clusters com proporção de exemplos $3.07 \%$, $38.30 \%$ e 58.63\%. Observa-se que os dois clusters menores (o cluster à esquerda e o cluster central no dendograma) contêm valores médio de distância interna menores que a média de distância interna do cluster maior (à direita no dendograma). Entretanto, a última junção realizada no maior cluster, foi feita entre um cluster unitário e um cluster já bem formado, 
nesse caso, o sub-cluster contendo todos os outros exemplos do cluster maior. Esse agrupamento, evidente a partir do dendograma, é indicado pelo arco com traço desenhado em uma tonalidade mais clara. Esse fato demonstra a presença de um outlier no conjunto de dados, que, se removido, diminuiria a distância interna média do cluster maior.

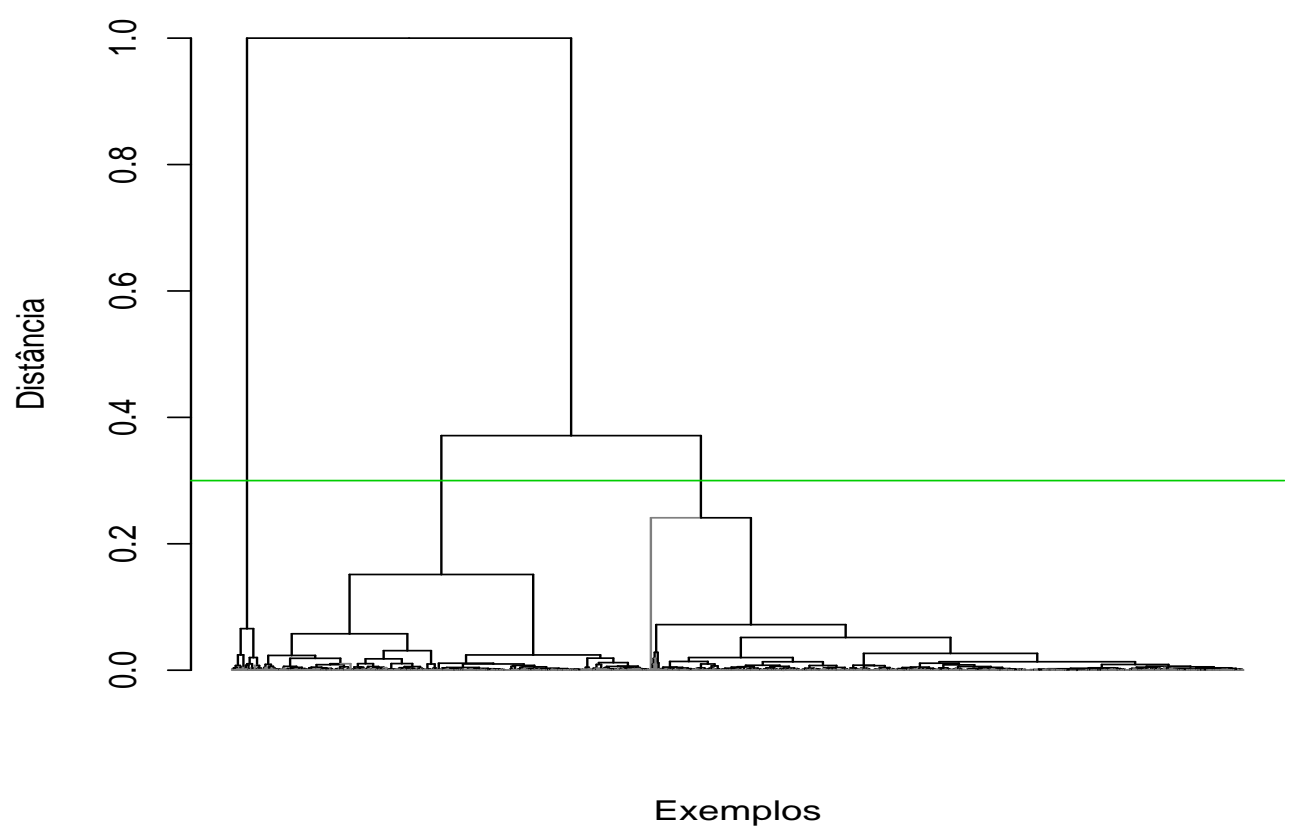

Figura 6.6: Dendograma obtido por meio do algoritmo Average Link utilizando a medida de distância Euclidiana sobre o conjunto de dados Vehicle.

Considerando-se o atributo classe que rotula os exemplos no conjunto de dados supervisionado Vehicle, observa-se que, assim como nos casos anteriores, esses clusters representam algum conceito não relacionado à classe atribuída aos exemplos. Entretanto, analisando apenas os 199 exemplos classificados como classe 4, percebe-se que todos os exemplos, com excessão de um, foram agrupados em um mesmo cluster, o cluster maior à direita no dendograma. Além disso, esse cluster agrupa 66.51\% dos exemplos classe 3, mostrando que os exemplos classificados como classe 3 e 4 predominam no cluster maior. O cluster central, em contrapartida, agrupa $65.57 \%$ dos exemplos de classe 1 e $63.13 \%$ dos exemplos de classe 2. Desse modo, observa-se que há possibilidade de existir algum relacionamento entre as classes 1 e 2 representado pelo cluster central e, também, algum outro relacionamento entre as classes 3 e 4 representado pelo cluster à direita.

Como pode ser observado, em todos esses experimentos os clusters gerados não contém exemplos rotulados com um mesmo valor da classe atri- 
buída a esses exemplos. Esse resultado é esperado, pois o uso de medidas de distância para agrupar os exemplos e os critérios utilizados para atribuição de rótulos à esses mesmos exemplos, não necessariamente mapeiam os mesmos conceitos. Em outras palavras, o conceito embutido nos clusters difere do conceito representado pelo valor do rótulo da classe. Essa observação foi destacada anteriormente na Seção 2.4. Um dos objetivos deste trabalho consiste em tentar descobrir o conceito embutido nos clusters utilizando a metodologia de interpretação de clusters proposta, a qual é ilustrada a seguir para cada uma das bases de dados consideradas nos experimentos.

\subsection{Interpretação de Clusters e Discussão dos Resultados}

Como mencionado, é necessária uma análise visual dos dendogramas para determinar o nível onde o mesmo deve ser cortado para a determinação dos clusters a serem interpretados inicialmente. Após esse corte, os clusters encontrados são utilizados pelo aplicativo SHELLCluster para rotular os exemplos de cada conjunto de dados, utilizando o identificador do cluster ao qual cada exemplo pertence como seu rótulo. Em seguida, esse novo conjunto de dados rotulado deve ser submetido a algum indutor simbólico para assim tentar interpretar os clusters. Neste trabalho, utilizamos o algoritmo simbólico $\mathcal{C} 4.5$ rules (Quinlan, 1996) para induzir regras de decisão proposicionais.

O algoritmo $\mathcal{C} 4.5$ rules é considerado pela comunidade como um dos melhores algoritmos de indução de regras de decisão, as quais são agrupadas pelos valores da classe, como ilustrado a seguir para três classes $C l_{1}, C l_{2}$ e $\mathrm{Cl}_{3}$.

$$
\begin{gathered}
\operatorname{Regra}_{11} \text { : if }<\text { condições }_{11}>\text { then class }=C l_{1} \\
\vdots \\
\operatorname{Regra}_{i 1} \text { : if }<\text { condições }_{i 1}>\text { then class }=C l_{1} \\
\operatorname{Regra}_{12} \text { : if }<\text { condições }_{12}>\text { then class }=C l_{2} \\
\vdots \\
\operatorname{Regra}_{j 2} \text { : if }<\text { condições }_{j 2}>\text { then class }=C l_{2} \\
\operatorname{Regra}_{13} \text { : if }<\text { condições }_{13}>\text { then class }=C l_{3} \\
\vdots \\
\text { Regra }_{l 3} \text { : if }<\text { condições }_{l 3}>\text { then class }=C l_{3}
\end{gathered}
$$

As regras induzidas são regras não ordenadas para uma mesma classe, mas se comportam como regras ordenadas entre as classes. Em outras palavras, existe um else implícito que separa os conjuntos de regras de 
classes diferentes. Para ilustrar, considere que um novo exemplo deve ser classificado utilizando esse conjunto de regras. Primeiramente, o primeiro conjunto de regras $\left\{R_{11}, R_{21}, \ldots, R_{i 1}\right\}$ é utilizado. Caso nenhuma regra desse conjunto cubra o exemplo, então o segundo conjunto de regras $\left\{R_{12}, R_{22}, \ldots, R_{j 2}\right\}$ é utilizado, e assim sucessivamente. Caso nenhuma regra dos três conjuntos consiga cobrir o novo exemplo, então, o exemplo é classificado pela regra default (regra padrão). Deve ser observado que a classe predita pela regra default pelo $\mathcal{C} 4.5$ rules não é necessariamente a classe majoritária, como acontece na maioria dos algoritmos simbólicos. O C 4.5 rules escolhe a classe da regra default a partir do valor da classe que contém mais exemplos de treinamento que não são cobertos pelas regras induzidas.

Neste trabalho, o $\mathcal{C} 4.5$ rules foi executado com valores padrão para seus parâmetros. Na Tabela 6.4 é apresentado, para cada conjunto de dados, a distância de corte utilizada em cada dendograma para determinar os clusters iniciais, o identificador atribuído a cada cluster (Ident.), a média de distância interna e externa (DI e DE, respectivamente), o erro médio do classificador induzido pelo $\mathcal{C} 4.5$ rules utilizando 10 -fold cross validation ${ }^{3}$ e o desvio padrão.

\begin{tabular}{|c|c|c|c|c|c|c|c|}
\hline \multirow{2}{*}{$\begin{array}{l}\text { Conjunto } \\
\text { de Dados }\end{array}$} & \multirow{2}{*}{$\begin{array}{c}\mathrm{N}^{o} \cdot \text { de Classes } \\
\text { originais }\end{array}$} & \multirow{2}{*}{$\begin{array}{l}\text { distância } \\
\text { de corte }\end{array}$} & \multirow[t]{2}{*}{ Ident. } & \multirow[t]{2}{*}{ DI } & \multirow[t]{2}{*}{$\mathrm{DE}$} & \multicolumn{2}{|c|}{ Erro do Classificador } \\
\hline & & & & & & erro médio & $\sigma_{\text {erro }}$ \\
\hline \multirow[t]{3}{*}{ Bupa } & \multirow[t]{3}{*}{2} & \multirow[t]{3}{*}{$\overline{0.4}$} & C684 & 0.11 & 0.87 & \multirow[t]{3}{*}{$\overline{0.29}$} & \multirow[t]{3}{*}{0.87} \\
\hline & & & C685 & 0.12 & 0.86 & & \\
\hline & & & C686 & 0.12 & 0.99 & & \\
\hline \multirow[t]{2}{*}{ German } & \multirow[t]{2}{*}{2} & \multirow[t]{2}{*}{0.3} & C1997 & 0.30 & 0.54 & \multirow[t]{2}{*}{0.00} & \multirow[t]{2}{*}{0.00} \\
\hline & & & C1998 & 0.18 & 0.54 & & \\
\hline \multirow[t]{3}{*}{ Hungaria } & \multirow[t]{3}{*}{2} & \multirow[t]{3}{*}{0.4} & C515 & 0.09 & 0.60 & \multirow[t]{3}{*}{0.75} & \multirow[t]{3}{*}{1.50} \\
\hline & & & C517 & 0.27 & 0.77 & & \\
\hline & & & C518 & 0.29 & 0.50 & & \\
\hline \multirow[t]{2}{*}{ Pima } & \multirow[t]{2}{*}{2} & \multirow[t]{2}{*}{0.4} & C1534 & 0.06 & 1.00 & \multirow[t]{2}{*}{0.52} & \multirow[t]{2}{*}{0.63} \\
\hline & & & C1535 & 0.06 & 1.00 & & \\
\hline \multirow[t]{3}{*}{ Vehicle } & \multirow[t]{3}{*}{4} & \multirow[t]{3}{*}{0.3} & C1685 & 0.08 & 0.28 & \multirow[t]{3}{*}{0.94} & \multirow[t]{3}{*}{1.14} \\
\hline & & & C1687 & 0.06 & 0.15 & & \\
\hline & & & C1688 & 0.06 & 0.24 & & \\
\hline
\end{tabular}

Tabela 6.4: Resultado do indutor sobre os conjuntos de dados naturais.

Como pode ser observado, exceto para o conjunto German que não apresentou erro, em todos os outros casos o erro médio é muito pequeno. Assim, o próximo passo da metodologia proposta consiste em submeter as regras geradas pelo indutor para a análise do especialista com o objetivo de interpretar os clusters considerados.

Para o conjunto de dados Bupa, o $\mathcal{C} 4.5$ rules induziu as três regras a seguir, uma única regra para descrever cada cluster. O número entre colchetes ("[ ]") indica a precisão esperada da regra para classificar novos exemplos.

\footnotetext{
${ }^{3}$ Para realizar esses experimentos e calcular essas medidas, foi utilizado o ambiente de gerenciamento de experimentos SNIFFER (Batista \& Monard, 2003)
} 


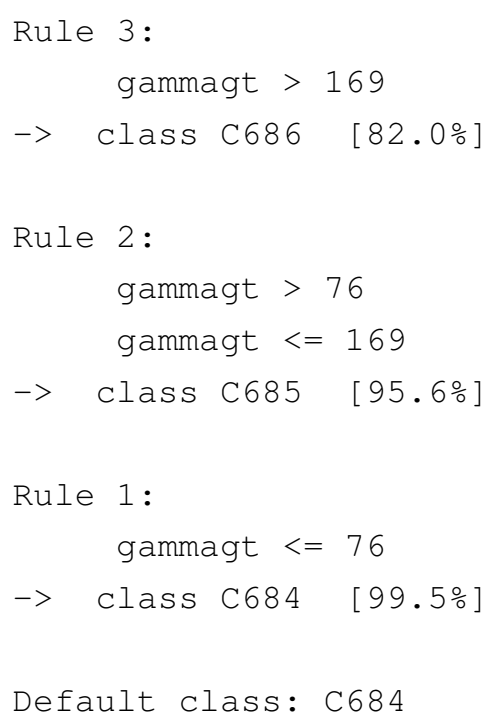

Essas regras cobrem perfeitamente os 345 exemplos do conjunto de dados Bupa, como mostra a matriz de confusão gerada pelo $\mathcal{C} 4.5$ rules:

$\begin{array}{rrrr}\text { (a) } & \text { (b) } & \text { (c) } & <- \text { classified as } \\ ------- & ---- & & \\ 7 & & & \text { (a) }: \text { Class } C 686 \\ & 31 & \text { (b) }: \text { Class C685 } \\ & & 307 & \text { (c) }: \text { class C684 }\end{array}$

Pelas regras induzidas, é possivel concluir que o valor de um único atributo, o atributo gammagt, é o responsável pelo agrupamento dos exemplos nesses três clusters. Esse conhecimento poderia ser refinado considerando, por exemplo, o cluster C684 que contém a maioria dos exemplos, 307 exemplos no total. Segundo o dendograma construído sobre os conjunto de dados Bupa - Figura 6.2 - esse cluster contém dois sub-clusters no qual o processo poderia ser repetido para discriminar melhor os 307 exemplos com o atributo gammagt $\leq 76$.

Para o conjunto de dados German, o $\mathcal{C} 4.5$ rules induziu as duas regras a seguir, que discriminam perfeitamente os dois clusters.

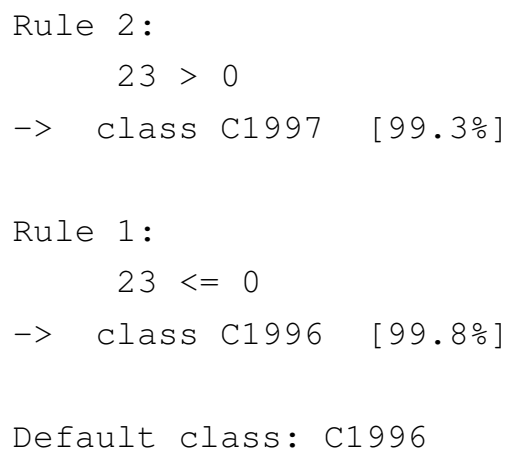

Essas regras cobrem perfeitamente os 1000 exemplos desse conjunto de dados, sendo 200 exemplos presentes no cluster C1997 e 800 no cluster 
C1996, utilizando o valor de um único atributo, o atributo 23. Nesse caso, como os dois clusters contêm um bom número de exemplos, um especialista de domínio poderia refinar a explicação de ambos. Entretanto, segundo o dendograma desse experimento - Figura 6.3 - é possivel observar que os sub-clusters de ambos não se mostram apropriados para continuar aplicando a metodologia proposta.

Para o conjunto de dados Hungaria, o $\mathcal{C} 4.5$ rules induziu três regras que, também, discriminam perfeitamente os clusters. As três regras geradas e a matriz de confusão correspondente são apresentadas a seguir:

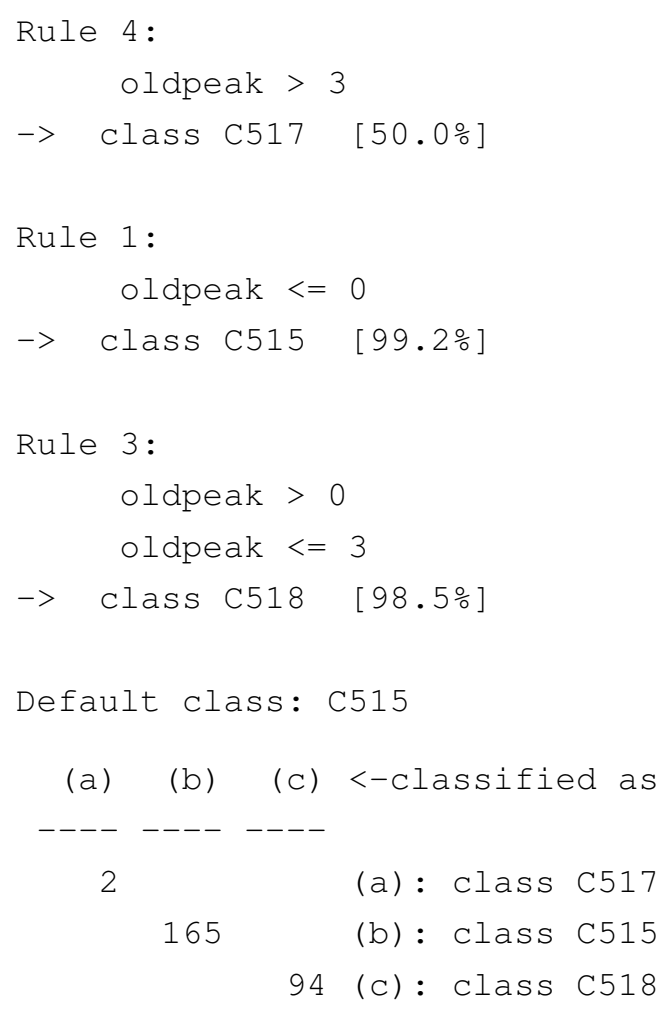

Observe que a regra 4 tem uma precisão baixa, de 50\%, para classificar novos exemplos. Isso deve-se ao fato de ter sido gerada utilizando somente 2 exemplos que pertencem ao cluster C517. Apenas um atributo é responsável pelo agrupamento dos exemplos nesses três clusters, o atributo oldpeak. Como os clusters C515 e C518 contêm um bom número de exemplos, a explicação dos clusters poderia ser refinada. Segundo o dendograma do conjunto de dados - Figura 6.4 - poderia ser interessante analisar o cluster mais à direita, que corresponde ao cluster C518 com 94 exemplos, analisando os três sub-clusters principais. O cluster no meio do dendograma, que corresponde ao cluster C515 com 165 exemplos também poderia ser analisado, considerando os três sub-clusters principais. Porém, nesse caso, é possivel observar que um desses sub-clusters no dendograma contém poucos exemplos e não será muito informativo.

Para o conjunto de dados Pima, o $\mathcal{C} 4.5$ rules induziu as seis regras a seguir: 


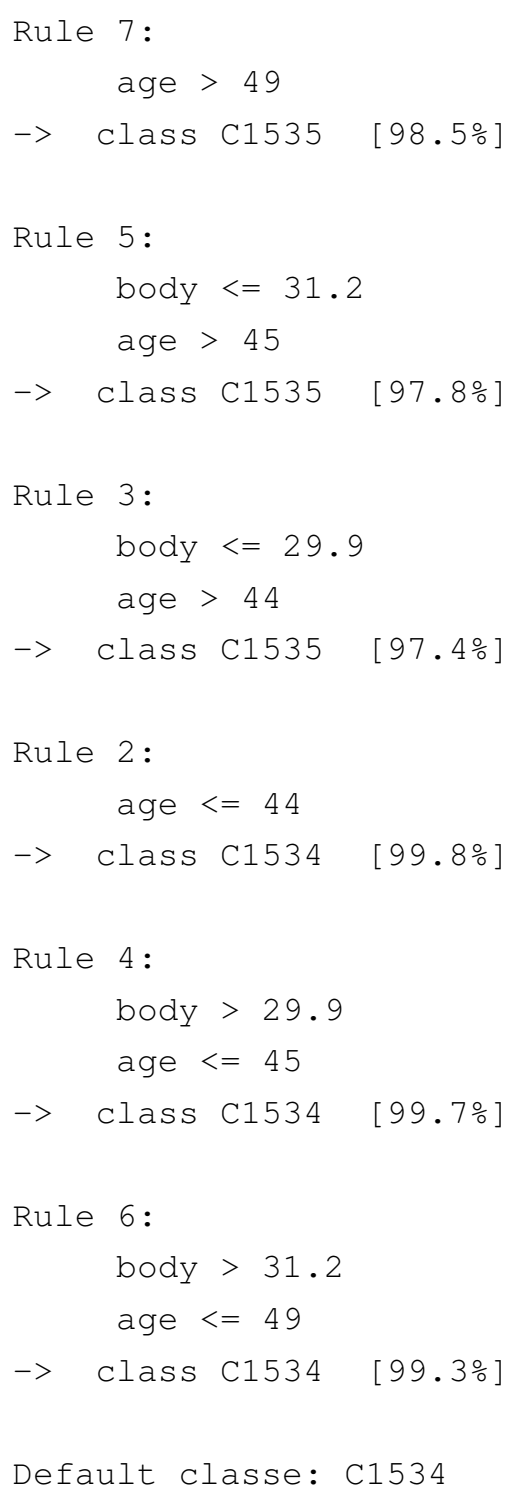

Essas regras somente não conseguem cobrir um exemplo do cluster C1535, como mostra a matriz de confusão correspondente:

(a) (b) <-classified as

$105(\mathrm{a}):$ class C1535
$663(\mathrm{~b}):$ class C1534

Nesse caso, os valores de dois atributos, o atributo body e o age, são os responsáveis pelo agrupamento dos exemplos nesses dois clusters. Considerando o número de exemplos em cada cluster, a explicação dos mesmos poderia ser refinada. Segundo o dendograma gerado para esse conjunto de dados - Figura 6.5 - o cluster C 1534 que contém a maioria dos exemplos, totalizando 663, mostra-se mais promissor. Assim, para um especialista seria interessante aplicar a metodologia para analisar os três sub-clusters desse cluster.

Para o conjunto de dados Vehicle, foram induzidas as seis regras a seguir: 


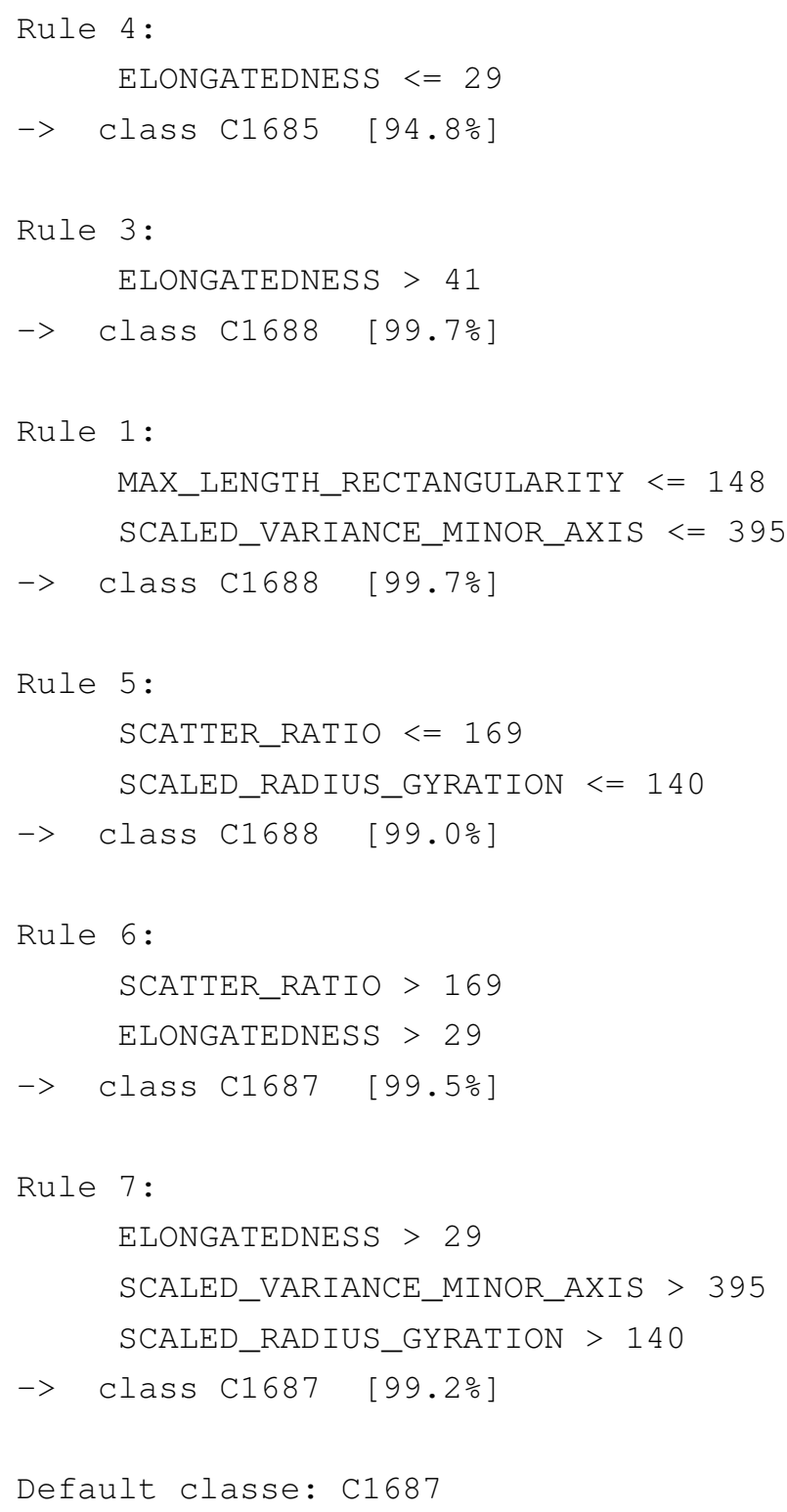

Observe que essas regras não conseguem cobrir um exemplo do cluster C1688, como ilustrado na matriz de confusão correspondente:

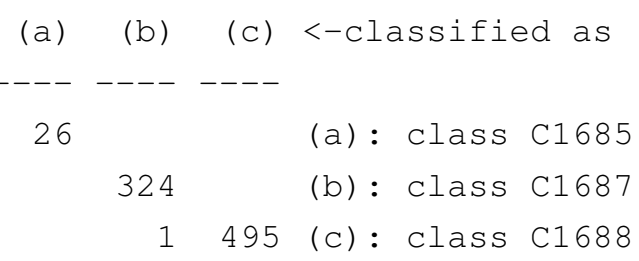

Nesse caso, os valores de cinco atributos foram utilizados para a construção dos clusters. Desconsiderando o cluster C1685, que contém somente 26 exemplos, a explicação dos outros clusters poderia ser refinada pelo especialista. A partir do dendograma gerado para esse conjunto de dados - Figura 6.6 - o cluster C 1687, que contém 324 exemplos, possui dois sub-clusters que poderiam ser melhor analisados. O outro cluster C1688, que encontra-se à direita no dendograma, também tem dois sub-clusters. Porém, pode ser observado que um deles contém somente um exemplo, que 
é aquele que não foi coberto pelas regras induzidas pelo indutor $\mathcal{C} 4.5$ rules. O segundo sub-cluster possui dois sub-clusters que poderiam ser melhor analisados pelo especialista.

\subsection{Considerações Finais}

Neste Capítulo ilustramos o uso do módulo de clustering do Discover, proposto e implementado neste trabalho, bem como o uso da metodologia de interpretação de clusters e análise de dendogramas para tentar interpretar os clusters encontrados. Como pode ser observado, a hierarquia de clusters construída por algoritmos de clustering hierárquico é muito dependente dos parâmetros e métodos utilizados. Assim, é importante analisar os dendogramas correspondentes para verificar qual a hierarquia de clusters mais apropriada para a aplicação dessa metodologia. No próximo capítulo apresentamos um estudo de caso que teve a participação de um especialista de domínio para avaliação dos clusters. 



\section{Estudo de caso}

\subsection{Considerações Iniciais}

Neste capítulo é apresentado um estudo de caso realizado sobre um conjunto de dados real proveniente da área médica, o qual trata especificamente do problema da infertilidade masculina. O trabalho foi desenvolvido com a participação de especialistas do domínio que atuam em projetos de Computação Aplicada à Medicina e Análise Inteligente de Dados. Este projeto está sendo desenvolvido em uma parceria entre o Laboratório de Bioinformática - LABI - Universidade Estadual do Oeste do Paraná, UNIOESTE; o Laboratório de Inteligência Computacional - LABIC - Universidade de São Paulo, USP/São Carlos e o Centro de Referência em Infertilidade Masculina - Androfert.

O conjunto de dados utilizado nesse estudo de caso consiste de laudos médicos semi-estruturados, que contêm informações sobre exames de processamento de sêmen. Esses dados foram convertidos para o formato atributo-valor por meio de uma metodologia proposta em (Lee, 2005), a qual foi implementada em um sistema computacional utilizado para a construção de bases de dados estruturadas a partir de laudos médicos semiestruturados (Honorato et al., 2005). Deve ser observado que as etapas de aquisição de conhecimento do domínio, coleta, limpeza e preparação dos dados foram realizadas por Lee (2005).

A seguir são descritas as tarefas executadas em cada etapa do processo de mineração do conjunto de dados deste estudo de caso. 


\subsection{Domínio da Aplicação - Análise Seminal e Processamento de Sêmen Diagnóstico}

O insucesso na tentativa de gravidez pode ser causado por diversos fatores, os quais podem causar a infertilidade. Um casal é considerado infértil caso não ocorra a gravidez após um período de um ano de relacionamento sexual ativo, sem uso de qualquer método anti-concepcional. Esse problema ocorre entre $10 \%$ a $20 \%$ dos casais em fase reprodutiva, dos quais aproximadamente $55 \%$ estão relacionados com fatores masculinos. Além disso, os fatores masculinos são responsáveis exclusivos por cerca de $35 \%$ dos casos de infertilidade (Bendhack \& Damião, 1999).

Os motivos que freqüentemente interferem na fertilidade masculina são o uso de anabolizantes e entorpecentes, o alcoolismo, o tabagismo, o contato excessivo com defensivos agrícolas, trauma testicular, anomalias congênitas, como criptorquidia ${ }^{1}$, cirurgias vesicais ${ }^{2}$, retroperitoneais ${ }^{3}$ e pélvicas (Medeiros, 1993). Além desses motivos, disfunções hormonais também podem acarretar a infertilidade masculina, uma vez que todo o processo de produção, maturação e transporte dos espermatozóides, bem como a ejaculação, sofrem interferência hormonal. Assim, esses fatores podem interferir na espermatogênese e afetar negativamente a quantidade, a estrutura e a motilidade dos espermatozóides, levando conseqüentemente, à infertilidade masculina.

Os estudos desenvolvidos e os avanços nos métodos de diagnóstico têm possibilitado identificar uma série de condições que causam infertilidade masculina. A Varicocele ${ }^{4}$, tem sido apontada como a causa mais comum da infertilidade masculina (Esteves, 2005). Nesses casos, as veias ao redor dos testículos tornam-se dilatadas dando origem às varizes, o que impossibilita a circulação sanguínea adequada. Esse fato faz com que o sangue seja retido ao redor do testículo aumentando a temperatura testicular e prejudicando o processo de produção dos espermatozóides. Além do aumento da temperatura na bolsa escrotal, o sangue acumulado nesses vasos sangüíneos, freqüentemente, contém substâncias tóxicas que podem levar a diminuição da produção, da movimentação e do funcionamento dos espermatozóides (Esteves, 2005).

Para que ocorra a fecundação do óvulo, é necessário que exista um número suficiente de espermatozóides, e que os mesmos tenham movimenta-

\footnotetext{
${ }^{1}$ Testículo retido; ausência completa ou incompleta da descida dos testículos intraabdominais para o saco escrotal.

${ }^{2}$ Cirurgias de bexiga.

${ }^{3}$ Região que fica atrás do peritôneo.

${ }^{4}$ Dilatação das veias do testículo
} 
ção progressiva no interior do aparelho reprodutor feminino, a fim de que possam atingir e penetrar no interior do óvulo. Outra condição fundamental é que exista um número adequado de espermatozóides com tamanho e formato normais. Os espermatozóides que apresentam estrutura anormal, por exemplo, duas cabeças, cauda enrolada, cabeça muito grande ou muito pequena, têm pouca probabilidade de fecundar o óvulo.

Nesse contexto, é indispensável uma avaliação completa do homem para que a infertilidade seja corretamente diagnosticada. Essa avaliação deve considerar o histórico médico, exames físicos e laboratoriais do paciente, para identificar a causa da infertilidade e assim, recomendar o melhor tratamento para cada caso.

A análise seminal é um dos primeiros exames a serem realizados para a avaliação da fertilidade masculina. A partir desse exame, o médico especialista tem acesso à uma série de informações que possibilitam detectar a normalidade aparente do ejaculado (Medeiros, 1993). Inicialmente, é importante avaliar se o volume do esperma, o $\mathrm{pH}$, a viscosidade, a cor, o odor e a liquefação do sêmen estão dentro dos parâmetros considerados normais. Após, outros testes são realizados para identificar, por exemplo, a vitalidade e a morfologia dos espermatozóides, a presença de leucócitos no sêmen e a contagem do número de espermatozóides além da motilidade dos mesmos.

Outro exame laboratorial usualmente realizado com pacientes que apresentam problemas de infertilidade é o processamento de sêmen diagnóstico, utilizado para quantificar a qualidade do sêmen. Esse exame constitui um processo bastante caro, cuja realização pode elevar o custo da avaliação em aproximadamente $70 \%$ do valor de uma análise seminal. Essa elevação de custo se deve principalmente a três fatores: necessidade de equipamentos especiais, mão-de-obra qualificada e tempo gasto para a realização do exame (Lee, 2005).

Deve ser observado que algumas informações são obtidas tanto pelo exame de análise seminal (baixo custo) quanto pelo exame de processamento de sêmen (alto custo), tal como a motilidade, a qual pode ser classificada como:

1. Grau A: motilidade rápida, linear e progressiva;

2. Grau B: motilidade linear lenta ou movimentos não-lineares;

3. Grau C: motilidade não-progressiva; e

4. Grau D: imóveis.

A Organização Mundial de Saúde define alguns parâmetros que determinam a normalidade do ejaculado de acordo com suas características, as 
quais são obtidas por meio dos exames de análise seminal e processamento de sêmen. Esses valores são apresentados na Tabela 7.1.

\begin{tabular}{l|l}
\hline \hline Atributos & Valor de referência para normalidade \\
\hline \hline $\mathrm{pH}$ & entre 7.2 e 7.8 \\
\hline volume & $\geq 2 \mathrm{ml}$ \\
\hline concentracao & $\geq 20$ milhões por mililitro (ml) \\
\hline concentracao-total & $\geq 40$ milhões por mililitro (ml) \\
\hline motilidade & $\geq 50 \%$ de progressão (Classe grau A e grau B) \\
& $\geq 25 \%$ de progressão rápida e linear (Classe grau A) \\
\hline vitalidade & $\geq 75 \%$ vivos \\
\hline morfologia & $\geq 30 \%$ normais \\
\hline \hline
\end{tabular}

Tabela 7.1: Valores normais do espermograma segundo a OMS (Bendhack \& Damião, 1999).

Bendhack \& Damião (1999) discutem as causas mais comuns para alterações no ejaculado. Segundo esse trabalho, nos casos em que o volume seminal é inferior a $2 \mathrm{ml}$, a causa mais comum é a perda de parte do ejaculado, fato que sempre deve ser questionado. Outras causas incluem obstrução do sistema canalicular, malformações de vesículas seminais/deferentes e ejaculação retrógrada ${ }^{5}$. O pH de um ejaculado normal pode variar entre $7.2 \mathrm{e}$ 7.8. Quando o valor do $\mathrm{pH}$ está acima desse intervalo, considera-se que o paciente pode apresentar um processo infeccioso, enquanto um $\mathrm{pH}$ abaixo desse intervalo sugere um processo obstrutivo de ductos deferentes. A baixa concentração espermática (oligospermia), a baixa motilidade (astenospermia) e o alto número de formas anormais (teratospermia) são indicativos da Varicocele. Astenospermia isolada, por outro lado, é mais sugestiva de processo inflamatório ou de presença de anticorpos anti-espermatozóides.

A análise da vitalidade é indicada para todas as amostras com concentração acima de 1 milhão de espermatozóides/ml. Quando todos os espermatozóides ou a maioria forem imóveis, é imprescindível distingüir os espermatozóides vivos e imóveis dos mortos. O indivíduo normal deve possuir pelo menos 75\% de espermatozóides vivos. Assim, presença de elevado número de espermatozóides vivos e imóveis (motilidade grau D) é uma situação rara e sugere ser a síndrome de Kartagener; outras causas possíveis são o uso de drogas e exposição à radiação. O choque térmico também pode provocar imobilização total dos espermatozóides.

Bendhack \& Damião (1999) encorajam também, a contagem de leucócitos, uma vez que a presença de um grande número dessas células (superior a 1 milhão/ml) é um indicativo de processo infeccioso. Essa análise deve ser cuidadosa, pois outras células redondas podem fornecer um falso resultado.

\footnotetext{
${ }^{5}$ Passagem do sêmen, total ou parcialmente, da uretra prostática para a bexiga, por falta de fechamento do colo vesical na ejaculação.
} 
Existem algumas condições bem definidas que causam infertilidade masculina. Para estes casos, existem tratamentos clínicos específicos, que podem contribuir para restaurar a fertilidade do indivíduo. Caso não seja possivel a recuperação da fertilidade, a gravidez pode ser obtida por meio de técnicas de reprodução assistida. São três as técnicas de reprodução assistida

1. Inseminação Intra-uterina - IUI;

2. Fertilização In Vitro - FIV; e

3. Injeção Intracitoplasmática do Espermatozóide no Oócito - ICSI.

Para que possa ser realizado um estudo com técnicas computacionais sobre esse tipo de domínio, é necessário que seja feito um mapeamento das informações do domínio de tal forma que os sistemas e/ou ferramentas possam processar essas informações. Na próxima seção são descritas as transformações realizadas para obter esse mapeamento, incluindo as tarefas de coleta, limpeza e preparação dos dados.

\subsection{Coleta, Limpeza e Preparação dos Dados}

Como mencionado, os dados coletados consistem de laudos médicos que contêm informações relacionadas à análise seminal e ao processamento de sêmen. A coleta, a limpeza e a preparação bem como a conversão desses dados para o formato atributo-valor, foram realizadas em um trabalho anterior desenvolvido por Lee (2005), que coletou 717 laudos provenientes do Centro de Reprodução Assistida Androfert ${ }^{6}$. Esses laudos são referentes ao período de 31/03/1997 a 01/04/2005. O mapeamento das informações identificadas a partir dos 717 laudos com o auxílio dos especialistas do domínio, e o processo de limpeza e preparação dos dados realizado em (Lee, 2005), resultaram em um conjunto de dados com 407 exemplos descritos por 17 atributos numéricos, 6 atributos nominais e o atributo classe - Tabela 7.2 .

\begin{tabular}{c|c|c|cc|c}
\hline \hline $\begin{array}{c}\text { Conjunto } \\
\text { de Dados }\end{array}$ & $\mathrm{N}^{o}$. de Exemplos & $\begin{array}{c}\mathrm{N}^{o} \text {. de Atributos } \\
\text { (num.,nom.) }\end{array}$ & Classes & Classe \% & Erro da CM \\
\hline Proc & 407 & $23(17,6)$ & 1 & $20.88 \%$ & $40.05 \%$ \\
& & & 2 & $19.17 \%$ & sobre 3 \\
& & & 3 & $59.95 \%$ & \\
\hline \hline
\end{tabular}

Tabela 7.2: Resumo do conjunto de dados Processamento de Sêmen (Lee, 2005).

\footnotetext{
$6_{\text {http }}: / /$ ww $\cdot$ androfert.com.br
} 
No estudo de caso desenvolvido neste trabalho, os atributos nominais não foram considerados, pois o interesse está em descobrir relacionamentos entre os atributos quantitativos. Além dos atributos nominais, o atributo classe também foi descartado, resultando em um conjunto de dados com 407 exemplos não-supervisionados descritos por 17 atributos numéricos, os quais estão relacionados na Tabela 7.3. Para cada atributo são apresentadas as seguintes informações:

- Id.: identificação do atributo;

- Id. Orig.: identificação original do atributo de acordo com o conjunto de atributos utilizados em (Lee, 2005);

- Nome do Atributo;

- Descrição do Atributo; e

- $\mathrm{N}^{o}$. de Valores Distintos: quantidade de valores distintos do atributo.

\begin{tabular}{|c|c|c|c|c|}
\hline Id. & $\begin{array}{l}\text { Id. } \\
\text { Orig. }\end{array}$ & $\begin{array}{l}\text { Nome do } \\
\text { Atributo }\end{array}$ & Descrição do Atributo & $\begin{array}{c}\mathrm{N}^{o} \text {. de Valores } \\
\text { Distintos }\end{array}$ \\
\hline$\# 0$ & $\# 0$ & idade & Idade do paciente & 33 \\
\hline$\# 1$ & $\# 5$ & processamento & $\begin{array}{l}\text { Processamento do sêmen } \\
\text { realizado após esta } \\
\text { quantidade de minutos } \\
\text { depois da coleta }\end{array}$ & 22 \\
\hline$\# 2$ & \#6 & $\mathrm{pH}$ & pH do sêmen coletado & 6 \\
\hline$\# 3$ & $\# 7$ & tempo-abstinencia & $\begin{array}{l}\text { Tempo de abstinência } \\
\text { (dias) }\end{array}$ & 12 \\
\hline$\# 4$ & $\# 8$ & volume & $\begin{array}{l}\text { Volume de sêmen coletado } \\
(\mathrm{ml})\end{array}$ & 69 \\
\hline \#5 & $\# 10$ & concentracao & $\begin{array}{l}\text { Concentração de } \\
\text { espermatozóides por } \\
\text { ml coletado }\end{array}$ & 337 \\
\hline \#6 & $\# 11$ & concentracao-total & $\begin{array}{l}\text { Concentração total de } \\
\text { espermatozóides }\end{array}$ & 396 \\
\hline$\# 7$ & $\# 12$ & motilidade-grau-a & $\begin{array}{l}\text { Classificação da } \\
\text { motilidade Grau A }\end{array}$ & 24 \\
\hline$\# 8$ & $\# 13$ & motilidade-grau-b & $\begin{array}{l}\text { Classificação da } \\
\text { motilidade Grau B }\end{array}$ & 70 \\
\hline$\# 9$ & $\# 14$ & motilidade-grau-c & $\begin{array}{l}\text { Classificação da } \\
\text { motilidade Grau C }\end{array}$ & 41 \\
\hline$\# 10$ & $\# 15$ & motilidade-grau-d & $\begin{array}{l}\text { Classificação da } \\
\text { motilidade Grau D }\end{array}$ & 74 \\
\hline$\# 11$ & $\# 16$ & motilidade & $\begin{array}{l}\text { \% de espermatozóides } \\
\text { móveis }(A+B+C)\end{array}$ & 74 \\
\hline$\# 12$ & 17 & motilidade-progressiva & $\begin{array}{l}\text { \% de espermatozóides } \\
\text { móveis }(\mathrm{A}+\mathrm{B})\end{array}$ & 74 \\
\hline$\# 13$ & $\# 18$ & vitalidade & \% de espermatozóides vivos & 64 \\
\hline$\# 14$ & $\# 20$ & nro-leu-pol & $\begin{array}{l}\text { Número de leucócitos } \\
\text { polimorfonucleares }\end{array}$ & 106 \\
\hline$\# 15$ & $\# 21$ & nro-cel-red & $\begin{array}{l}\text { Número de células redondas } \\
\text { peroxidase-negativas }\end{array}$ & 176 \\
\hline$\# 16$ & $\# 22$ & morfologia-Kruger & $\begin{array}{l}\text { \% de espermatozóides com } \\
\text { morfologia normal segundo } \\
\text { técnica estrita de Kruger }\end{array}$ & 23 \\
\hline
\end{tabular}

Tabela 7.3: Atributos do conjunto de dados utilizados no estudo de caso(Lee, 2005). 


\subsection{Avaliação Experimental}

O objetivo deste estudo de caso é verificar a viabilidade do uso da metodologia proposta para interpretação de clusters hierárquicos em um caso real, no qual atua um especialista de domínio. Para isso, contamos com a inestimável colaboração do especialista Prof. Dr. Feng Chung Wu, do Laboratório de Bioinformática - LABI/UNIOESTE — , responsável pela área de medicina do projeto conjunto de Computação Aplicada à Medicina e Análise Inteligente de Dados.

Como mencionado, quando o clustering hierárquico é utilizado, uma decisão a ser tomada está relacionada ao nível no qual o dendograma deve ser cortado para a construção dos clusters, os quais são utilizados na etapa de análise e interpretação. Para a aplicação da metodologia de interpretação, essa decisão deve levar em conta não somente a qualidade dos clusters segundo alguma medida de avaliação, mas também a distribuição do número de exemplos nesses clusters, a fim de não introduzir o problema de desbalanceamento de classes, i.e., um cluster com muitos exemplos e outros com poucos exemplos. O fato de existirem clusters desbalanceados dificulta a construção de bons modelos a partir de algoritmos de aprendizado supervisionado (Batista et al., 2005, 2004; Prati, 2006).

Os clusters podem ser analisados, inicialmente, de maneira objetiva sem a intervenção do especialista do domínio, com intuito de identificar os melhores dendogramas para uma análise mais detalhada. Esse procedimento foi adotado neste trabalho. Para isso, foram realizados diversos experimentos, dos quais os "melhores" foram selecionados para apresentação posterior ao especialista. Ainda que a seleção dos "melhores" experimentos foi realizada com base em critérios objetivos, como os valores do coeficiente de correlação cophenético e as médias de distância interna e externa dos clusters, foram também considerados os dendogramas para identificar as "melhores" hierarquias.

Os experimentos foram realizados utilizando os três algoritmos Single Link, Average Link e Complete Link e quatro medidas de similaridade para cada um dos três algoritmos, totalizando 12 experimentos. Como mencionado, as medidas implementadas no módulo de clustering do Discover são baseadas em distâncias do espaço Euclidiano ou em índices de correlação. Para a execução dos experimentos, foram selecionadas duas medidas de cada família:

- Medidas de distância: Euclidiana e Manhattan; e

- Medidas de correlação: Pearson e Spearman. 
Com a execução desses 12 experimentos, obteve-se o valor do índice de correlação cophenético para cada dendograma construído. É importante lembrar que esse índice indica o grau de correlação entre o dendograma criado pelo algoritmo de clustering e a matriz de similaridade dos dados utilizados como entrada para o algoritmo. Assim, o objetivo é, em princípio, maximizar o valor desse índice. Na Tabela 7.4 são apresentados os valores dos coeficientes de correlação cophenético para cada um dos doze experimentos.

\begin{tabular}{c|c|c|c|c|c|c}
\hline \hline Medida de similaridade & $\#$ Exp & Aver. Link & \#Exp & Comp. Link & $\#$ Exp & Sing. Link \\
\hline \hline Euclidiana & $\# 1$ & $48.60 \%$ & $\# 5$ & $43.25 \%$ & $\# 9$ & $31.57 \%$ \\
Manhattan & $\# 2$ & $48.09 \%$ & $\# 6$ & $35.56 \%$ & $\# 10$ & $68.60 \%$ \\
Cor. Pearson & $\# 3$ & $40.63 \%$ & $\# 7$ & $33.21 \%$ & $\# 11$ & $59.40 \%$ \\
Cor. Spearman & $\# 4$ & $44.78 \%$ & $\# 8$ & $32.55 \%$ & $\# 12$ & $25.68 \%$ \\
\hline \hline
\end{tabular}

Tabela 7.4: Coeficiente cophenético para o clustering sobre o conjunto de dados original.

A partir de uma análise mais detalhada dos respectivos dendogramas, observou-se que os resultados obtidos pelo algoritmo Single Link, apesar de apresentarem os valores mais altos para o coeficiente cophenético, não construíram "boas" hierarquias de clusters. Desse modo, foi decidido continuar a análise apenas com os oito experimentos que envolvem as execuções dos algoritmos Average Link e Complete Link. Para esses oito experimentos, foram retirados alguns exemplos considerados outliers, os quais foram identificados a partir da inspeção visual do dendograma. Na Tabela 7.5, são apresentados os exemplos retirados em cada um desses oito experimentos. Cada linha nessa tabela representa um exemplo identificado pela primeira coluna, e em cada coluna são identificados os respectivos experimentos. A última coluna indica a quantidade de experimentos em que cada exemplo foi considerado um outlier e a última linha indica a quantidade de outliers identificados em cada experimento. Os outliers foram eliminados dos experimentos respectivos, e, após, o conjunto de dados sem os outliers correspondentes a cada experimento, foi novamente submetido ao algoritmo declustering para encontrar a nova hierarquia de clusters, recalculando os valores do coeficiente de correlação cophenético para cada experimento, apresentados na Tabela 7.6.

A partir das novas hierarquias de clusters geradas com a execução do clustering sobre os conjuntos de dados sem os outliers, foram determinados os níveis nos quais os dendogramas deveriam ser cortados para a identificação dos clusters em cada experimento. A escolha do nível de corte do dendograma foi feita mediante a análise dos valores médios de distância interna dos clusters e, principalmente, com auxílio da inspeção visual dos dendogramas. Um resumo dos clusters identificados nesses experimentos 


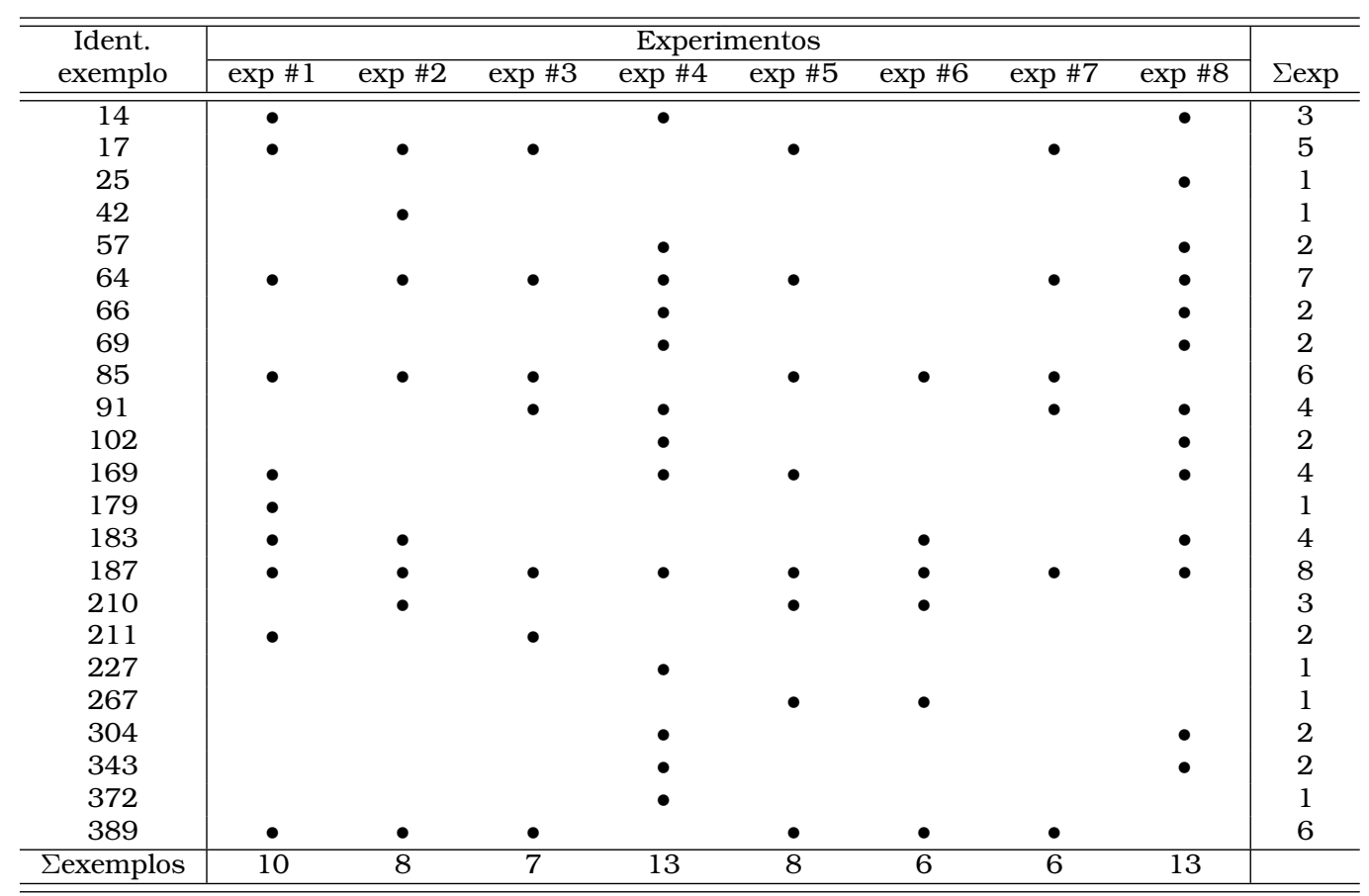

Tabela 7.5: Relação de exemplos considerados outliers em cada experimento.

\begin{tabular}{c|c|cc|c|cc}
\hline \hline Medida de similaridade & $\#$ Exp & Aver. Link & & \#Exp & Comp. Link & \\
\hline \hline Euclidiana & $\# 1$ & $47.52 \%$ & $\nabla$ & $\# 5$ & $39.60 \%$ & $\nabla$ \\
Manhattan & $\# 2$ & $48.56 \%$ & $\triangle$ & $\# 6$ & $43.38 \%$ & $\triangle$ \\
Cor. Pearson & $\# 3$ & $30.93 \%$ & $\nabla$ & $\# 7$ & $33.30 \%$ & $\triangle$ \\
Cor. Sperman & $\# 4$ & $46.00 \%$ & $\triangle$ & $\# 8$ & $31.44 \%$ & $\nabla$ \\
\hline \hline
\end{tabular}

Tabela 7.6: Coeficiente cophenético para o clustering sobre o conjunto de dados sem os outliers. Os símbolos $\nabla e \triangle$ são utilizados como indicativo de melhora ou piora em relação ao primeiro modelo gerado, i.e., ao modelo obtido com a presença dos outliers. 
para uma possível análise posterior é apresentado na Tabela 7.7, onde as colunas \#Exp representam os experimentos, as colunas Eexemplos os totais de exemplos em cada cluster e as colunas DI a média de distância interna para cada cluster.

\begin{tabular}{|c|c|c|c|c|c|c|c|}
\hline \multicolumn{4}{|c|}{ Average Link } & \multicolumn{4}{|c|}{ Complete Link } \\
\hline \#Exp & Cluster & इexemplos & DI & \#Exp & Cluster & Lexemplos & DI \\
\hline \multirow{5}{*}{ \#1 } & C776 & 164 & 0.10 & \multirow{5}{*}{ \#5 } & C784 & 14 & 0.08 \\
\hline & C778 & 134 & 0.07 & & C791 & 64 & 0.06 \\
\hline & C780 & 14 & 0.07 & & C793 & 67 & 0.11 \\
\hline & C785 & 24 & 0.08 & & C795 & 228 & 0.10 \\
\hline & C790 & 61 & 0.07 & & C796 & 28 & 0.09 \\
\hline \multirow{5}{*}{ \#2 } & C776 & 14 & 0.18 & \multirow{5}{*}{ \#6 } & C791 & 23 & 0.20 \\
\hline & C787 & 8 & 0.19 & & C794 & 37 & 0.24 \\
\hline & C788 & 55 & 0.25 & & C796 & 275 & 0.23 \\
\hline & C789 & 296 & 0.25 & & C797 & 66 & 0.25 \\
\hline & C790 & 25 & 0.21 & & & & \\
\hline \multirow{5}{*}{ \#3 } & C786 & 27 & 0.09 & \multirow{5}{*}{ \#7 } & C796 & 60 & 0.16 \\
\hline & C789 & 21 & 0.12 & & C797 & 221 & 0.10 \\
\hline & C792 & 23 & 0.08 & & C798 & 120 & 0.12 \\
\hline & C793 & 41 & 0.16 & & & & \\
\hline & C794 & 288 & 0.10 & & & & \\
\hline \multirow{4}{*}{ \#4 } & C781 & 270 & 0.19 & \multirow{4}{*}{ \#8 } & C770 & 9 & 0.21 \\
\hline & C785 & 124 & 0.19 & & C772 & 42 & 0.14 \\
\hline & & & & & C780 & 258 & 0.18 \\
\hline & & & & & C781 & 84 & 0.17 \\
\hline
\end{tabular}

Tabela 7.7: Clusters identificados em cada experimento selecionado para análise.

A análise desses clusters foi realizada considerando-se os valores de referência para cada atributo, indicados pela Organização Mundial de Saúde e descritos em (Telöken et al., 1999), apresentados na Tabela 7.8. Os valores de referência para os atributos \#0, \#7, \#8, \#9, \#10 e \#15 não foram definidos pela OMS. A coluna com título Normal representa os valores considerados dentro da normalidade para os respectivos atributos, enquanto que as colunas Abaixo-do-normal e Acima-do-normal representam variações onde os valores são menores ou maiores que o valor normal, respectivamente.

Por meio da análise da distribuição dos valores dos atributos dos exemplos de cada cluster, e considerando os valores médios de similaridade interna e externa dos cluster, foram selecionados os melhores dendogramas para a investigação mais detalhada. Desse modo, os experimentos \#1, \#3, \#4 e \#7 foram selecionados. Nesses casos, foi utilizada a metodologia proposta neste trabalho para a construção de regras com objetivo de auxiliar o especialista na interpretação dos clusters.

Na Tabela 7.9 são apresentados os erros médios dos classificadores simbólicos obtidos com $\mathcal{C} 4.5$ rules (Quinlan, 1993), executados com valores padrão para seus parâmetros, a partir do novo conjunto de dados rotulados com o clusters ao qual os exemplos pertencem. A partir dos valores dos erros dos classificadores, foi decidido retirar da análise os experimentos \# 1 e \#7, uma vez que o erro apontado para esses experimentos foi alto em relação aos experimentos \#3 e \#4. Assim, os dois melhores experimentos 


\begin{tabular}{ll|c|c|c}
\hline \hline$\#$ id & Atributo & Abaixo-do-normal & Normal & Acima-do-normal \\
& & $\nabla$ & $\diamond$ & $\triangle$ \\
\hline$\# 0$ & idade & - & - & - \\
$\# 1$ & processamento & - & $\leq 50$ & $>50$ \\
$\# 2$ & pH & {$[0,7.2)$} & {$[7.2,7.9)$} & $\geq 7.9$ \\
$\# 3$ & tempo_abstinencia & {$[0,3)$} & {$[3,5]$} & $\geq 5$ \\
$\# 4$ & volume & {$[0,2)$} & $\geq 2$ & - \\
$\# 5$ & concentracao & {$[0,20)$} & $\geq 20$ & - \\
$\# 6$ & concentracao-total & {$[0,40)$} & $\geq 40$ & - \\
$\# 7$ & mot-grau-a & - & - & - \\
$\# 8$ & mot-grau-b & - & - & - \\
$\# 9$ & mot-grau-c & - & - & - \\
$\# 10$ & mot-grau-d & {$[0,75)$} & $\geq 75$ & - \\
$\# 11$ & motilidade & {$[0,50)$} & $\geq 50$ & - \\
$\# 12$ & mot-progressiva & {$[0,75)$} & $\geq 75$ & - \\
$\# 13$ & vitalidade & - & $\leq 1.0$ & $>1.0$ \\
$\# 14$ & nro-leu-pol & - & - & - \\
$\# 15$ & nro-cel-re & {$[0,14)$} & $\geq 14$ & - \\
$\# 16$ & morfologia-Kruger & \multicolumn{3}{c}{} \\
\hline \hline
\end{tabular}

Tabela 7.8: Padrões para análise dos clusters. O símbolo - indica atributos cujos valores de normalidade não estão definidos pela OMS.

foram selecionados para serem apresentados ao especialista para análise e interpretação. Os resultados obtidos são descritos nas próximas seções.

\begin{tabular}{c|c|c|c}
\hline \hline$\#$ Exp & $\mathrm{N}^{o}$. de regras (média) & erro médio & $\sigma_{\text {erro }}$ \\
\hline \hline$\# 1$ & 10.8 & 7.82 & 4.47 \\
$\# 3$ & 7.9 & 4.00 & 2.28 \\
$\# 4$ & 6.6 & 3.81 & 3.20 \\
$\# 7$ & 8.8 & 8.98 & 5.61 \\
\hline \hline
\end{tabular}

Tabela 7.9: Erro do classificador $\mathcal{C} 4.5$ rules.

\subsubsection{Experimento \#3}

Esse experimento foi executado por meio do módulo de clustering do Discover utilizando o algoritmo Average Link e correlação de Pearson como medida para o cálculo da distância entre exemplos e clusters. Os outliers identificados, e retirados do conjunto de dados, nesse experimento são os exemplos: 17, 64, 85, 91, 187, 211 e 389 - Tabela 7.5. Na Figura 7.1 são apresentados os dendogramas obtidos com o conjunto de dados completo (a) e após retirar os outliers (b). Como pode ser observado, a hierarquia de clusters construída sem os outliers apresenta melhores resultados. A partir do corte feito na altura igual a 0.2 no dendograma construído sobre o conjunto de dados sem os outliers, foram identificados 5 (cinco) clusters, apresentados na Tabela 7.10, onde DI e DE representam, respectivamente, a média de distância interna e a média de distância externa dos clusters.

Na Tabela 7.11 é apresentado um resumo da tendência dos valores dos atributos dos exemplos que pertencem a cada cluster. É importante lembrar que somente os atributos para os quais a OMS define valores de referência são apresentados nessa tabela. Os símbolos $\nabla, \diamond$ e $\triangle$, são utilizados para 


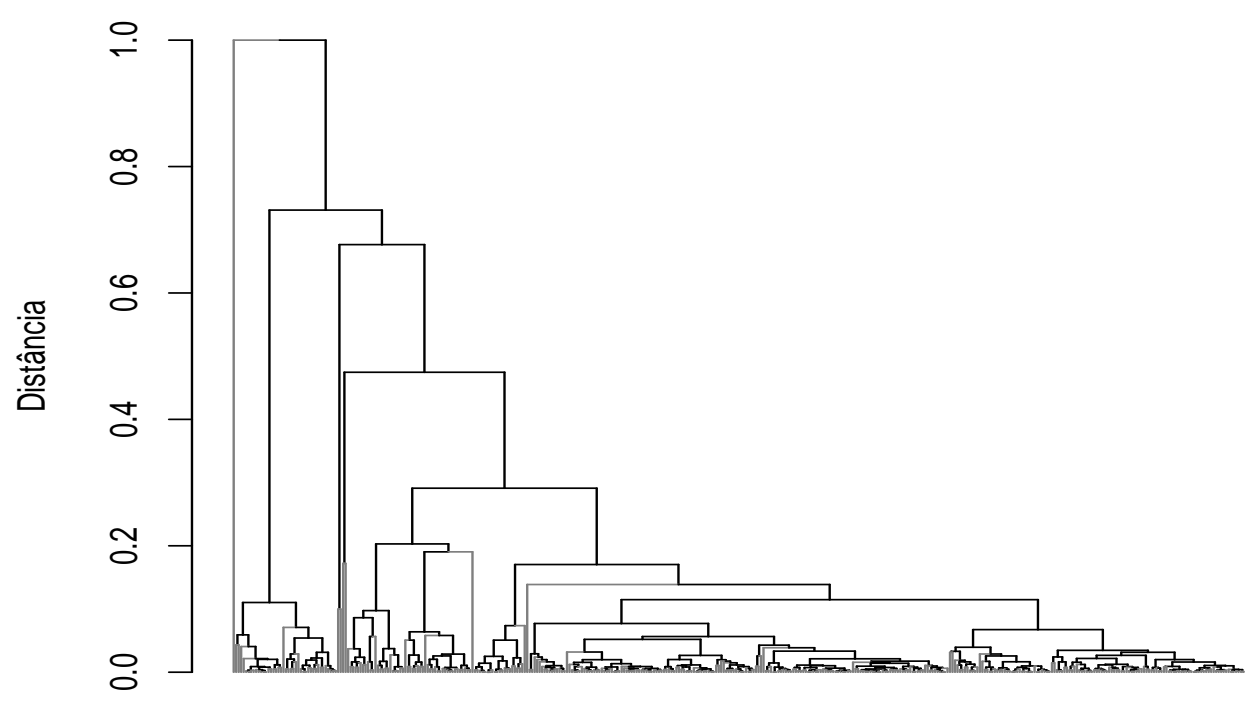

Exemplos

(a) Dendograma sobre o conjunto de dados original.

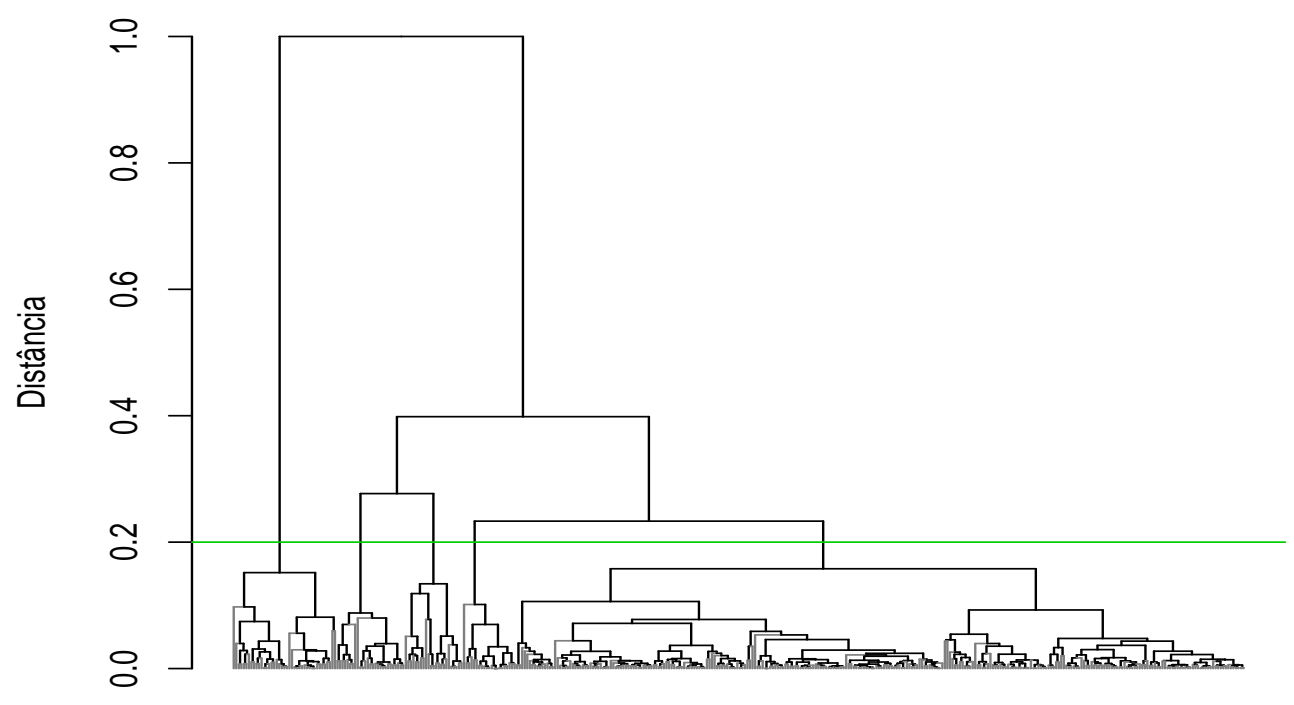

Exemplos

(b) Dendograma sobre o conjunto de dados sem outliers.

Figura 7.1: (a) e (b): Dendogramas obtidos a partir do exp \#3. 


\begin{tabular}{c|c|c|c}
\hline \hline Ident. do Cluster & $\mathrm{N}^{o}$. de Exemplos & $\mathrm{DI}$ & $\mathrm{DE}$ \\
\hline \hline C786 & 27 & 0.09 & 0.27 \\
C789 & 21 & 0.12 & 0.22 \\
C792 & 23 & 0.08 & 0.27 \\
C793 & 41 & 0.16 & 0.27 \\
C794 & 288 & 0.10 & 0.19 \\
\hline \hline
\end{tabular}

Tabela 7.10: Experimento 3: clusters encontrados.

indicar a variação média dos atributos com relação aos valores de referência da OMS apresentados na Tabela 7.8. Para os clusters nos quais os atributos apresentam valores variando entre as diferentes faixas de referência, o símbolo ? (interrogação) é utilizado. Os atributos para os quais a OMS não define os valores de referência são apresentados na Tabela 7.12, nesse caso com o valor médio e desvio padrão em cada cluster.

\begin{tabular}{|c|c|c|c|c|c|c|c|c|c|c|c|}
\hline \multirow{2}{*}{ Clusters } & \multicolumn{11}{|c|}{ Atributos } \\
\hline & $\# 1$ & $\# 2$ & $\# 3$ & $\# 4$ & $\# 5$ & $\# 6$ & $\# 11$ & $\# 12$ & $\# 13$ & $\# 14$ & $\# 16$ \\
\hline C786 & $\diamond$ & $\triangle$ & $\diamond$ & $\diamond$ & $?$ & $?$ & $\nabla$ & $\nabla$ & $\nabla$ & $\diamond$ & $\nabla$ \\
\hline C789 & $\diamond$ & $\triangle$ & $\diamond$ & $\diamond$ & $?$ & $?$ & $\diamond$ & $\nabla$ & $\diamond$ & $\diamond$ & $\nabla$ \\
\hline C792 & $\diamond$ & $\triangle$ & $\diamond$ & $\diamond$ & $?$ & $?$ & $\nabla$ & $\nabla$ & $\bar{\nabla}$ & $\diamond$ & $\nabla$ \\
\hline C793 & $\diamond$ & $\triangle$ & $\diamond$ & $?$ & $?$ & $?$ & $\nabla$ & $\nabla$ & $\nabla$ & $\diamond$ & $\nabla$ \\
\hline C794 & $\diamond$ & $\triangle$ & $?$ & $\diamond$ & $?$ & $?$ & $\nabla$ & $\diamond$ & $\diamond$ & $\diamond$ & $\nabla$ \\
\hline
\end{tabular}

Tabela 7.11: Experimento 3: comparação entre os clusters.

\begin{tabular}{l|cccccc}
\hline \hline \multirow{2}{*}{ Clusters } & \multicolumn{6}{|c}{ Atributos } \\
\cline { 2 - 7 } & $\# 0$ & $\# 7$ & $\# 8$ & $\# 9$ & $\# 10$ & $\# 15$ \\
\hline \hline C786 & $36.65(6.65)$ & $1.41(3.25)$ & $39.70(5.13)$ & $9.41(3.26)$ & $49.48(4.37)$ & $1.49(1.74)$ \\
\hline C789 & $36.48(5.32)$ & $0.95(2.06)$ & $44.71(7.29)$ & $28.00(5.07)$ & $25.38(4.12)$ & $0.64(0.65)$ \\
\hline C792 & $36.22(5.64)$ & $0.35(1.67)$ & $26.96(8.89)$ & $27.30(6.82)$ & $45.39(6.60)$ & $0.74(0.81)$ \\
\hline C793 & $34.98(5.67)$ & $0.00(0.00)$ & $14.29(9.33)$ & $9.20(5.89)$ & $76.78(12.63)$ & $1.11(1.72)$ \\
\hline C794 & $35.52(5.80)$ & $2.23(4.56)$ & $55.78(8.48)$ & $12.67(4.93)$ & $29.30(6.61)$ & $1.22(1.14)$ \\
\hline \hline
\end{tabular}

Tabela 7.12: Experimento 3: comparação entre os clusters utilizando atributos cujos valores de referência não são definidos pela OMS.

Como mencionado, as tarefas de mineração de dados fazem uso de diversas ferramentas gráficas para a interpretação dos resultados ou mesmo para análise e apresentação dos dados. Entretanto, a representação de dados de alta dimensionalidade em um espaço bidimensional não é uma tarefa simples, e muitas vezes pode haver a perda de informação relevante quando os dados são projetados em um sistema de menor dimensão que a dimensão original dos dados. Por outro lado, a apresentação gráfica dos dados pode ser bastante útil se forem simples o suficiente para que pesquisados possam interpretá-los. O gráfico de coordenadas paralelas é um dos métodos de visualização comumente utilizados em tarefas de análise de dados. Esse gráfico é construído a partir de barras paralelas eqüidistantes que representam cada atributo da base de dados, nas quais os valores mínimos e máximos dos atributos são representados pelas extremidades das barras. Assim, os exemplos são representados por linhas que cruzam 
todas as barras no ponto respectivo ao valor do atributo correspondente à barra. As linhas podem ainda ser coloridas para indicar a classe dos exemplos supervisionados. Neste trabalho, as linhas coloridas com a mesma cor representam os exemplos presentes em um mesmo cluster. Um exemplo desse gráfico de coordenadas paralelas, construído utilizando as facilidades do ambiente R (Voltolini, 2005), é apresentado na Figura 7.2.

Sobreposição das curvas: C685 e C686

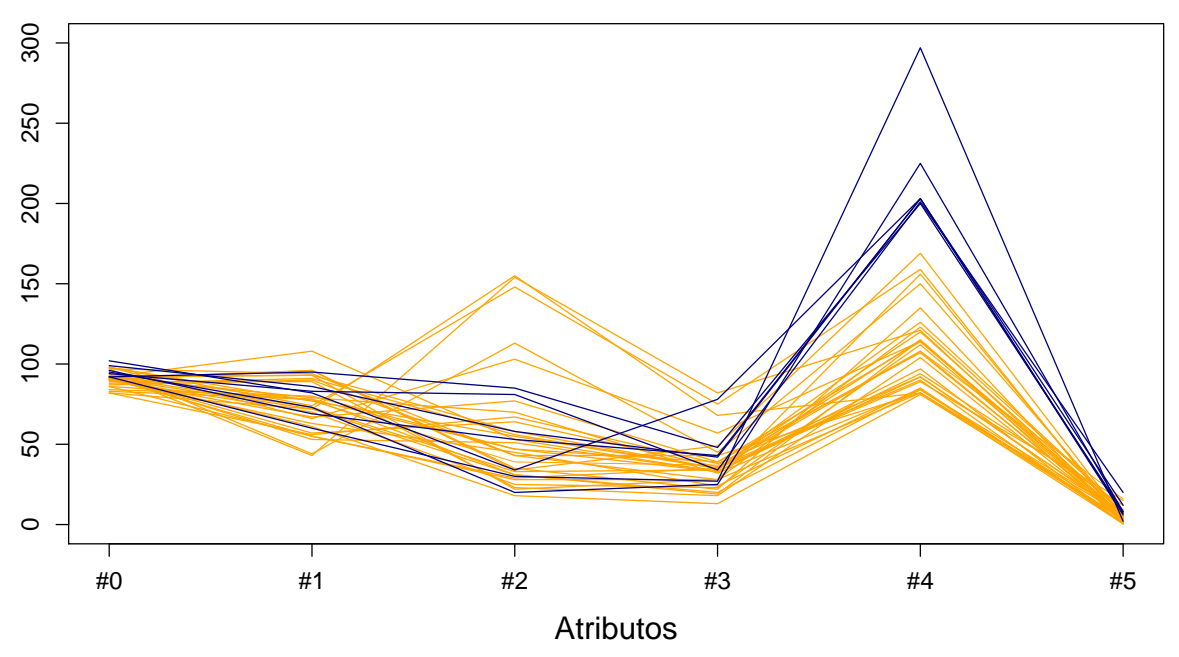

$-\mathrm{C} 685-\mathrm{c} 686$

Figura 7.2: Exemplo de um gráfico de coordenadas paralelas sobre um conjunto de dados com 5 atributos.

Outra característica interessante dessa representação gráfica é a possibilidade de sobrepor diversas curvas em um mesmo gráfico. Essa característica auxilia o pesquisador ao confrontar curvas geradas a partir de diferentes clusters. A sobreposição das curvas geradas sobre os clusters C786, C789, C792, C793 e C794 é apresentada na Figuras 7.3(a). Para facilitar a visualização, os atributos \#5 e \#6 foram retirados do conjunto de dados apenas para a confecção de outros gráficos de coordenadas paralelas. Esses dois atributos foram retirados para que a escala do eixo vertical pudesse ser reduzida e, assim, facilitar a análise do comportamento das curvas. Os gráficos construídos sem os atributos \#5 e \#6 são apresentados na Figura 7.3(b).

Com base na metodologia proposta, a partir desses clusters um novo conjunto de dados rotulados foi criado, no qual o atributo classe corresponde ao cluster ao qual o exemplo pertence. Esse novo conjunto de dados foi utilizado para a construção das regras por meio do indutor simbólico 

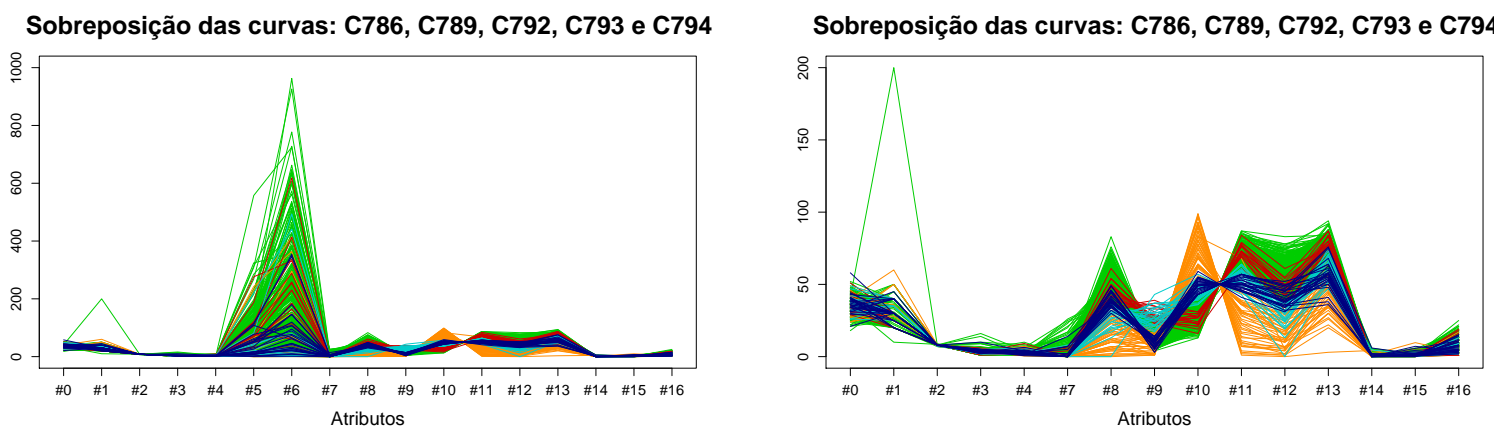

(a) Sobreposição das curvas considerando to- (b) Sobreposição das curvas sem considerar dos os atributos dos exemplos. os atributos \#5 e \#6.

$\longrightarrow \mathrm{C} 794-\mathrm{C} 793-\mathrm{C} 789-792-\mathrm{C} 786$

Figura 7.3: Representação dos clusters do experimento \#3 por meio de coordenadas paralelas.

C4.5rules. O erro médio do classificador obtido, a partir da execução da validação cruzada com 10 partições, sobre esse novo conjunto de dados supervisionado foi de 4.00 com desvio padrão de 2.28 - Tabela 7.9.

Algumas das regras mais informativas induzidas pelo $\mathcal{C} 4.5$ rules, para esse novo conjunto de dados, são apresentadas a seguir.

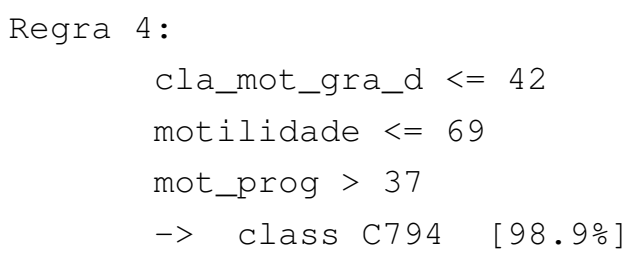

Como pode ser observado pela regra 4 , três atributos foram utilizados para a construção do cluster 794. Utilizando as informações das Tabelas 7.11 e 7.12 , percebe-se que os exemplos presentes nesse cluster apresentam valores de motilidade e motilidade progressiva próximos da normalidade. De maneira análoga, a partir da análise da regra 5, observa-se que 
apenas 2 atributos foram necessários para definir o cluster C789. Essa regra indica que os exemplos presentes nesse cluster, apesar de apresentarem valores relativamente altos para o atributo \#9 - grau de motilidade C (não progressiva) - , apresentam valores próximos do valor de referência para normalidade do atributo \#11 - motilidade.

Segundo a regra 6, o atributo \#10 - grau de motilidade D (imóveis) dos exemplos presentes no cluster C786, apresenta valores no intervalo $(42,59]$. Conseqüentemente, os valores dos atributos motilidade e motilidade_progressiva diminuem, fazendo com que os exemplos desse cluster estejam fora dos padrões de normalidade definidos para esses atributos, \#11 e \#12 respectivamente. Nesse sentido, o especialista acredita que o cluster C786 representa um agrupamento de pacientes (exemplos) com algum tipo de disfunção, a qual deve ser melhor investigada com intuito de identificar a causa da diminuição da motilidade para esses pacientes.

Com a análise da regra 10, observa-se que apenas o atributo \# 10 foi responsável pela definição do cluster C793. Entretanto, segundo a avaliação do especialista, somente por meio dessa regra não é possível atribuir uma interpretação ao cluster. Por outro lado, com o auxílio das Tabelas 7.11 e 7.12 , usando outros atributos ou correlacionando-os, seria possivel identificar conceito descrito pelo cluster, caso esse conceito exista.

A partir do conjunto de regra induzidas, observou-se que apenas um sub-conjunto dos atributos foi realmente importante para a construção dos clusters. Somente os atributos relacionados à movimentação dos espermatozóides (\#7, \#8, \#9, \#10, \#11 e \#12) e o atributo \#3 foram utilizados. Segundo o especialista, esses atributos possibilitariam identificar as formas de tratamento indicadas para os pacientes agrupados em cada cluster. Na Tabela 7.13 são apresentadas as possíveis indicações de tratamento para pacientes em cada cluster, mas esses resultados necessitariam ser melhor investigados.

\begin{tabular}{c|l}
\hline \hline Clusters & Tratamento \\
\hline \hline C786 & ICSI e/ou FIV \\
\hline C789 & IUI \\
\hline C792 & ICSI e/ou FIV \\
\hline C793 & ICSI e/ou FIV \\
\hline C794 & ICSI e/ou FIV \\
\hline \hline
\end{tabular}

Tabela 7.13: Tratamento indicado.

\subsubsection{Experimento \#4}

Esse experimento foi executado utilizando o algoritmo Average Link e correlação de Spearman como medida para o cálculo da distância entre 
exemplos e clusters. Os outliers identificados nesse experimentos são os exemplos: 14, 57, 64, 66, 69, 91, 102, 169, 187, 227, 304, 343 e 372. Na Figura 7.4 são apresentados os dendogramas obtidos com o conjunto de dados completo (a) e após retirar os outliers (b). Assim como no experimento anterior, a hierarquia de clusters construída sem os outliers para esse experimento, apresenta melhores resultados. A partir do corte feito na altura igual a 0.7 no dendograma construído sobre o conjunto de dados sem os outliers - Figura 7.4(b) - , foram identificados 2 (dois) clusters, apresentados na Tabela 7.14, onde DI e DE representam, respectivamente, a média de distância interna e a média de distância externa dos clusters.

\begin{tabular}{c|c|c|c}
\hline \hline Ident. do Cluster & $\mathrm{N}^{o}$. de Exemplos & $\mathrm{DI}$ & $\mathrm{DE}$ \\
\hline \hline C781 & 270 & 0.19 & 0.31 \\
C785 & 124 & 0.19 & 0.31 \\
\hline \hline
\end{tabular}

Tabela 7.14: Experimento 4: clusters encontrados.

Na Tabela 7.15 é apresentado um resumo da tendência dos valores dos atributos dos exemplos que pertencem a cada cluster. Assim como no experimento anterior, somente os atributos para os quais a OMS define valores de referência são apresentados nessa tabela; os símbolos $\nabla$, $\diamond$ e $\triangle$, são utilizados para indicar a variação média dos atributos com relação aos valores de referência definidos pela OMS. Para os clusters nos quais os atributos apresentam valores variando entre as diferentes faixas de referência, o símbolo ? (interrogação) é utilizado. Os atributos para os quais a OMS não define os valores de referência são apresentados na Tabela 7.16, nesse caso com o valor médio e desvio padrão em cada cluster.

\begin{tabular}{l|ccccccccccc}
\hline \hline Clusters & \multicolumn{11}{c}{ Atributos } \\
& \#1 & $\# 2$ & $\# 3$ & $\# 4$ & $\# 5$ & \#6 & \#11 & \#12 & \#13 & \#14 & \#16 \\
\hline \hline C781 & $\diamond$ & $\triangle$ & $\diamond$ & $\diamond$ & $\triangle$ & $\triangle$ & $\nabla$ & $?$ & $?$ & $\diamond$ & $?$ \\
\hline C785 & $\diamond$ & $\triangle$ & $?$ & $\diamond$ & $\nabla$ & $\nabla$ & $\nabla$ & $\nabla$ & $\nabla$ & $\diamond$ & $\nabla$ \\
\hline \hline
\end{tabular}

Tabela 7.15: Experimento 4: comparação entre os clusters.

\begin{tabular}{l|cccccc}
\hline \hline \multirow{2}{*}{ Clusters } & \multicolumn{5}{|c}{ Atributos } \\
\cline { 2 - 7 } & $\# 0$ & $\# 7$ & $\# 8$ & $\# 9$ & $\# 10$ & $\# 15$ \\
\hline \hline C785 & $35.24(5.83)$ & $0.31(1.14)$ & $41.28(18.86)$ & $14.48(7.79)$ & $43.85(19.26)$ & $1.07(1.78)$ \\
\hline C786 & $35.92(5.37)$ & $2.28(4.53)$ & $52.93(10.73)$ & $13.77(7.08)$ & $30.89(9.26)$ & $1.33(1.61)$ \\
\hline \hline
\end{tabular}

Tabela 7.16: Experimento 4: comparação entre os clusters utilizando atributos cujos valores de referência não são definidos pela OMS.

A sobreposição das curvas geradas sobre os clusters C785 e C786 é apresentada na Figuras 7.5(a). Da mesma maneira que no experimento anterior, os atributos \#5 e \#6 foram retirados do conjunto de dados para a confecção de outros gráficos de coordenadas paralelas para facilitar a 


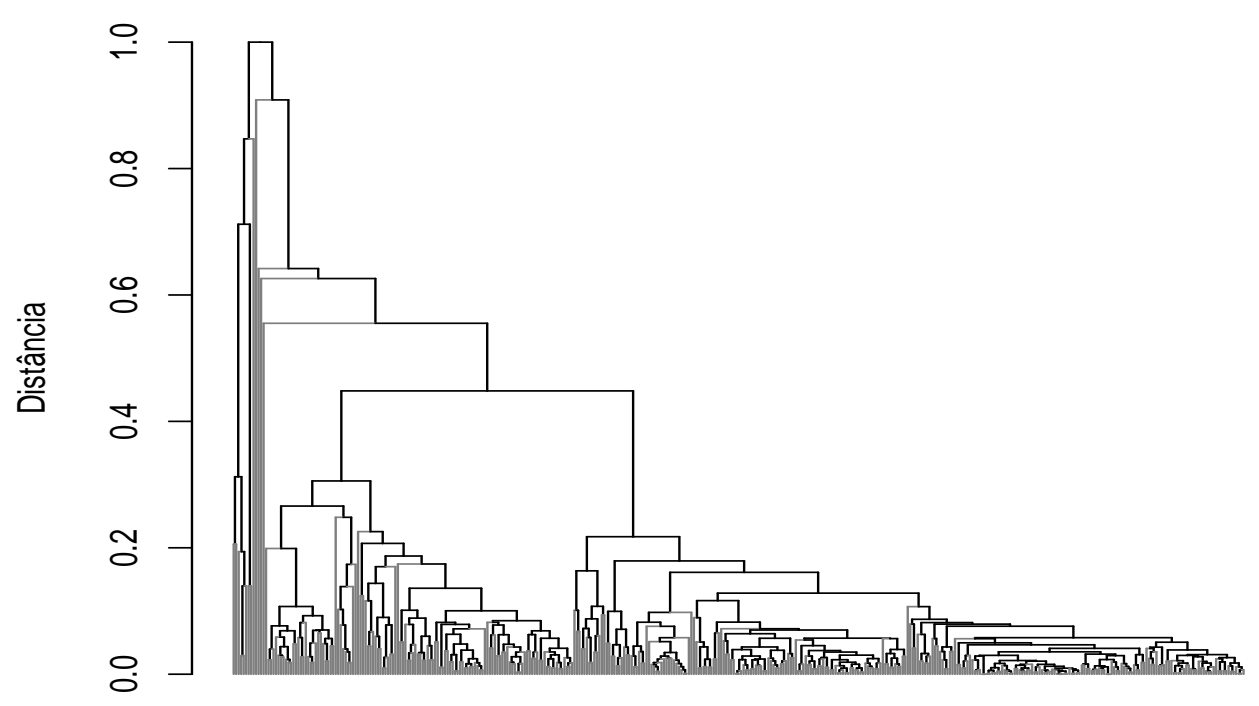

Exemplos

(a) Dendograma sobre o conjunto de dados original.

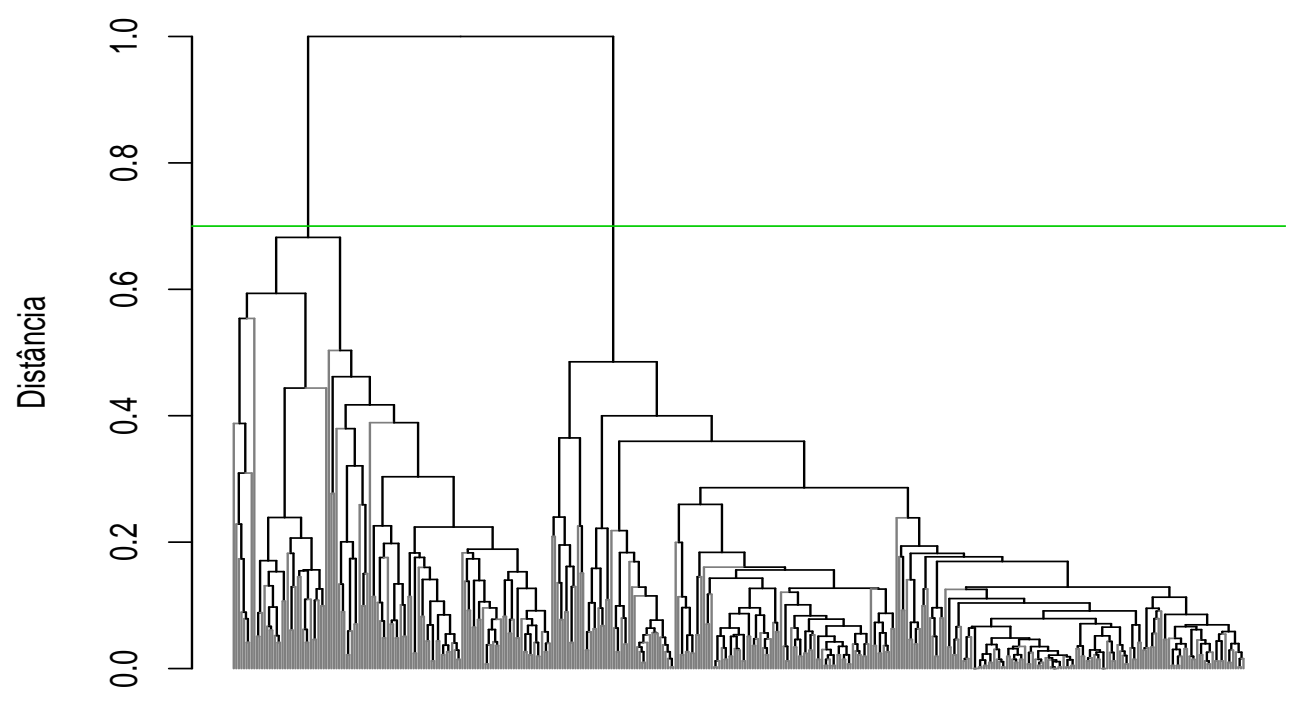

Exemplos

(b) Dendograma sobre o conjunto de dados sem outliers.

Figura 7.4: (a) e (b): Dendogramas obtidos a partir do exp \#4. 
visualização das curvas. Os gráficos construídos sem os atributos \#5 e \#6 são apresentados na Figura 7.5(b).
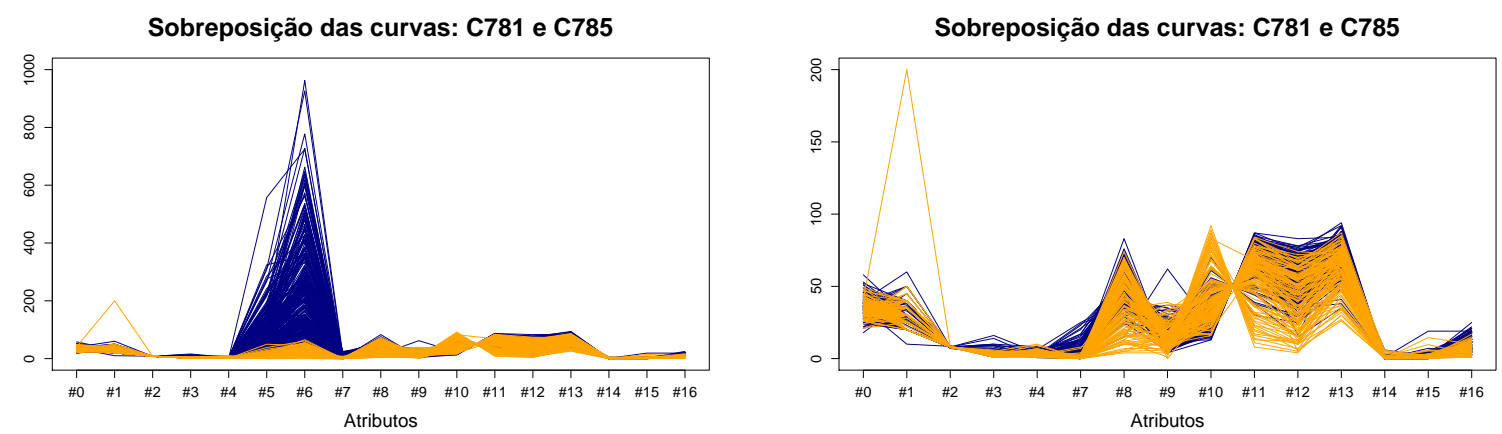

(a) Sobreposição das curvas considerando to- (b) Sobreposição das curvas sem considerar dos os atributos dos exemplos. os atributos \#5 e \#6.

Figura 7.5: Representação dos clusters do experimento \#4 por meio de coordenadas paralelas.

Para facilitar a interpretação dos clusters, utilizou-se o novo conjunto de dados rotulado com os clusters correspondentes para induzir um classificador simbólico por meio do $\mathcal{C} 4.5$ rules para a construção de regras de decisão. O erro médio do classificador obtido, a partir da execução da validação cruzada com 10 partições, sobre esse novo conjunto de dados supervisionado foi de 3.81 com desvio padrão de 3.20 - Tabela 7.9.

A partir das regras e das outras informações gráficas dos clusters, o especialista fez uma análise dos clusters para a possível identificação dos padrões por eles representados. Segundo opinião do especialista, o cluster C785 parece agrupar pacientes com problemas de infertilidade para os quais, os tratamentos indicados são possivelmente ICSI e/ou FIV. No caso do cluster C786, por outro lado, a técnica IUI seria mais indicada.

\subsection{Considerações Finais}

O processo de descoberta de conhecimento por meio da técnica de clustering e a metodologia proposta para a interpretação de clusters com auxílio 
do especialista mostrou-se altamente trabalhoso e complexo. A metodologia utilizada para interpretação dos clusters identificados pelo algoritmo de clustering hierárquico, mostrou-se viável, mas não satisfatória. Segundo a opinião do especialista, os modelos gerados são muito trabalhosos para analisar e não dispõem de algumas informações importantes para o especialista, como o relacionamento entre valores de atributos. Além disso, o especialista acredita que os parâmetros, como a medida de distância e o algoritmo utilizado, realmente influenciam no poder de descrição conceitual dos clusters.

Com a realização deste estudo de caso, foi possível identificar diversas melhorias a serem realizadas. Algumas das sugestões feitas pelo especialista são: melhorar a forma de apresentação dos exemplos contidos em cada cluster; dispor de uma análise estatística da distribuição dos atributos em cada cluster, tanto isoladamente quanto combinados; identificar melhor o grau de participação e importância dos atributos em cada cluster. Outra melhoria sugerida, é a implementação de uma medida de avaliação de clusters individuais e não somente de todo o dendograma gerado.

A interação e participação do especialista neste estudo de caso, utilizando uma base de dados real, foi de extrema importância. Como o especialista não é, necessariamente, da área de computação, observamos a necessidade do desenvolvimento de uma interface gráfica interativa e bastante completa, que permita ao especialista interagir confortavelmente com o sistema para analisar os dados e a hierarquia de clusters, e, com isso, testar diferentes níveis de corte nessa hierarquia para construir as regras por meio do classificador simbólico. Consideramos muito importante o futuro desenvolvimento desse ambiente gráfico para que a participação do especialista possa ser melhor aproveitada. 


\section{Conclusões}

Neste trabalho apresentamos o projeto e a implementação de um módulo de aprendizado não-supervisionado baseado na abordagem de clustering hierárquico, integrado ao ambiente computacional DISCOvER, o qual está em desenvolvimento no nosso laboratório de pesquisa e é composto por diversas ferramentas de pré-processamento de dados, extração de padrões e pós-processamento de conhecimento. No desenvolvimento desse novo módulo do Discover, foram utilizadas diversas facilidades implementadas no ambiente computacional DLE - Discover LEARNING ENVIRONMENT, que proporcionaram uma grande flexibilidade para a execução de experimentos e para a análise dos resultados.

Esse trabalho foi motivado, entre outros fatores, pela possibilidade de simplificar a etapa de interpretação de clusters, e, em conseqüência, auxiliar o especialista de domínio nessa tarefa por meio da aplicação de uma metodologia de interpretação de clusters obtidos a partir da execução de algoritmos de clustering hierárquico. O fato de existirem diversas ferramentas de aprendizado de máquina implementadas no Discover, simplificou a utilização dessa metodologia para a avaliação e interpretação dos clusters, pois todas essas ferramentas compartilham uma mesma sintaxe padrão para a descrição de dados e de conhecimento, e fazem parte de um ambiente único com suporte às tarefas envolvidas no processo de mineração de dados. Entretanto, para viabilizar essa metodologia, é necessário que os resultados obtidos pelos algoritmos de clustering disponiveis nesse módulo compartilhem uma mesma forma de representação. Mas, não há uma sintaxe simples e eficiente para representar os agrupamentos encontrados pelos algoritmos que utilizam diferentes abordagens de clustering. Porém, é possível determinar um padrão para os algoritmos de uma mesma abordagem, por exemplo os algoritmos hierárquicos, que utilizam uma mesma representação da hierarquia de agrupamento, o dendograma. Assim, neste 
trabalho definimos uma sintaxe para a descrição de clusters de modo que as saídas de diferentes algoritmos de clustering hierárquico representem de maneira coerente e padronizada as informações necessárias para a interpretação dos cluster encontrados.

Também, realizamos diversos experimentos com conjuntos de dados naturais, obtidos do repositório de dados da University of California at Irvine (UCI). Esses experimentos foram realizados para ilustrar a utilização da metodologia de interpretação de clusters proposta e verificar a qualidade dos dendogramas construídos pelos algoritmos disponíveis no módulo implementado. Para isso, a etapa de avaliação e validação do clustering foi realizada. Para a execução das tarefas dessa etapa, os índices de validação do clustering podem ser aplicados, em geral, utilizando três critérios: relativos, internos e externos. No módulo de clustering apresentado neste trabalho, implementamos um índice de validação interno, chamado de coeficiente de correlação cophenético. Esse índice é freqüentemente utilizado e recomendado para validar a estrutura encontrada por algoritmos de clustering hierárquico, confrontando as distâncias cophenéticas obtidas a partir do dendograma com a matriz de distâncias do conjunto de dados original.

Nos experimentos realizados, os dendogramas foram inicialmente avaliados considerando o valor do coeficiente de correlação cophenético. Entretanto, a partir de uma análise mais detalhada dos dendogramas, constatamos que esse índice nem sempre é uma boa medida de avaliação da qualidade do clustering hierárquico, pois há uma alta variância dependente do algoritmo e medida de similaridade utilizada. Além disso, observamos que, para alguns casos, ainda que o valor desse coeficiente esteja muito abaixo do que a literatura referencia como valor ideal, foi possível identificar alguma estrutura "provavelmente boa" na hierarquia de agrupamentos. Por outro lado, em alguns experimentos que apresentaram um bom valor para o coeficiente de correlação cophenético, a hierarquia desses clusters não apresentou uma boa estrutura. Assim, acreditamos que esse coeficiente não tem sempre a capacidade de refletir a qualidade da hierarquia dos clusters encontrados pelos diferentes algoritmos de clustering hierárquico, e não pode ser utilizado para guiar a escolha dos melhores dendogramas. Na nossa opinião, essa escolha deve ser baseada na análise dos dendogramas, os quais fornecem um conjunto de informação muito rico.

Com objetivo de verificar a adequabilidade da metodologia proposta para interpretação do clusters, realizamos um estudo de caso utilizando um conjunto de dados real, que trata do problema da infertilidade masculina. Esse estudo de caso teve a participação e colaboração de um especialista do domínio. A partir das sugestões e críticas do especialista, foi possível enu- 
merar diversas melhorias que devem ser feitas no módulo implementado. Essas sugestões visam facilitar a interação do especialista com o sistema de modo que sua participação possa ser melhor aproveitada em todo o processo de análise da hierarquia dos clusters. Uma vez que o especialista não é necessariamente da área da computação, é necessário que uma interface gráfica amigável, interativa e bastante completa seja implementada para o sistema, e, assim, permitir que o usuário interaja confortavelmente com todas as funcionalidades disponíveis.

Com esse trabalho, de natureza inter-disciplinar, verificou-se a viabilidade da metodologia proposta. O processo de mineração de dados, por meio da técnica de clustering e a metodologia proposta, mostrou-se bastante trabalhoso e complexo. Portanto, ainda que com o comprometimento do especialista de domínio e do especialista da computação seja possível a aplicação dessa metodologia, ela não se mostrou inteiramente satisfatória. Mas, acreditamos que atendendo às solicitações feitas pelo especialista do domínio, será possível facilitar a aplicação da metodologia em casos reais para a interpretação de clusters e para a descoberta de conhecimento.

É importante lembrar que em nosso grupo de pesquisa não tinha sido explorado ainda o tema de clustering hierárquico. Desse modo, consideramos que este trabalho traz uma contribuição importante, no sentido de que servir como base para futuros trabalhos relacionado ao clustering hierárquico, e, também, como referência para análise de dados não-supervisionados.

São vários os trabalhos futuros decorrentes deste trabalho, entre eles podemos citar:

- pesquisa e implementação de outros métodos de validação do clustering e agregação de vários índices estatísticos que possam ser utilizados nessa tarefa, não só para a validação do dendograma como um todo, mas, também, para a validação individual dos clusters. Além disso, a seleção de atributos relevantes pode ser utilizada para diminuir o conjunto de atributos dos exemplos selecionando apenas os atributos que melhor descrevem os exemplos. A avaliação dessa seleção de atributos pode ser realizada observando se há melhorias nos dendogramas construídos.

- estudo das diversas possibilidades para a melhoria da metodologia proposta, além de implementar as sugestões feitas pelo especialista do domínio para simplificar o processo de análise de clusters, e, conseqüentemente, facilitar o trabalho do especialista na interpretação dos clusters.

- aplicação das técnicas de clustering hierárquico para realizar aprendi- 
zado construtivo. Em outras palavras, para a construção de atributos em função de atributos primitivos que descrevem os exemplos, por meio de um processo semi-automático com auxílio de um especialista. Nesse processo, o especialista ajudaria a selecionar um sub-conjunto de atributos que ele considera que podem estar relacionados, e, então, esses atributos seriam utilizados como entrada de um algoritmo de clustering para verificar, aplicando a metodologia proposta para interpretar clusters, se essa relação existe e qual a possível relação entre os valores desses atributos. Após essa verificação, o sub-conjunto de atributos pode ser substituído pelo valor dessa relação, reduzindo assim a dimensão do espaço de descrição de exemplos e, eventualmente, melhorando a hierarquia de clusters do conjunto de dados. 


\section{Referências Bibliográficas}

Aggarwal, C. C., Hinneburg, A., \& Keim, D. A. (2001). On the surprising behavior of distance metrics in high dimensional spaces. In ICDT '01: Proceedings of the 8th International Conference on Database Theory, pages 420-434. Springer-Verlag. Citado na página 32.

Agrawal, R., Gehrke, J., Gunopulos, D., \& Raghavan, P. (1998). Automatic subspace clustering of high dimensional data for data mining applications. In SIGMOD '98: Proceedings of the 1998 ACM SIGMOD international conference on Management of data, pages 94-105. ACM Press. Citado na página 21.

Alpaydin, E. (2004). Introduction to Machine Learning. MIT Press. Citado nas páginas 10 e 12 .

Ankerst, M., Breunig, M. M., Kriegel, H.-P., \& Sander, J. (1999). OPTICS: Ordering points to identify the clustering structure. In Delis, A., Faloutsos, C., \& Ghandeharizadeh, S., editors, Sigmod 1999, proceedings ACM Sigmod International Conference on Management of Data, june 1-3, 1999, Philadephia, Pennsylvania, USA, pages 49-60. ACM Press. Citado nas páginas 21 e 25.

Baranauskas, J. A. \& Batista, G. E. A. P. A. (2000). O projeto Discover: idéias iniciais. Comunicação pessoal. Citado nas páginas 5 e 65 .

Batista, G. E. A. P. A. \& Monard, M. C. (2003). Descrição da arquitetura e do projeto do ambiente computacional DISCOVER LEARNING ENVIRONMENT DLE. Relatório Técnico 187, ICMC-USP. ftp://ftp.icmc.sc.usp.br/ pub/BIBLIOTECA/rel_tec/RT_187.pdf. Citado nas páginas 5, 65, 67, e 88 .

Batista, G. E. A. P. A. \& Monard, M. C. (2006). The Discover ObJect LIBRARY - DOL user's manual. Relatório técnico, ICMC-USP. (em preparação). Citado na página 66.

Batista, G. E. A. P. A., Prati, R. C., \& Monard, M. C. (2004). A study of the behavior of several methods for balancing machine learning training data. SIGKDD Explorations, 6(1):20-29. Citado nas páginas 80 e 101.

Batista, G. E. A. P. A., Prati, R. C., \& Monard, M. C. (2005). Balancing strategies and class overlapping. In International Symposium on Intelligent Data Analysis (IDA'2005), volume 3646 of Lecture Notes in Computer Science, pages 24-35, Madrid (Spain). Springer. Citado nas páginas 80 e 101. 
Bendhack, D. A. \& Damião, R., editors (1999). Guia Prático de Urologia. BG Editora e Produções Culturais, rio de Janeiro, 1 edition. http://www. sbu-mg.org.br/Guia_pratico.htm. Citado nas páginas 96, 98, e 126.

Bentley, J. L. (1975). Multidimensional binary search trees used for associative searching. Commun. ACM, 18(9):509-517. Citado na página 51.

Berkhin, P. (2002). Survey of clustering data mining techniques. Relatório técnico, Accrue Software, San Jose, CA. http://citeseer.nj.nec.com/ berkhin02survey.html. Citado na página 20.

Berry, M. J. A. \& Linoff, G. S. (2002). Mastering data mining. John Wiley \& Sons. Citado na página 20.

Bhatia, S. \& Deogun, J. (1998). Conceptual clustering in information retrieval. IEEE Transactions on Systems, Man, and Cybernetics, Part B: Cybernetics, 28(3):427-436. http://citeseer.ist.psu.edu/ bhatia98conceptual.html. Citado na página 23.

Blake, C. \& Merz, C. (1998). UCI repository of machine learning databases. http://www.ics.uci.edu/ mlearn/MLRepository.html. Citado na página 77 .

Blum, A. \& Mitchell, T. (1998). Combining labeled and unlabeled data with co-training. In Proceendings of 11th Annual Conference on Computational Learning Theory (COLT 98), pages 92-100. ACM Press. Citado na página 11.

Cheeseman, P. \& Stutz, J. (1996). Bayesian classification (autoclass): theory and results. In Fayyad, U. M., Piatetsky-Shapiro, G., Smyth, P., \& Uthurusamy, R., editors, Advances in Knowledge Discovery and Data Mining., pages 153-180. American Association for Artificial Intelligence, Menlo Park, CA, USA. Citado na página 21.

Clark, P. \& Niblett, T. (1989). The CN2 induction algorithm. Machine Learning, 3(4):261-283. Citado na página 73.

Demsar, J. \& Zupan, B. (2004). Orange: From experimental machine learning to interactive data mining. White paper, http://www.ailab.si/ orange/doc. Citado nas páginas 3 e 61.

Duda, R. O., Hart, P. E., \& Stork, D. G. (2000). Pattern Classification. Wiley Inter-Science, New York, 2 edition. Citado nas páginas 23 e 53.

Ernst, G. \& Newell, A. (1969). GPS: A Case Study in Generality and Problem Solving. Academy Press, New York. Citado na página 9.

Ester, M., Kriegel, H.-P., Sander, J., \& Xu, X. (1996). A density-based algorithm for discovering clusters in large spatial databases with noise. In Simoudis, E., Han, J., \& Fayyad, U., editors, Second International Conference on Knowledge Discovery and Data Mining, pages 226231, Portland, Oregon. American Association for Artificial Intelligence. http://citeseer.ist.psu.edu/chu02incremental.html. Citado na página 21 . 
Esteves, S. C. (2005). Infertilidade masculina. http://www . androfert. com.br/masculina.asp. Citado na página 96.

Everitt, B. S. (1993). Cluster Analysis. Edward Arnold, 3 edition. Citado nas páginas 19, 29, 38, e 47.

Fisher, D. \& Langley, P. (1986). Conceptual clustering and its relation to numerical taxonomy. In Artificial intelligence and statistics, pages 77-116. Addison-Wesley, Boston, MA, USA. Citado na página 22.

Guha, S., Rastogi, R., \& Shim, K. (1998). CURE: an efficient clustering algorithm for large databases. In ACM Sigmod International Conference on Management of Data, pages 73-84. http://citeseer.nj.nec.com/ article/guha98cure.html. Citado nas páginas 43, 55, e 57.

Guha, S., Rastogi, R., \& Shim, K. (2000). ROCK: A robust clustering algorithm for categorical attributes. Information Systems, 25(5):345-366. http://citeseer.nj.nec.com/guhaoorock.html. Citado nas páginas 43,55 , e 59 .

Guttman, A. (1984). R-trees: a dynamic index structure for spatial searching. In Sigmod'84: Proceedings of the 1984 ACM Sigmod International Conference on Management of Data, pages 47-57, Boston, Massachusetts. ACM Press. Citado na página 51.

Halkidi, M., Batistakis, Y., \& Vazirgiannis, M. (2002a). Cluster validity methods: Part I. SIGMOD Rec., 31(2):40-45. Citado na página 38.

Halkidi, M., Batistakis, Y., \& Vazirgiannis, M. (2002b). Cluster validity methods: Part II. SIGMOD Rec., 31(3):19-27. Citado na página 38.

Hamerly, G. \& Elkan, C. (2002). Alternatives to the k-means algorithm that find better clusterings. In CIKM '02: Proceedings of the eleventh international conference on Information and knowledge management, pages 600-607, New York, NY, USA. ACM Press. Citado na página 20.

Haykin, S. (1999). Neural Networks: A Comprehensive Foundation. Prentice Hall. Citado na página 21.

Herrero, J., Valencia, A., \& Dopazo, J. (2001). A hierarchical unsupervised growing neural network for clustering gene expression patterns. Bioinformatics, 1(17):126-136. Citado na página 22.

Hinneburg, A. \& Keim, D. A. (1998). An efficient approach to clustering in large multimedia databases with noise. In Knowledge Discovery and Data Mining, pages 58-65. http:// citeseer.ist.psu.edu/ hinneburg98efficient.html. Citado na página 21.

Hinneburg, A. \& Keim, D. A. (1999). Optimal grid-clustering: Towards breaking the curse of dimensionality in high-dimensional clustering. In The VLDB Journal, pages 506-517. http://citeseer.ist.psu.edu/ hinneburg99optimal.html. Citado na página 21. 
Honorato, D. D. F., Lee, H. D., monard, M. C., Wu, F. C., Machado, R. B., Neto, A. P., \& Ferrero, C. A. (2005). Uma metodologia para auxiliar no processo de construção de bases de dados. In Anais do V Encontro Nacional de Inteligência, XXV Congresso da Sociedade Brasileira de Computação, pages 593-601, Porto Alegre, RS. http://www.unisinos.br/_diversos/ congresso/sbc2005/_dados/anais/pdf/arq0239.pdf. Citado na página 95.

Hoon, M. J. L., Imoto, S., \& Miyano, S. (2005). The C Clustering Library. The University of Tokyo, Institute of Medical Science, Human Genome Center, Tokyo. http://bonsai.ims.u-tokyo.ac.jp/ mdehoon/software/ cluster. Citado na página 62.

Hoon, M. J. L., Imoto, S., Nolan, J., \& Miyano, S. (2004). Open source clustering software. Bioinformatics, 20(2):1453-1454. Citado na página 62.

IBM (2000). DB2 Intelligent Miner Brochure. IBM inc. http://www-4.ibm . $\mathrm{com} / \mathrm{software/data/iminer/fordata/.} \mathrm{Citado} \mathrm{na} \mathrm{página} 61$.

Jain, A. K. \& Dubes, R. C. (1988). Algorithms for Clustering Data. Prentice Hall. Citado nas páginas 26, 27, 29, 38, e 47.

Jain, A. K., Murty, M. N., \& Flynn, P. J. (1999). Data clustering: a review. ACM Computing Surveys, 31(3):264-323. http://citeseer.nj. nec.com/jain99data.html. Citado nas páginas 20, 27, e 28.

Johnson, S. C. (1967). Hierarchical clustering schemes. Psychometrika, 3(32):241-54. Citado na página 52.

Kanungo, T., Mount, D. M., Netanyahu, N. S., Piatko, C. D., Silverman, R., \& Wu, A. Y. (2002). A local search approximation algorithm for $\mathrm{k}$-means clustering. In SCG '02: Proceedings of the eighteenth annual symposium on Computational geometry, pages 10-18, New York, NY, USA. ACM Press. Citado na página 20.

Karypis, G. (2003). CLUTO: a clustering toolkit. University of Minnesota, Department of Computer Science, Minneapolis. http://www-users.cs . umn.edu/ karypis/cluto/download.html. Citado nas páginas 4, 48, e 61 .

Karypis, G., Han, E.-H. S., \& Kumar, V. (1999). CHAMELEON: Hierarchical clustering using dynamic modeling. Computer, 32(8):68-75. http: //citeseer.nj.nec.com/karypis99chameleon.html. Citado nas páginas 43, 55, e 58 .

Kaufman, L. \& Rousseeuw, P. J. (1990a). Agglometarive nesting (program AGNES), chapter 5, pages 199-252. Volume 1 of Kaufman \& Rousseeuw (1990c), 1 edition. Citado nas páginas 43 e 55.

Kaufman, L. \& Rousseeuw, P. J. (1990b). Divisive analysis (program DIANA), chapter 6, pages 253-279. Volume 1 of Kaufman \& Rousseeuw (1990c), 1 edition. Citado nas páginas 24, 43, 55, e 61 . 
Kaufman, L. \& Rousseeuw, P. J. (1990c). Finding Groups in Data: An introduction to cluster analysis, volume 1 of 1 . Wiley Inter-Science, New York, 1 edition. Citado nas páginas 122 e 123.

Kaufman, L. \& Rousseeuw, P. J. (1990d). Monothetic analysis (program MONA), chapter 7, pages 280-311. Volume 1 of Kaufman \& Rousseeuw (1990c), 1 edition. Citado nas páginas 43 e 55.

Kohonen, T. (1990). Self-organized formation of topologically correct feature maps. In Shavlik, J. W. \& Dietterich, T. G., editors, Readings in Machine Learning, pages 326-336. Morgan Kaufman, San Matheo. Citado na página 21 .

Kohonen, T., Hynninen, J., Kangas, J., \& Laaksonen, J. (1996). Sompak: the selforganizing map program package. Relatório técnico, Helsinki University of Technology, Laboratory of Computer and Information Science, Espoo. Citado na página 22.

Lance, G. \& Willams, W. (1967). A general theory of classification sorting strategies. Computer Journal, 1(9):373-380. Citado na página 55.

Lee, H. D. (2005). Seleção de atributos importantes para a extração de conhecimento de bases de dados. Tese de Doutorado, Departamento de Ciência de Computação. http: //www.teses.usp.br/teses/disponiveis/ 55/55134/tde-22022006-172219/. Citado nas páginas 28, 95, 97, 99, e 100 .

Liu, H. \& Motoda, H. (1998). Feature Selection for Knowledge Discovery and Data Mining. Kluver Academic Press, Boston. Citado na página 28.

Martins, C. A. (2003). Uma Abordagem para Pré-processamento de Dados Textuais em Algoritmos de Aprendizado. Tese de Doutorado, Instituto de Matemática e Computação, Universidade de São Paulo, Brasil. http://www.teses.usp.br/teses/disponiveis/55/55134/ tde-08032004-164855/. Citado nas páginas 7, 15, 40, 41, e 75 .

Matsubara, E. T. (2004). Algoritmo de aprendizado de máquina semisupervisionado co-training e sua aplicação para a rotulação de textos. Dissertação de Mestrado, Instituto de Matemática e Computação, Universidade de São Paulo, Brasil. http://www.teses.usp.br/teses/ disponiveis/55/55134/tde-19082004-092311/. Citado na página 16.

Medeiros, A. S. (1993). Semiologia Urológica. Medesi, Rio de Janeiro, RJ. Citado nas páginas 96 e 97.

Metz, J. \& Monard, M. C. (2005). Clustering hierárquico: uma metodologia para auxiliar na interpretação dos clusters. In Encontro Nacional de Inteligência Artificial — ENIA, São Leopoldo, RS. Citado na página 75.

Metz, J. \& Monard, M. C. (2006a). Estudo e análise das diversas representações e estruturas de dados utilizadas nos algoritmos de clustering hierárquico. Relatório Técnico 269, ICMC-USP. http://www. i cmc . usp. br/ biblio/download/RT_269.pdf. Citado nas páginas 6, 43, 47, e 48. 
Metz, J. \& Monard, M. C. (2006b). Projeto e implementação do módulo de clustering hierárquico do Discover. Relatório Técnico 278, ICMC-USP. Citado nas páginas 39, 71, e 73 .

Michalski, R. S., Bratko, I., \& Kubat, M., editors (1998). Machine Learning and Data Mining: Methods and Applications. John Wiley \& Sons. West Sussex, England. Citado nas páginas 10 e 14.

Michalski, R. S., Carbonell, J. G., \& Mitchell, T. M., editors (1983). Machine Learning: An Artificial Intelligence Approach. Tioga Publishing Company, Palo Alto, CA. Citado na página 11.

Mishra, N., Ron, D., \& Swaminathan, R. (2004). A new conceptual clustering framework. Machine Learning, 56(1-3):115-151. Citado na página 23.

Mitchell, T. M. (1997). Machine Learning. McGraw-Hill Series in Computer Science. Citado na página 9.

Monard, M. C. \& Baranauskas, J. A. (2003). Conceitos sobre aprendizado de máquina, chapter 4, pages 89-114. Volume 1 of Rezende (2003), 1 edition. Citado nas páginas 10 e 13.

Murtagh, F. (1983). A survey of recent advances in hierarchical clustering algorithms. The Computer Journal, 26(40):354-359. Citado na página 24.

Nagesh, H., Goil, S., \& Choudhary, A. (1999). Mafia: Efficient and scalable subspace clustering for very large data sets. Relatório Técnico 9906-010, Northwestern University. Citado na página 21.

Newman, D., Hettich, S., Blake, C., \& Merz, C. (1998). UCI repository of machine learning databases. Citado nas páginas 7 e 77 .

Prati, R. C. (2003). O framework de integração do sistema Discover. Dissertação de Mestrado, Instituto de Matemática e Computação, Universidade de São Paulo, Brasil. http://www.teses.usp.br/teses/ disponiveis/55/55134/tde-20082003-152116/. Citado nas páginas 5 e 65.

Prati, R. C. (2006). Novas Abordagens em Aprendizado de Máquina para a Geração de Regras, Classes Desbalanceadas e Ordenação de Casos. Tese de Doutorado, ICMC-USP. a ser defendida. Citado nas páginas 80 e 101.

Prati, R. C., Baranauskas, J. A., \& Monard, M. C. (2001a). Extração de informações padronizadas para a avaliação de regras induzidas por algoritmos de aprendizado de máquina simbólico. Relatório Técnico 145, ICMCUSP. ftp://ftp.icmc.sc.usp.br/pub/BIBLIOTECA/rel_tec/RT_145. ps.zip. Citado na página 5.

Prati, R. C., Baranauskas, J. A., \& Monard, M. C. (2001b). Uma proposta de unificação da linguagem de representação de conceitos de algoritmos de aprendizado de máquina simbólicos. Relatório Técnico 137, ICMCUSP. ftp://ftp.icmc.sc.usp.br/pub/BIBLIOTECA/rel_tec/RT_137. p.s.zip. Citado na página 5. 
Quinlan, J. R. (1993). C4.5: Programs for Machine Learning. Morgan Kaufman. San Francisco, CA. Citado nas páginas 73 e 104.

Quinlan, J. R. (1996). Bagging, boosting and c4.5. In Proceedings of the Thirteenth National Conference on Artificial Intelligence, pages 725-730. American Association for Artificial Intelligence. Citado na página 87.

Rathjens, D. (2000). MineSet ${ }^{T M} 3.0$ Enterprise Edition. Silicon Graphics. http://www.sgi.com/software/mineset/mineset_data.html. Citado nas páginas 2 e 61 .

Rezende, S. O. (2003). Sistemas Inteligentes: fundamentos e aplicações, volume 1 of 1 . Editora Manole, Barueri, SP, Brasil, 1 edition. Citado nas páginas 2 e 124.

Ritthoff, O., Klinkenberg, R., Fischer, S., Mierswa, I., \& Felske, S. (2001). YALE: Yet Another Machine Learning Environment. In Klinkenberg, R., Rüping, S., Fick, A., Henze, N., Herzog, C., Molitor, R., \& Schröder, O., editors, LLWA 01 - Tagungsband der GI-Workshop-Woche Lernen - Lehren - Wissen - Adaptivität, number 763 in Forschungsberichte des Fachbereichs Informatik, Universität Dortmund, pages 84-92. http://yale.sf.net/. Citado na página 3.

Rohlf, F. J. (1973). Hierachical clustering using minimal spannign tree. The Computer Journal, 1(16):93-95. Citado na página 52.

Rohlf, M. E. (1978). A probabilistic minimum spanning tree algorithm. Inform. Process. Lett, 1(8):44-49. Citado na página 52.

Rozante, T. A. A. (2003). Implantação do reuso de componentes no processo de desenvolvimento de software. Dissertação de Mestrado, ICMC-USP. Citado na página 5.

Sanches, M. K. (2003). Aprendizado de máquina semi-supervisionado: porposta de um algoritmo para rotular exemplos a partir de poucos exemplos rotulados. Dissertação de Mestrado, Instituto de Matemática e Computação, Universidade de São Paulo, Brasil. http://www.teses.usp.br/ teses/disponiveis/55/55134/tde-12102003-140536/. Citado na página 32 .

Seo, J. (2005). Hierarchical Clustering Explorer 3.0: User's guide. University of Maryland, College Park. http://www.cs.umd.edu/hcil/hce/. Citado na página 62.

Sheikholeslami, G., Chatterjee, S., \& Zhang, A. (1998). WaveCluster: A multi-resolution clustering approach for very large spatial databases. In Proc. 24th Int. Conf. Very Large Data Bases, VLDB, pages 428-439. http: //citeseer.ist.psu.edu/sheikholeslami98wavecluster.html. Citado na página 21.

Sibson, R. (1973). SLINK: An optimally efficient algorithm for the singlelink cluster method. The Computer Journal, 1(16):30-34. Citado nas páginas 48 e 52. 
Sneath, P. H. A. (1957). The applications of computers to taxonomy. Gen. Microbiol, 1(17):201-226. Citado na página 52.

Stepp, R. E. \& Michalski, R. S. (1986). Conceptual clustering: Inventing goal oriented classifications of structured objects. Machine Learning: An artificial intelligence approach, 2:471-498. Citado na página 22.

Stroustrup, B. (1997). The C++ Programming Language. Addison-Wesley. Citado na página 3.

Team, R. D. C. (2005). R: a language and environment for statistical computing. R Foundation for Statistical Computing, Vienna, Austria. http: //www.r-project.org. Citado nas páginas 4, 55, e 62.

Telöken, C., Badalotti, M., \& Palka, M. T. F. (1999). Infertilidade Masculina, chapter 52, pages 305-312. Volume 1 of Bendhack \& Damião (1999), 1 edition. http://www.sbu-mg.org.br/Guia_pratico.htm. Citado na página 104.

Voltolini, R. F. (2005). Discretização e visualização de dados em aprendizado de máquina. Monografia de exame de qualificação ICMC-USP. Citado nas páginas 80 e 108.

Wall, L., Christiansen, T., \& Schwartz, R. L. (1996). Programming Perl. O’Reilly \& Associates, 2 edition. Citado na página 71 .

Wang, W., Yang, J., \& Muntz, R. R. (1997). STING: A statistical information grid approach to spatial data mining. In Jarke, M., Carey, M. J., Dittrich, K. R., Lochovsky, F. H., Loucopoulos, P., \& Jeusfeld, M. A., editors, Twenty-Third International Conference on Very Large Data Bases, pages 186-195, Athens, Greece. Morgan Kaufman. http://citeseer.ist. psu.edu/wang97sting.html. Citado na página 21.

Ward, J. H. (1963). Hierarchical grouping to optimize an objective funtion. Journal of American Statistics Association, 1(58):236-244. Citado na página 54.

Webb, A. (2005). Statistical Pattern Recognition. John Wiley \& Sons, 2 edition. Citado nas páginas 31 e 39.

Witten, I. H. \& Frank, E. (2000). Data mining: Pratical Machine Learning Tools and Techniques with Java Implementations. Morgan Kaufman. Citado nas páginas 3 e 61 .

Zhang, Q. \& Couloigner, I. (2005). A new and efficient k-medoid algorithm for spatial clustering. Lecture Notes in Computer Science, 3482:181-189. http://www. springerlink. com/openurl.asp?genre= article\&id=doi:10.1007/11424857_20. Citado na página 21 .

Zhang, T., Ramakrishnan, R., \& Livny, M. (1996). BIRCH: an efficient data clustering method for very large databases. In Simoudis, E., Han, J., \& Fayyad, U. M., editors, Second International Conference on Knowledge Discovery and Data Mining, pages 103-114, Portland, Oregon, USA. American Association for Artificial Intelligence. http://citeseer.nj.nec. com/zhang96birch.html. Citado nas páginas 43 e 55. 